AUTARQUIA ASSOCIADA À UNIVERSIDADE DE SÃO PAULO

VALIDAÇÃO E AVALIAÇÃO DOSIMÉTRICA EMPREGANDO AS TÉCNICAS DE TL E OSL DE MATERIAIS TERMOLUMINESCENTES PARA APLICAÇÃO NA DOSIMETRIA DE FEIXES CLÍNICOS DE ELÉTRONS UTILIZADOS NA IRRADIAÇÃO TOTAL DA PELE - TSI

SHIRLANE BARBOSA DE ALMEIDA

Dissertação apresentada como parte dos requisitos para obtenção do Grau de Mestre em Ciências na Área de Tecnologia Nuclear - Aplicações

Orientadora:

Profa. Dra. Letícia Lucente Campos

Rodrigues 
INSTITUTO DE PESQUISAS ENERGÉTICAS E NUCLEARES

Autarquia associada à Universidade de São Paulo

\title{
VALIDAÇÃO E AVALIAÇÃO DOSIMÉTRICA EMPREGANDO AS TÉCNICAS DE TL E OSL DE MATERIAIS TERMOLUMINESCENTES PARA APLICAÇÃO NA DOSIMETRIA DE FEIXES CLÍNICOS DE ELÉTRONS UTILIZADOS NA IRRADIAÇÃO TOTAL DA PELE - TSI
}

Shirlane Barbosa de Almeida

\author{
Dissertação apresentada como parte dos \\ requisitos para obtenção do Grau de \\ Mestre em Ciências na Área \\ de Tecnologia Nuclear - Aplicações \\ Orientadora: \\ Profa. Dra. Letícia Lucente Campos \\ Rodrigues
}

Versão Corrigida

Versão Original disponível no IPEN 
Dedico à Deus, pelo seu amor incondicional, por está sempre ao meu lado e por me fazer florescer em meio a tantos espinhos. 
Onde estaria eu se não fosse o teu amor Senhor!

(Toca de Assis) 


\section{AGRADECIMENTOS}

À Deus, autor da vida e motivo da minha singela existência, pelos passos guiados, pela presença constante, pelo perdão ensinado e pelo amor doado.

À minha orientadora Dra. Letícia L. C. Rodrigues, pela grandeza de cultivar e regar sonhos, pela proeza de enxergar horizontes ainda não conquistados, pela sabedoria de acreditar no que eu poderia me tornar, me fazendo sair das minhas inseguranças para aprender a superá-las, por sua imensa capacidade de ser "mãe” que interpela, pergunta e desafia, gerando adultos.

Ao IPEN, na pessoa do Sr. Superintendente Dr. Wilson A. Parejo Calvo, pela oportunidade de execução desse trabalho.

À Fundação de Amparo à Pesquisa do Estado de São Paulo (FAPESP) e ao Conselho Nacional de Desenvolvimento Científico e Tecnológico (CNPq), pelo suporte financeiro.

À Dra. Linda Caldas e à Dra. Maria da Penha, pela disponibilidade e incentivo para a realização deste trabalho.

Ao Hospital Israelita Albert Einstein, pelas irradiações e pela oportunidade de realização e conclusão desse trabalho.

Ao Dr. Roberto Kenji Sakuraba, por ter tido a proeza dos sábios, sendo um condutor da mais pura sabedoria, me fazendo sair de mim mesma para encontrar o conhecimento na sua total essência, sendo sinônimo de igualdade teve a humanidade de dispôr o tempo que lhe cabia para trazer mais sabedoria. Obrigada por fazer parte deste sonho.

Aos Físicos Vinicius Demanboro Gonçalves e Bruno de Loos Gialluisi, pelo auxílio e disposições nas medidas e pelas valiosas sugestões que enriqueceram este trabalho.

À Biomédica Adriana da Silva Santos, pelo conhecimento transmitido, pela disponibilidade e auxílios prestados, pela amizade e incentivo. 
À Bióloga Maria Ruth Delatorre Rigatto e à Tecnóloga Ângela Rosa Ribeiro, pela amizade e por colaborarem e me auxiliarem nas medidas no decorrer deste projeto.

Às minhas duas Mães, Virgem Santíssima, por todo amor e intercessão, à minha mãe Maria José, exemplo sublime de amor. Foi o amor das minhas duas mães que me trouxeram até aqui. Obrigada por segurarem sempre em minhas mãos.

À minha irmã Shirleide Barbosa, você foi o maior presente que Deus me concedeu. Obrigada por caminhar sempre ao meu lado e por fazer parte deste sonho. Te amo.

À minha irmã de coração Andréa Meireles, obrigada por me emprestar os óculos de poeta e por me ensinar a escrever os versos e poemas nas linhas da vida. Obrigada por me presentear com novos sonhos e por teu amor que tantas vezes me ensinou a amar.

À Renata Bressane, por trazer a minha vida a beleza dos acordes e o esplendor das notas musicais, transformando os meus dias na mais bela melodia.

Aos amigos mais que especiais, Lilian Toshie, Ivón Oramas, Fábio Algarve, Caio Valeriano, obrigada por todos os ensinamentos, por me fazer crescer, por nunca me deixar sozinha e por acreditar em mim. Amo vocês.

Ao Stefanos Diamantopoulos, provastes que os quilômetros são insignificantes e que não existe fronteiras para se transmitir o conhecimento. Obrigada pela nobreza de sua amizade e por todas as palavras de incentivo. Anseio para conhecê-lo.

Aos amigos da alma Jacilene Luzia e Marcelo Nunes, obrigada pela caminhada, pela amizade e por está tão presente com suas orações. Que a cruz de cristo possa ser sempre o nosso refúgio.

À Rosely Sabongi, por está nas entrelinhas da minha história, aparentemente tão oculta mas tão presente, obrigada por me ensinar que o crescimento e a mudança envolvem riscos e que o desejo de ser feliz possa ser sempre maior do que o medo de tentar. 
À Elaine Wirney Martins, pelo incentivo, apoio e por me apresentar o mundo do conhecimento e do crescimento profissional.

Aos amigos que eu nem sabia que existiam e que hoje fazem parte das páginas que compõem a minha história, tornando-se a família escolhida pelo meu coração.

A todos da GMR/IPEN, pela amizade, conversas construtivas e por contribuírem para a realização deste trabalho.

E finalmente, com uma relevância incomparável, ao meu grande amigo Daniel Villani, por cada palavra escondida no silêncio, por cada olhar que não foi perdido pelo tempo, por cada sorriso oculto atrás de cada lágrima, por suas mãos seguras, por ter sido o meu maior incentivador na realização deste projeto. Obrigada por devolver o perfume a minha vida e curar as feridas do meu coração. À você os meus eternos agradecimentos. Te amo. 


\title{
VALIDAÇÃO E AVALIAÇÃO DOSIMÉTRICA EMPREGANDO AS TÉCNICAS DE TL E OSL DE MATERIAIS TERMOLUMINESCENTES PARA APLICAÇÃO NA DOSIMETRIA DE FEIXES CLÍNICOS DE ELÉTRONS UTILIZADOS NA IRRADIAÇÃO TOTAL DA PELE - TSI
}

\author{
Shirlane Barbosa de Almeida \\ RESUMO
}

A dosimetria in vivo têm se tornado um papel importante para o tratamento da irradiação total da pele dentro de um rigoroso programa de garantia de qualidade que deve ser parte integrante nos departamentos radioterápicos. A dosimetria em TSI é difícil, devido à complexidade do tratamento em avaliar a uniformidade da dose e medir a dose absorvida em profundidades rasas em toda extensão da superfície cutânea, tendo como consequência uma ampla variação na distribuição da dose. Os TLDs tem provado ser muito úteis para a distribuição e verificação da dose prescrita para o paciente, pois a dose pode diferir de local para local devido a geometria do corpo do paciente, sobreposições de estruturas e assimetrias do campo de radiação. A utilização de TLDs in vivo pode identificar variações da dose prescrita por apresentarem uma grande exatidão e precisão nas medidas. Nos setores de radioterapia vêm sendo empregado vários tipos de dosímetros, os mais utilizados são o Flureto de Lítio (TLD-100), onde obtém uma longa história neste tipo de aplicação. Novos materiais dosímetricos vêm ganhado grande importância na aplicação da dosímetria de feixes clínicos de elétrons, como o Sulfato de Cálcio dopado com Disprósio (TL) e o Óxido de Alumínio dopado com Carbono (OSL), este trabalho avalia o desempenho dosímetrico dos respectivos dosímetros termoluminescentes e a luminescência opticamente estimulada na aplicação da dosímetria de feixes clínicos de elétrons utilizados na irradiação total da pele. 


\title{
VALIDATION AND DOSIMETRIC EVALUATION EMPLOYING THE TECHNIQUES OF TL AND OSL OF THERMOLUMINESCENT MATERIALS FOR APPLICATION IN THE DOSIMETRY OF CLINICAL BEAMS OF ELECTRONS USED IN TOTAL IRRADIATION OF THE SKIN - TSI
}

\section{Shirlane Barbosa de Almeida}

\begin{abstract}
In vivo dosimetry has become an important role for the treatment of total skin irradiation within a rigorous quality assurance program that should be an integral part of the radiotherapy departments. TSI dosimetry is difficult because of the complexity of the treatment in assessing dose uniformity and measuring the dose absorbed at shallow depths throughout the skin surface extent, resulting in a wide variation in dose distribution. The TLDs have proven to be very useful for the distribution and verification of the dose prescribed for the patient as the dose may differ from place to place due to patient body geometry, overlapping of structures and asymmetries of the radiation field. The use of TLDs in vivo can identify variations in the prescribed dose because its measurement accuracy and great precision. Several types of dosimeters have been used in the radiotherapy sectors, the most commonly used are Lithium Fluride (TLD-100), where it obtains a long history in this type of application. New dosimetric materials have gained great importance in the dosimetry of clinical electron beams, such as Dysprosium-doped Calcium Sulphate (TL) and Carbon doped (OSL) based Aluminum Oxide, This work evaluates the performance of the respective thermoluminescent dosimeters and the optically stimulated luminescence in the dosimetry of clinical electron beams used in total irradiation of the skin.
\end{abstract}




\section{SUMÁRIO}

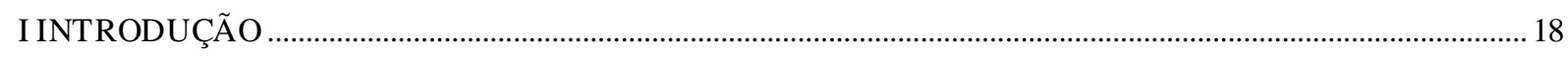

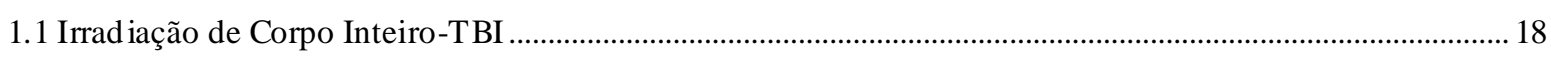

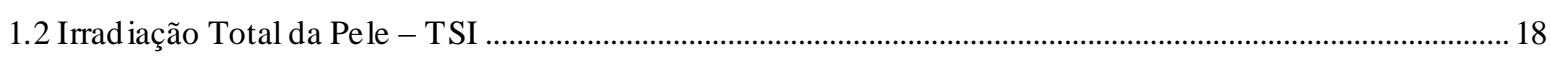

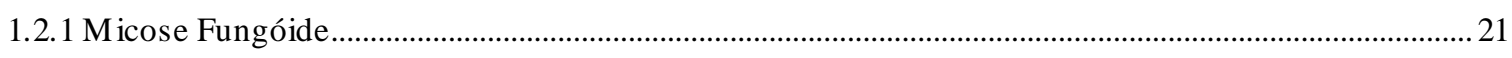

1.2.1.1 Classificação Patológica da Micose Fungóide _.......................................................................... 21

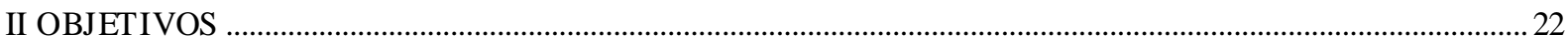

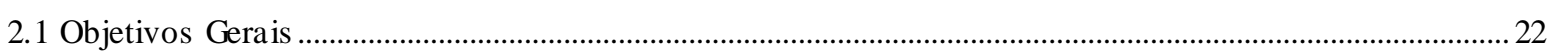

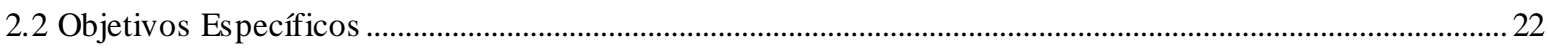

III FUNDAMENTA ÇÃO TEÓRICA ........................................................................................................... 23

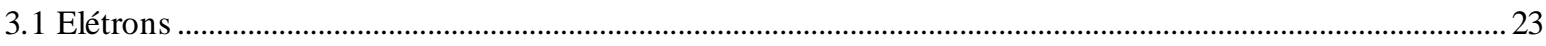

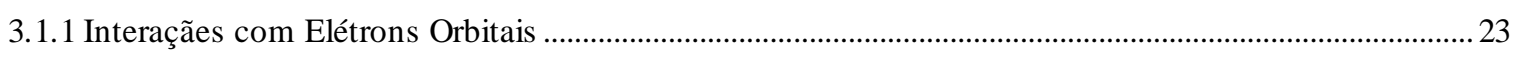

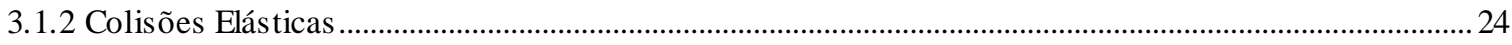

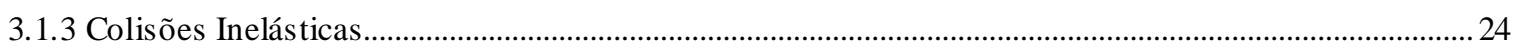

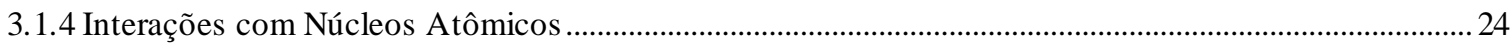

3.2 Poder de Frea mento ("Stopping Power ") ................................................................................................. 24

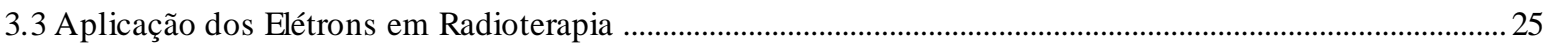

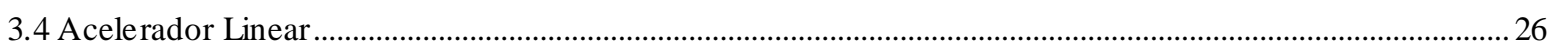

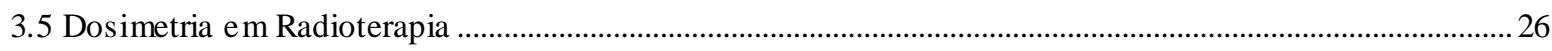

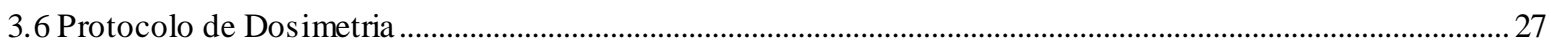

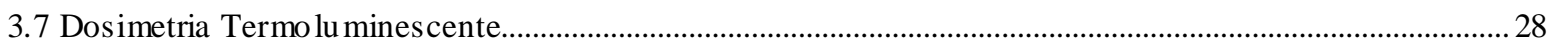

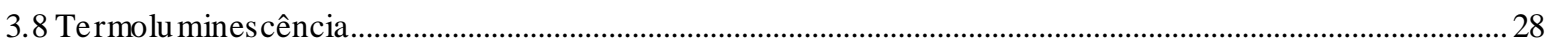

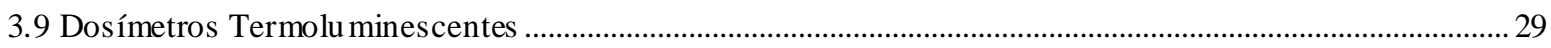

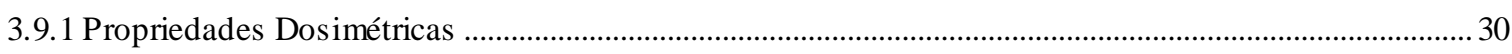

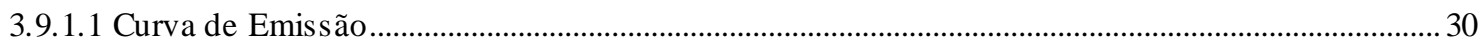

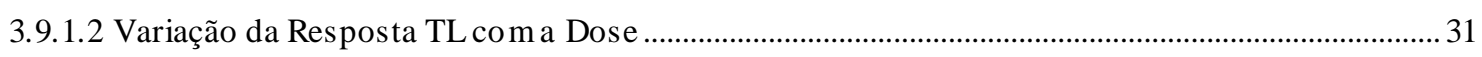

3.9.1.3 Sensibilidade ....................................................................................................................... 31

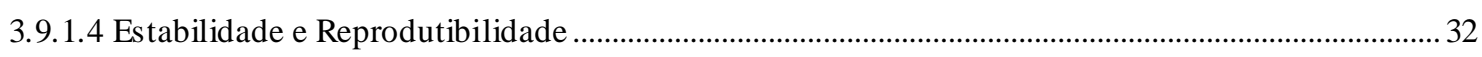

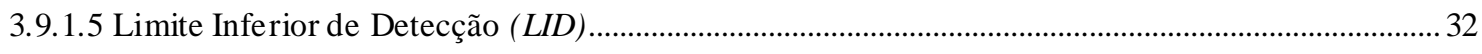

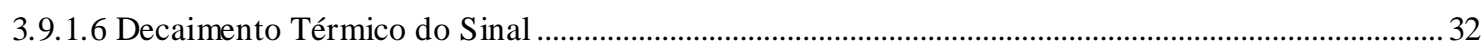

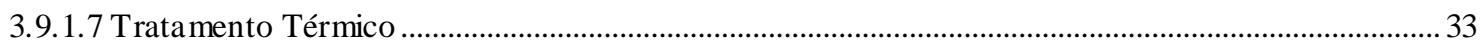

3.9.1.8 Armazena mento e Manuseio ........................................................................................................... 33

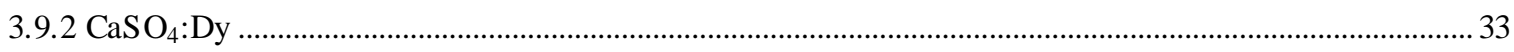

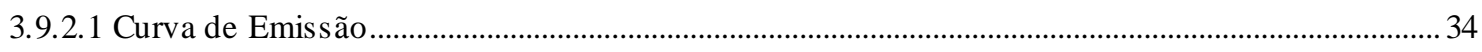

3.9.2.2 Curva Dose-Resposta....................................................................................................... 35

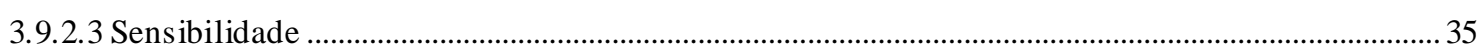

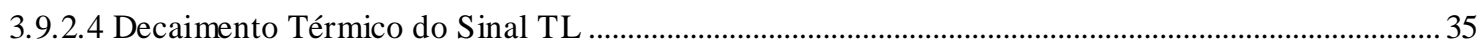

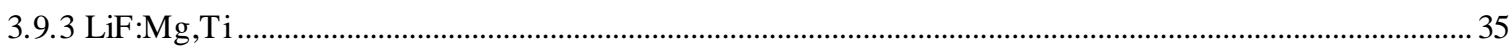

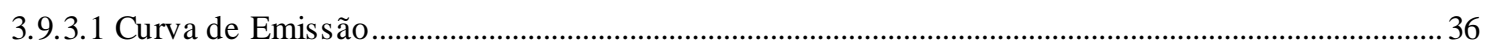




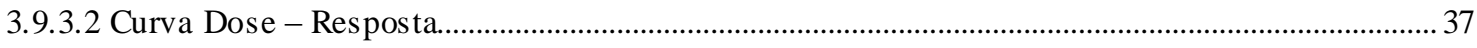

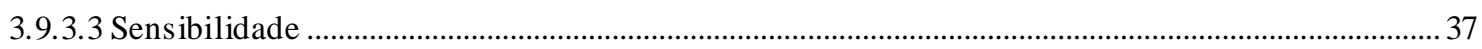

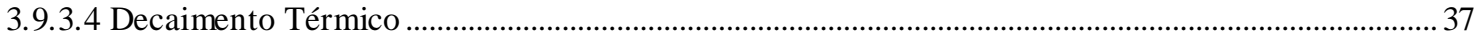

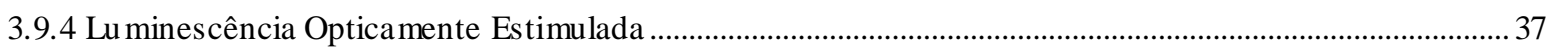

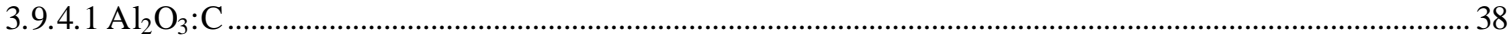

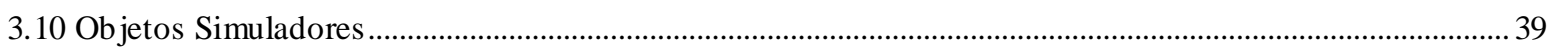

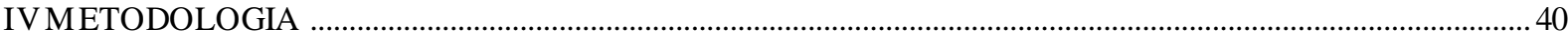

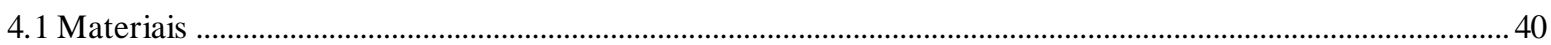

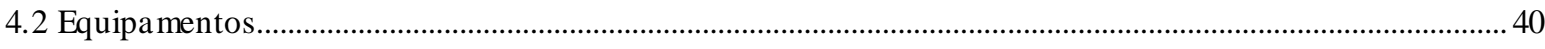

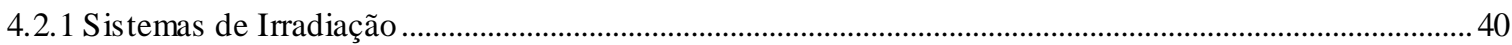

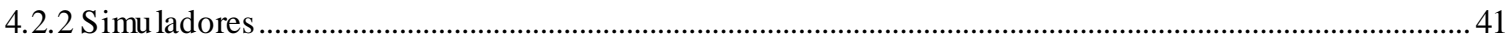

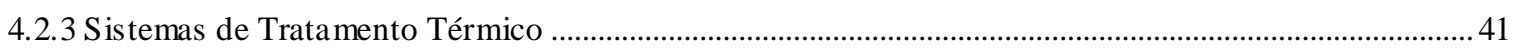

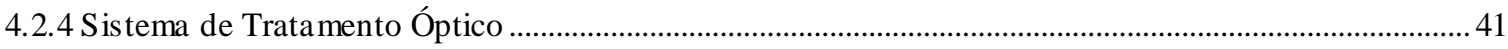

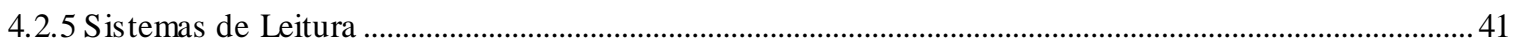

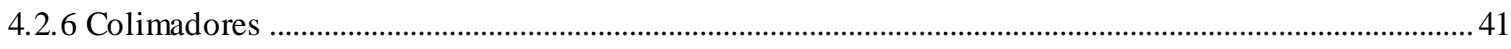

4.2.7 Acessório de Posicionamento e Degradador Utilizado para o Tratamento TSI ...................................... 41

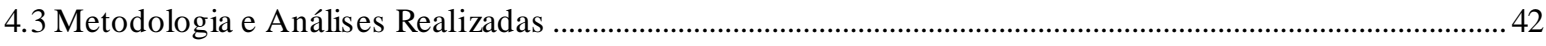

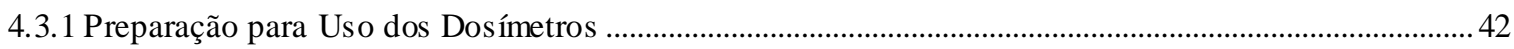

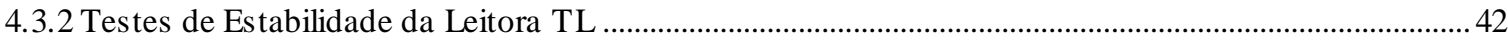

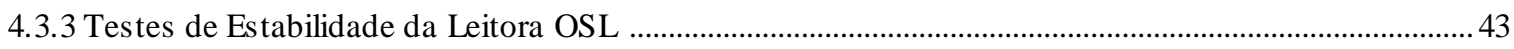

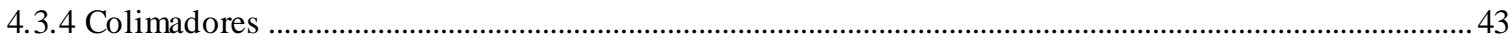

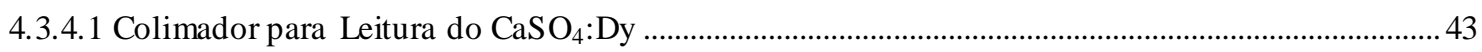

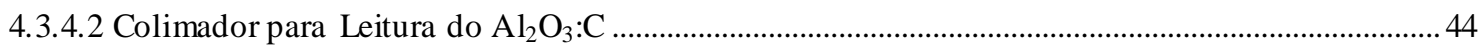

4.3.5 Se leção dos Dosímetros e Testes de Desempenho......................................................................................4

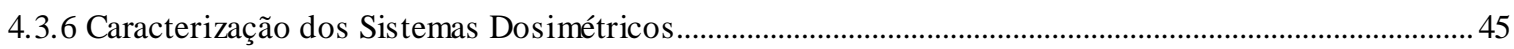

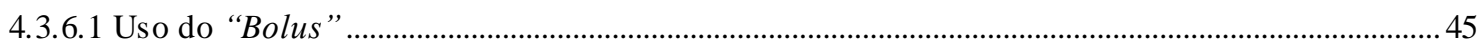

4.3.7 Sensibilidade Individual dos Dosímetros Lu minescentes ......................................................................... 46

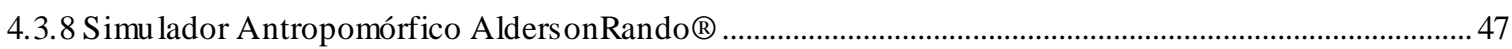

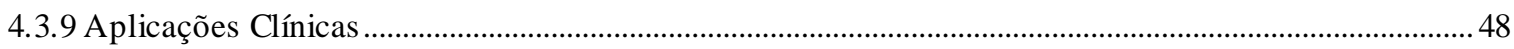

4.3.9.1 Ho mogeneidades do Campo para Irradiação T SI ............................................................................... 48

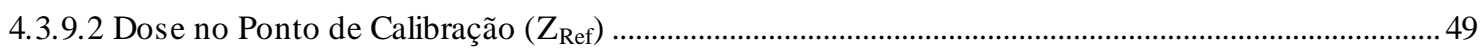

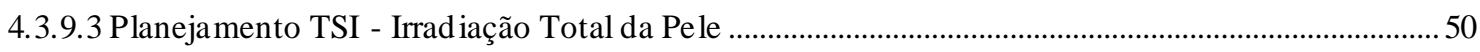

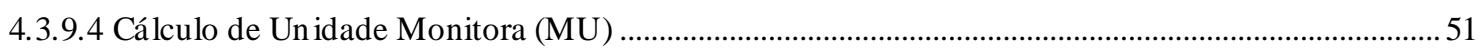

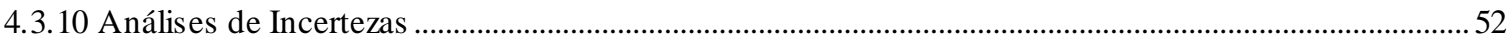

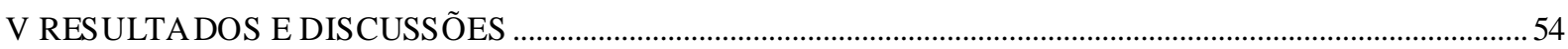

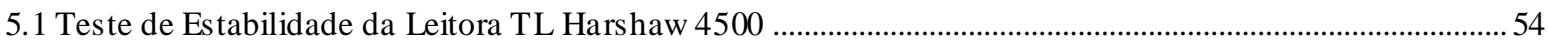

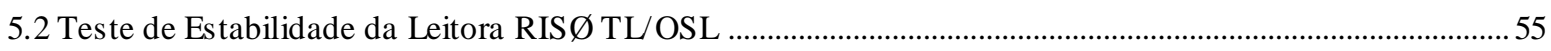

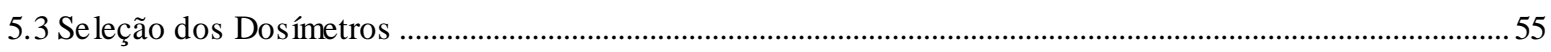

5.4 Caracterização das Leituras OSL dos TLD-500 na Leitora RIS Ø ${ }^{\mathrm{TM}}$ TL/OSL-DA-20 ..................................56

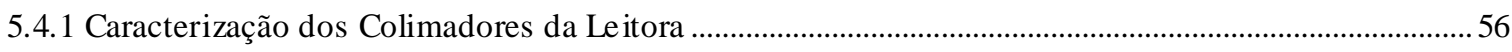

5.4.2 Caracterização da Potência do Arranjo de LEDs Azu is .................................................................................5

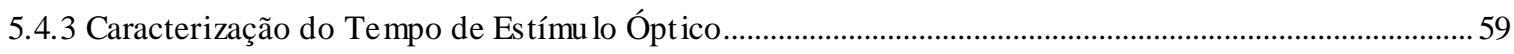


5.4.4 Estudo da Correlação entre o "Bleaching” do Sinal OSL e Efetividade do Tempo de Ilu minação para

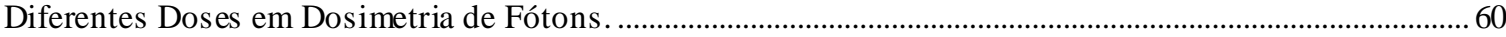

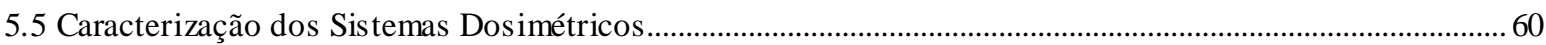

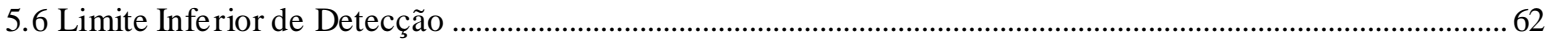

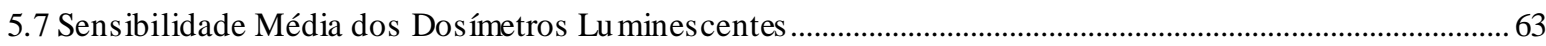

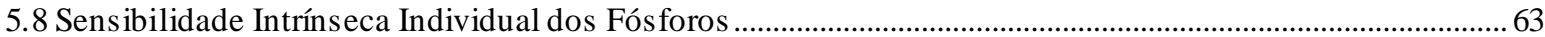

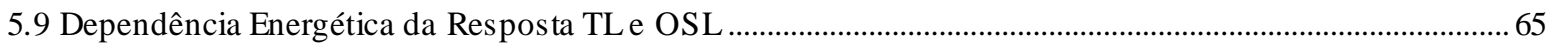

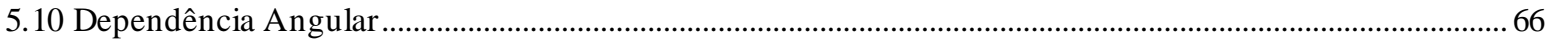

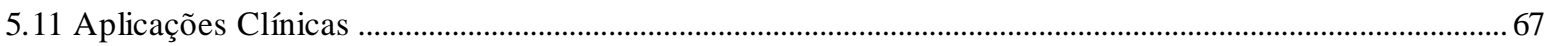

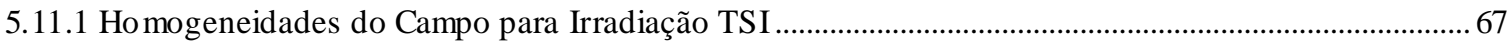

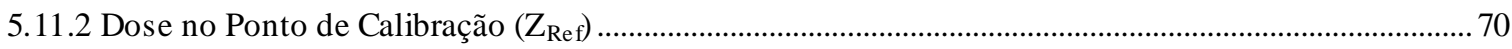

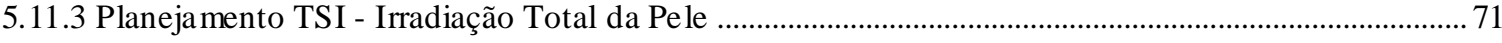

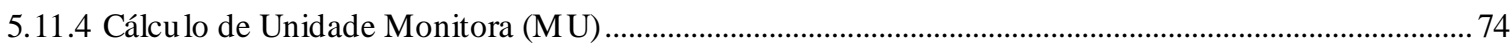

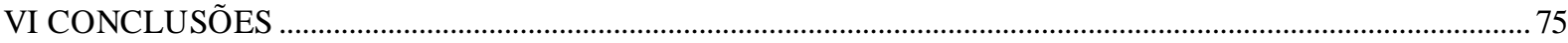

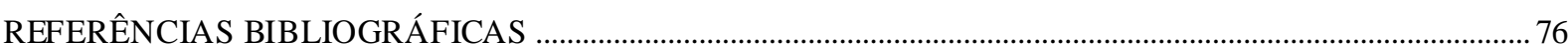

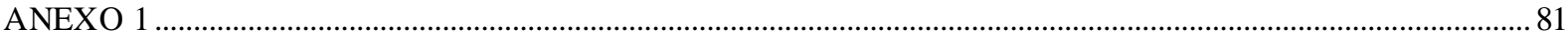

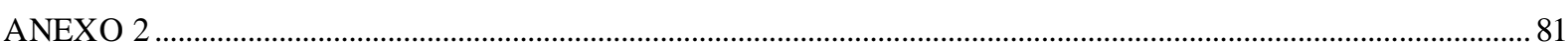

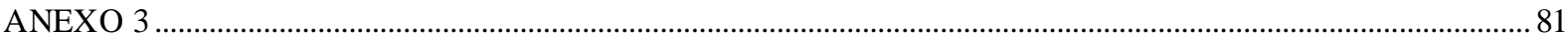

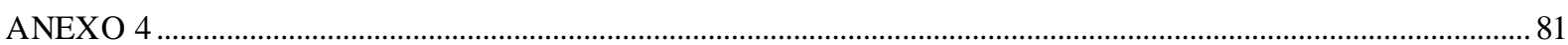




\section{LISTA DE FIGURAS}

Figura 1. Geo metrias de irradiação de áreas externas de pele para neoplasia de linfomas de células T. ...............20

Figura 2. Irradiação total da pele, utilizando a Técnica de Stanford.........................................................................20

Figura 3. Interação do elétron com u máto mo do meio. Adaptado de IAEA, 2005. ............................................23

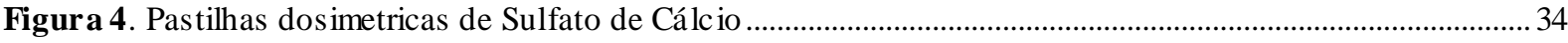

Figura 5. Curva de e mis são do $\mathrm{CaSO}_{4}$ :Dy. Adaptado de Campos e Lima, 1986. .................................................. 34

Figura 6. Curva de e mis são TL do LiF:Mg,Ti. Adaptado de Metcalfe et al, 2007. ............................................... 36

Figura 7. Teoria das bandas da Lu mines cência Optica mente Estimu lada. ............................................................... 38

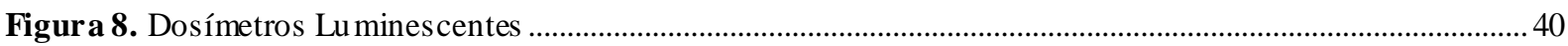

Figura 9. (a) Forno tipo mufla da marca Vulcan®, (b) Estufa cirúrgica da marca Fanen ${ }^{\circledR}$ e (c) Lâmpada de

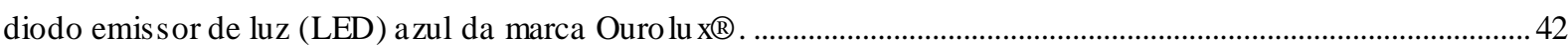

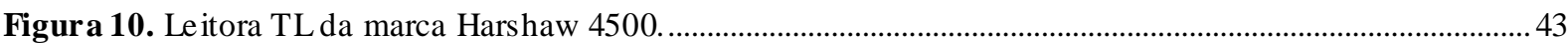

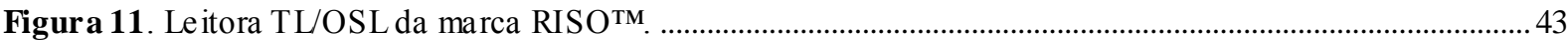

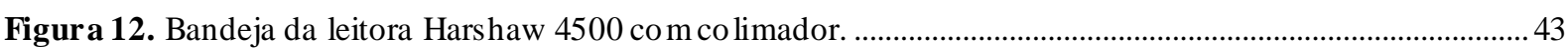

Figura 13. Colimadores utilizados na leitora OSL dos dosímetros $\mathrm{Al}_{2} \mathrm{O}_{3}: \mathrm{C}$ TLD-500. Eles apresentam $45 \mathrm{~mm}$ de diâmetro e suas aberturas centrais são de aproximadamente $10 \mathrm{~mm}, 5 \mathrm{~mm}, 2 \mathrm{~mm}$ e $1 \mathrm{~mm}$ respectivamente........ 44

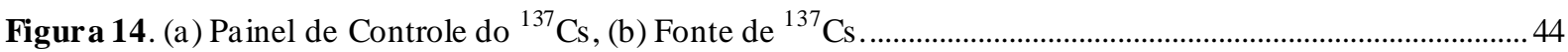

Figura 15. (a) Acelerador Clinac 23 EX (“High Dose Rate"-HDR=1000/minuto) da Varian ("RapidArc") -

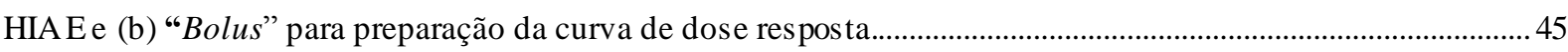

Figura 16. "Bolus" . .46

Figura 17. Arran jo experimental das amostras para determinação da sensibilidade dos dosímetros lu minescentes.

Figura 18. (a) Planejamento CT e (b) imagens CT do programa Elétron Monte Carlo Eclipse 13-6 da Varian Medical Systen.

Figura 19. Simu lador AldersonRando®. 48

Figura 20. (a) e (b) Posicionamento do degradador e da plataforma giratória para ho mog eneidade do campo...49

Figura 21. (a) Posicionamento dos dosímetros luminescentes, (b) Posicionamento do AldersonRando® para tratamento TSI.

Figura 22. Esquema demonstrativo sequencial de dois dias alternados dos angulos de orientações para seis campos duplos (Report 23).

Figura 23. Simu lação do tratamento TSI com seis campos duplos para obtenção da unidade monitora. 52

Figura 24. Teste da luz de referência. Valores médios dos conjuntos de leituras e limites de aceitação.Resultados para o teste de ruído

Figura 25. Histograma da média de quatro leituras dos dosímetros TL (a) LiF:Mg,Ti TLD-100 e (b) $\mu \mathrm{LiFpara}$ separação do lote.

Figura 26. Histograma da méd ia de quatro leituras dos dosímetros TL e OSL (c) CaSO $\mathrm{D}_{4}$ Dy e (d) $\mathrm{Al}_{2} \mathrm{O}_{3}: \mathrm{C}_{\text {para }}$ separação do lote. 
Figura 27. Curvas de decaimento OSL obtidas para aquisição dos fatores de correção de cada um dos colimadores.

Figura 28. Comportamento das integrais das curvas de decaimento OSL variando a potência do arranjo de LEDs azuis 58

Figura 29. Curvas de decaimento OSL obtidas pela variação da potência do arranjo de LEDs azuis . 58

Figura 30. Comportamento das curvas de decaimento OSL (a) das integrais das curvas de decaimento OSL, (b) em função davariação do tempo de estímu lo óptico.

Figura 31. Comportamento das integrais das curvas OSL de acordo co mo tempo de tratamento óptico. 60

Figura 32. Curvas de resposta TL em função da dose dos dosímetros $\mathrm{LiF}: \mathrm{Mg}, \mathrm{Ti}$ (a) e (b) $\mu \mathrm{LiF}: \mathrm{Mg}$,Ti para radiação gama do ${ }^{60} \mathrm{Co}$ liv res no ar e em equilíbrio eletrônico.

Figura 33. Curvas de resposta TL em função da dose dos dosímetros $\mathrm{CaSO}_{4}$ :Dy (c) e (d) OSL dos dosímetros $\mathrm{Al}_{2} \mathrm{O}_{3}: \mathrm{C}$ para radiação gama do ${ }^{60} \mathrm{Co}$ livres no ar e em equilíb rio eletrônico. 61

Figura 34. Curvas de resposta TL em função da dose dos dosímetros $\mathrm{LiF}: \mathrm{Mg}, \mathrm{Ti}$ (e) e (f) $\mu \mathrm{LiF}: \mathrm{Mg}, \mathrm{Ti}$ para elétrons de $6 \mathrm{MeV}$

Figura 35. Curvas de resposta TL em função da dose dos dosímetros $\mathrm{CaSO}_{4}$ :Dy (g) e (h) OSL dos dosímetros $\mathrm{Al}_{2} \mathrm{O}_{3}: \mathrm{C}$ para elétrons de $6 \mathrm{MeV}$.

Figura 36. Sensibilidade méd ia em função da dose dos dosímetros TL e OSL para feixes clín icos de elétrons de

$6 \mathrm{MeV}$. 63

Figura 37. Dependência energética da resposta dos Dosímetros TLe OSL 65

Figura 38. Arranjo experimental para determinação da dependência angular dos materiais estudados .66

Figura 39. Dependência Angular da resposta dos dosímetros: (a) LiF TLD-100, (b) Micro LiF, (c) CaSO 4 :Dy e (d) $\mathrm{Al}_{2} \mathrm{O}_{3}: \mathrm{C}$ 


\section{LISTA DE TABELAS}

Tabela 1. Estágios da MF, descritos por Funks e pelo grupo de Stanford. Silveira, 2010. .....................................2 21

Tabela 2. Propriedades dosimétricas do Sulfato de Cálcio. Ca mpos e Lima, 1986................................................ 34

Tabela 3. Características dos picos dosimétricos do LiF:Mg,Ti. Metcalfe et al, 2007 ........................................... 36

Tabela 4. Fatores de correção obtidos para cada um dos colimadores de sinal. .....................................................57

Tabela 5. Valores dos Limites Inferiores de Detecção (LID) dos dosímetros TL e OSL para os feixes clínicos de elétrons com energia de $6 \mathrm{MeV}$.

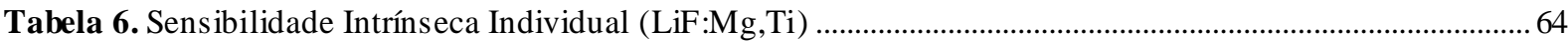

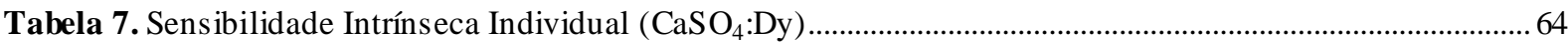

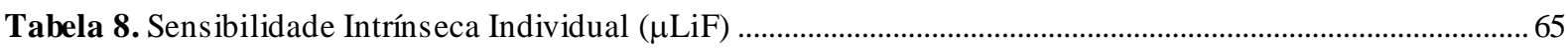

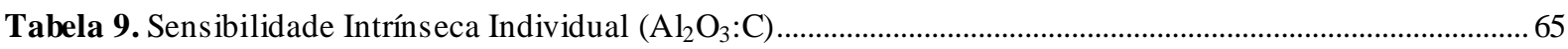

Tabela 10. Ho mogeneidade do campo para inclinações de $\pm 17^{\circ}$ com irradiação de campo duplo ( $\left.\mathrm{LiF}: \mathrm{Mg}, \mathrm{Ti}\right) .68$

Tabela 11. Homogeneidade do campo para inclinações de $\pm 17^{\circ}$ com irradiação de campo duplo ( $\left.\mu \mathrm{LiF}: \mathrm{Mg}, \mathrm{Ti}\right)$

Tabela 12. Ho mogeneidade do campo para inclinações de $\pm 17^{\circ}$ co m irradiação de campo duplo $\left(\mathrm{CaSO}_{4}: \mathrm{Dy}\right) .69$

Tabela 13. Ho mogeneidade do campo para inclinações de $\pm 17^{\circ} \mathrm{com}$ irradiação de campo duplo $\left(\mathrm{Al}_{2} \mathrm{O}_{3}: \mathrm{C}\right)$.....6 69

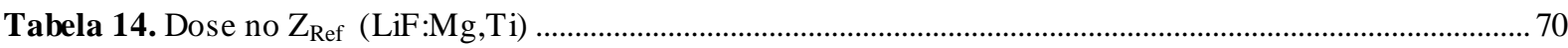

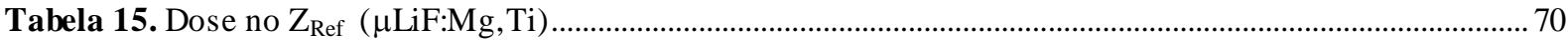

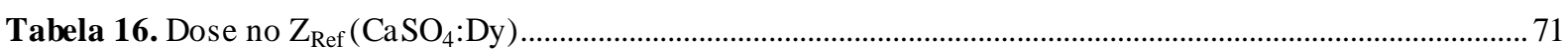

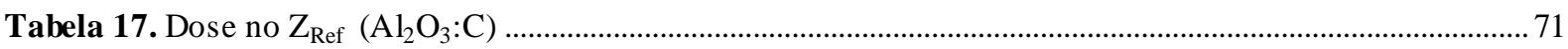

Tabela 18. Posicionamentos de Irradiação para Tratamento TSI (LiF:Mg,Ti) ...................................................... 72

Tabela 19. Posicionamentos de Irradiação para Tratamento TSI ( $\mu \mathrm{LiF}: \mathrm{Mg}$,Ti) ..................................................... 72

Tabela 20. Pos iciona mentos de Irradiação para Tratamento TSI $\left(\mathrm{CaSO}_{4}\right.$ :Dy $)$...................................................... 73

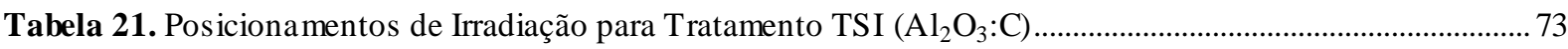

Tabela 22. Valores de dose por MU no $\mathrm{Z}_{\mathrm{Ref}}$ e fatores de correção re lativos ( $\left.\mathrm{LiF}: \mathrm{Mg}, \mathrm{Ti}\right)$...................................... 74

Tabela 23. Valores de dose por MU no $\mathrm{Z}_{\mathrm{Ref}}$ e fatores de correção re lativos $\left(\mathrm{CaSO}_{4}: \mathrm{Dy}\right)$..................................... 74 


\title{
LISTA DE ABREVIATURAS
}

\author{
AAPM - American Association of Physicists in Medicine \\ $\mathrm{BG}-$ Bremsstralung \\ CaS - Sulfeto de Cálcio \\ CD - Campos Duplos \\ CDS - Campo Duplo Simples \\ CSH - Campo Simples Horizontal \\ CT - Tomografia Computadorizada \\ DPM - Desvio Padrão da Média
}

ESTRO - Europian Society for Radiotherapy and Oncology

Eu - Európio

GQ - Garantia de Qualidade

HIAE - Hospital Israelita Albert Einstein

IAEA - Agência Internacional de Energia Atômica

ICRU - Comissão Internacional de Medidas e Unidades de Radiação

IPEN - Instituto de Pesquisas Energéticas e Nucleares

LID - Limite Inferior de Detecção

MF - Micose Fungóide

MgS - Sulfeto de Magnésio

MU - Unidade Monitora

OSL - Luminescência Opticamente Estimulada

PDP - Porcentagem de Dose Profunda

PMMA - Polimetilmétacrilato

Sm-Samário 
SrS - Sulfeto de Estrôncio

SSD - Distância Foco - Superfície

TBI - Irradiação Total do Corpo (Total Body Irradiation)

TLD - Dosímetros Termoluminescentes

TL - Termoluminescência

TSI - Irradiação Total da Pele (Total Skin Irradiation)

UV - Ultravioleta

$Z_{\text {Ref }}$ - Ponto de Calibração para Tratamento - TSI 


\section{INTRODUÇÃO}

\subsection{Irradiação de Corpo Inteiro-TBI}

A irradiação de corpo inteiro (do inglês - total body irradiation, TBI) é uma importante técnica radioterápica que libera uma dose de fótons de megavoltagem com uma uniformidade de dose dentro de $10 \%$ em todo o corpo do paciente. É uma técnica utilizada para administrar grandes campos de radiação no corpo inteiro. Trata-se de um complexo programa de tratamento para anemia aplásia, leucemias, linfomas e outros tipos de tumores que são combinados com altas doses de quimioterapia e utilizado na preparação para transplante de médula óssea (Habitzreuter, 2010).

Os pacientes normalmente fazem as aplicações nas posições ântero-posterior e póstero-anteriorou aplicações látero-laterais na posição sentado com os braços rentes ao tronco ou apoiados sobre os joelhos em doses iguais. As angulações do equipamento (gantry) dependem principalmente das dimensões da sala de tratamento e do posicionamento do

paciente. É relevante que, em qualquer que seja a posição de irradiação, deve-se levar em consideração o conforto do paciente durante a aplicação. $\mathrm{O}$ uso de absorvedores nas regiões de diferentes espessuras (cabeça, braços, pernas etc.) é normalmente necessário para uniformizar a distribuição da dose. O método de cálculo mais simples é considerar o TBI como um campo grande, irregular e com heterogeneidades. Para cada região de interesse, por exemplo cabeça, tórax, braços, etc. devemos determinar a quantidade de radiação espalhada para que com a radiação primária possamos determinar a dose na região por meio da relação tecido-ar (Scaff, 1997).

\subsection{Irradiação Total da Pele - TSI}

Irradiação de toda a pele (do inglês - total skin irradiation, TSI) é uma modalidade de tratamento radiotérapico utilizada para tratamento de certas doenças malignas generalizadas da pele. É geralmente usada para tratamento de linfomas cutâneos como micose fungóide e a Síndrome de Sézary (Gonzalez et al., 2014; Ibanez-Rosello, 2016), tendo normalmente uma boa resposta desde que a dose possa ser distribuida de maneira adequada (Bao et al, 2012). Este tipo de tratamento pretende irradiar toda a pele do paciente de modo uniforme com grandes campos de elétrons (Parida, 2014). 
A irradiação penetra poucos milímetros na pele e atinge completamente a parte afetada, sem penetrar nos órgãos internos. Se o tumor for detectado precocemente, o tratamento resulta no desaparecimento completo de todos os sinais e sintomas da doença.

Para este tipo de tratamento são utilizados aceleradores lineares com feixes de elétrons apresentando energia de 2 a $9 \mathrm{MeV}$, que são caracterizados por uma dose máxima na superfície da pele, pela queda rápida do valor da dose nas suas camadas mais profundas e um mínimo de "background" de raios X. Assim, as lesões superfíciais que se estendem em uma profundidade de $1 \mathrm{~cm}$ podem ser eficientemente tratadas, sem que a dose de tolerância de alguns órgãos seja excedida (Khan, 2010).

A irradiação de toda a pele (TSI) foi desenvolvida pela universidade de Stanford em 1950, sendo introduzido para o tratamento de linfomas cutâneo de células T, desde então, TSI foi considerada uma das melhores técnicas de tratamento para várias doenças confinadas à pele (Park et al., 2014). Esta técnica visa utilizar uma configuração, onde o paciente é tratado com seis campos duais (anterior, posterior e quatro campos oblíquos) tendo um posicionamento de 60 graus separados ao âmbito do paciente, ou seja o paciente é situado em uma geometria estratégica, para que possa obter uma melhor prestância dos feixes (Reisner et al., 2010; Nevelsky, 2017). O paciente é disposto em pé, sobre uma plataforma giratória para irradiar até completar uma volta, findando seis posições diferentes, como pode ser demonstrado na Fig. 1. Cada campo é integrado por dois elementos do feixe, pormenorizando para um ângulo favorável em relação à horizontal (Khan, 2010). O paciente é irradiado com dois feixes de elétrons tendo uma angulação de $\approx 20^{\circ}$ em relação à linha da cintura, para cima e para baixo.

Para as irradiações é utilizada uma placa de acrílico, sendo posta na frente do paciente para que possa homogeneizar a distribuição da dose em toda a extensão da superfície da pele Fig. 2 (Report 23, AAPM). 


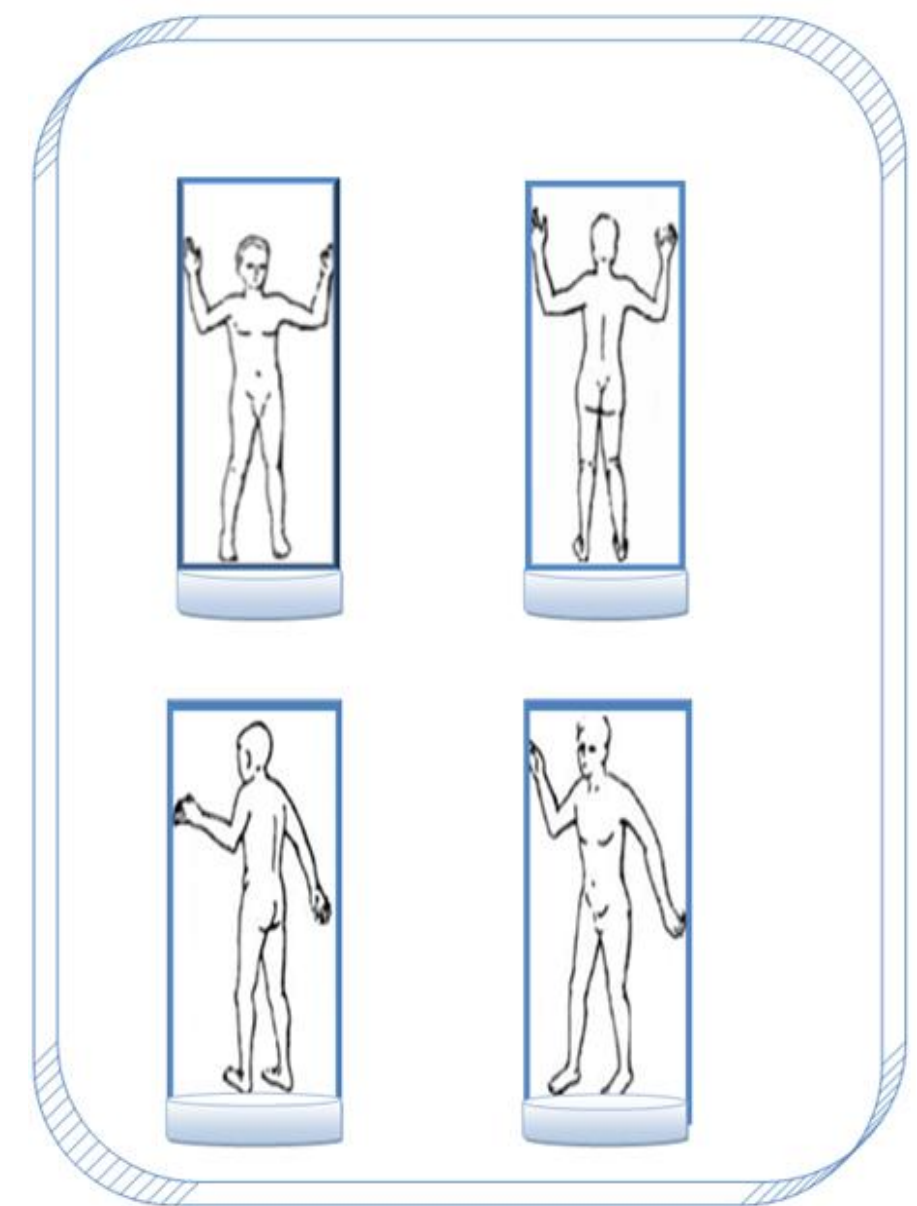

Figura 1. Geo metrias de irradiação de áreas externas de pele para neoplasia de lin fo mas de células $\mathrm{T}$.

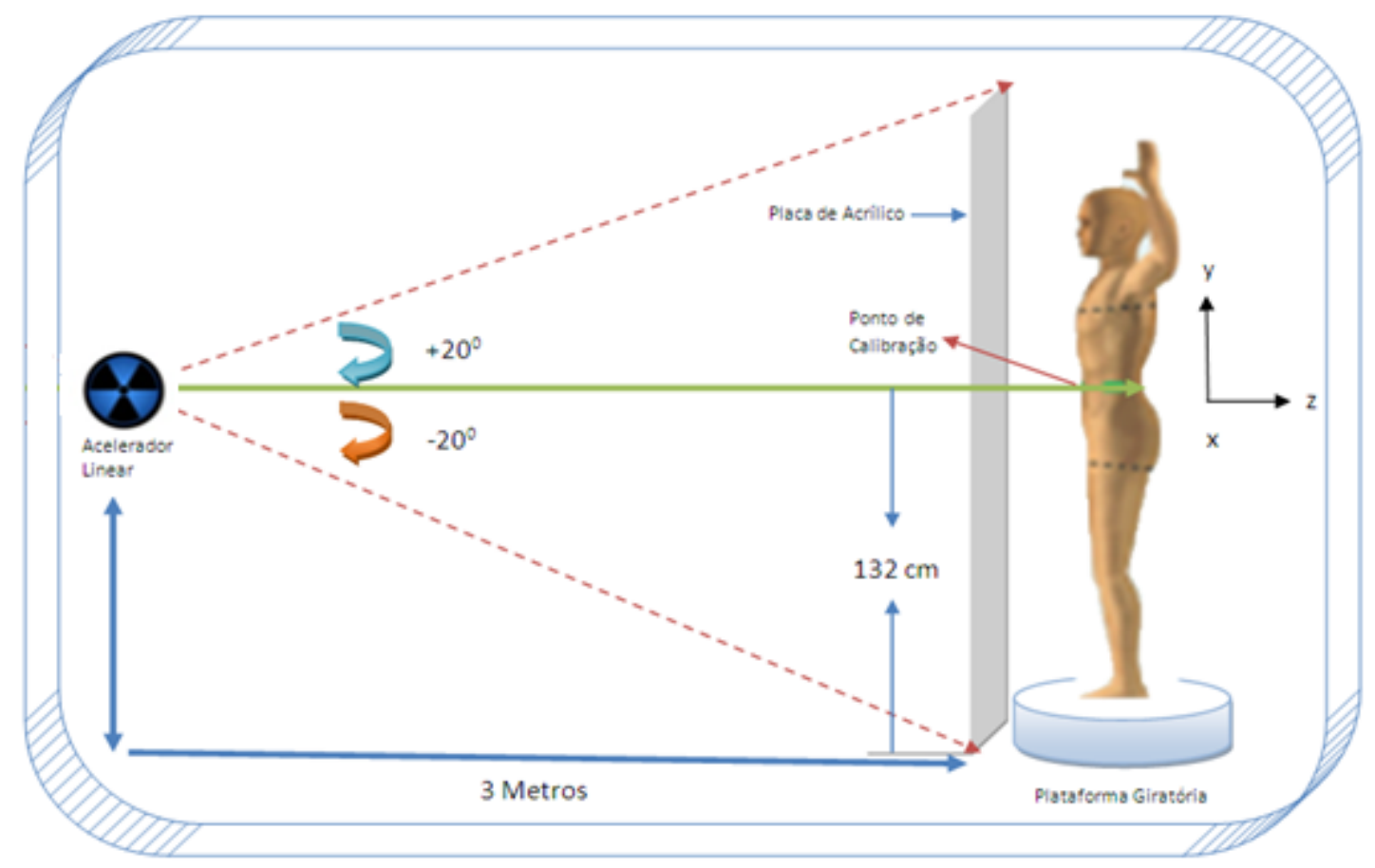

Figura 2. Irradiação total da pele, utilizando a Técnica de Stanford. 


\subsubsection{Micose Fungóide}

A micose fungóide é um tipo raro de linfoma não-Hodgkin, persistente e de crescimento lento, originário de linfócitos T maduro que afeta a pele, com probabilidades de avançar para os linfonódos e órgãos internos (Chowdhary, 2016; Kamstrup, 2015). Esta neoplasia inicia-se em uma pequena região da pele que depois é espessada e evolui para uma erupção pruriginosa e prolongada, que subsequente pode desenvolver nódulos e se disseminando lentamente em área e profundidade. Em casos mais graves pode evoluir para leucemia (síndrome de Sézary), na qual é possível presenciar linfócitos anormais na corrente sangüínea. A MF apresenta dificuldades no diagnóstico precoce devido aos estágios iniciais da doença por apresentarem similaridade com doenças benignas da pele (Jawed, 2014).

O tratamento para a MF tem sido utilizada em pacientes desde 1902. Em primeira instância eram utilizadas baixas doses absorvidas de fótons de raios $\mathrm{X}$, de baixa voltagem. Esses equipamentos não permitiam que houvesse campos grandes para irradiação de áreas extensas e superdosagens podiam ocorrer nas interfaces dos campos adjacentes. Tendo uma penetração significativa, os feixes de fótons podiam irradiar tecidos que não necessitavam ser irradiados. O uso de elétrons foi sujerido para o tratamento de MF no ano de 1940, onde o primeiro paciente foi tratado com feixes de elétrons em 1952, com um acelerador linear de Van der Graaff (Silveira, 2010; Hinds, 2013).

\subsubsection{Classificação Patológica da Micose Fungói de}

A micose fungóide foi descrita pela primeira vez em 1870, sendo dividida em três estágios clínicos: période erythermateuse (fase onde a doença se limita à superfície da pele), període lichenoide (fase onde há uma infiltração das placas da doença no tecido) e període fundoidique (fase onde tumores começam a aperecer). Em 1977, Fuks e o grupo de Stanford descre veram os estadiamentos da MF (Silveira, 2010; Elsayad, 2015).

Tabela 1. Estágios da MF, descritos por Funks e pelo grupo de Stanford. Silveira, 2010.

\begin{tabular}{cl}
\hline Estágio & Descrição \\
\hline 1 & MF com uma limitação à pele \\
$1 \mathrm{a}$ & Envolvimento da doença com menos de $25 \%$ de toda a superfície da pele \\
$1 \mathrm{~b}$ & Envolvimento de mais de $25 \%$ da superfície da pele \\
2 & Presença de tumores \\
3 & MF com envolvimento dos nódulos linfáticos \\
4 & MF com envolvimento nos órgãos internos \\
\hline
\end{tabular}




\section{OBJETIVOS}

\subsection{Objetivos Gerais}

- Validação dosimétrica empregando os dosímetros LiF:Mg,Ti, com feixes clínicos de elétrons utilizados na irradiação total da pele - TSI;

- Avaliação dosimétrica empregando as técnicas de TL e OSL de diferentes materiais termoluminescentes $\left(\mathrm{LiF}, \mathrm{CaSO}_{4}: \mathrm{Dy}\right.$ e $\left.\mathrm{Al}_{2} \mathrm{O}_{3}: \mathrm{C}\right)$ para aplicação na dosimetria de feixes clínicos de elétrons utilizados na irradiação total da pele - TSI .

\subsection{Objetivos Específicos}

- Avaliar o desempenho dos dosímetros termoluminescentes na dosimetria de feixes clínicos de elétrons aplicados em tratamento TSI;

- Comparar o desempenho dos dosímetros $\mathrm{LiF}: \mathrm{Mg}, \mathrm{Ti}$ e $\mathrm{Al}_{2} \mathrm{O}_{3}: \mathrm{C}$ com os dosímetros $\mathrm{CaSO}_{4}:$ Dy produzidos no IPEN. 


\section{FUNDAMENTAÇÃO TEÓRICA}

\subsection{Elétrons}

O elétron foi descrito pela primeira vez por J. J. Thompson na Grâ-Bretanha em 1897 (Ahmed, 2007). O elétron é uma partícula fundamental da natureza, negativamente carregada que pode ter a direção de sua trajetória alterada a cada interação com os átomos do meio ou perder sua energia cinética.

As colisões ou interações de partículas carregadas ocorrem através de forças colombianas entre o campo elétrico da partícula e de elétrons orbitais ou do núcleo atômico. Essas interações dos elétrons orbitais resultam em excitação ou ionização do átomo. Já as interações entre as partículas e núcleo atômico resultam em perda de energia radiativa ou Bremsstralung (Khan, 1994). A maneira que ocorrerá a interação consiste de um parâmetro de impacto " $b$ ” da interação, é determinado como a distância da trajetória do elétron antes da interação ao centro do núcleo atômico (IAEA, 2005). A interação de um elétron com um átomo de raio " $a$ " do meio que este elétron atravessa é demonstrado na Fig. 3.

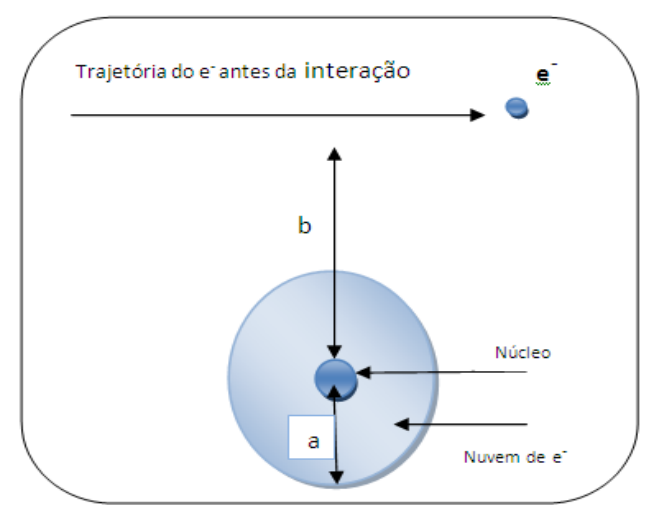

Figura 1. Interação do elétron com u máto mo do meio. Adaptado de IAEA, 2005.

\subsubsection{Interaçães com Elétrons Orbitais}

As interações resultam na excitação (que é a transferência de um elétron do átomo de sua órbita para uma outra de menor energia de ligação) e na ionização (que é a ejeção de um elétron do átomo). Isto pode ocorrer $\operatorname{se} b>a$ ou se $b \approx a$ onde o elétron interage com os elétrons orbitais. Essas perdas de energia acontecem por colisões, elásticas e inelásticas, com os elétrons orbitais do meio, sendo representadas pelo poder de freamento colisional na descrição estatística dos feixes de elétrons (IAEA, 2005). 


\subsubsection{Colisões Elásticas}

O elétron sofre uma colisão elástica quando $b>>$, o átomo como um todo e apenas uma fração de sua energia cinética é transferida para os elétrons orbitais, justificando a classificação desta interação, como uma interação entre o elétron e os elétrons orbitais do meio (IAEA, 2005).

\subsubsection{Colisões Inelásticas}

As colisões inelásticas acontecem quando uma fração significativa da energia cinética do elétron incidente é transferida ao elétron orbital. Isto ocorre quando $b \approx a$. Acarretando a viabilidade de espalhamento do elétron incidente (IAEA, 2005).

\subsubsection{Interações com Núcleos Atômicos}

Quando o elétron interage com o núcleo atômico, sucedendo em perdas de energia pela emissão de um fóton de radiação bremsstralung pelo espalhamento do elétron significa que $b<<a$.

O que conduz a produção de radiação de freamento que pode ser demonstrado pela equação de Larmor Eq. 1, que descreve a potência $P$ que uma partícula de carga elétrica $q$ emite na forma de fótons ao ser acelerada com uma aceleração $\alpha_{\mathrm{q}}$ (IAEA, 2005).

$$
P=\frac{q^{2} \cdot a_{q}^{2}}{6 \cdot \pi \cdot \varepsilon_{0} \cdot c^{3}}
$$

No qual: $\pi=3,14159265359$ é a razão da circunferência pelo diâmetro de um círculo;

$\varepsilon_{0}=$ é a permissividade elétrica do vácuo;

$c=$ velocidade da luz no vácuo.

\subsection{Poder de Freamento (“Stopping Power")}

O poder de freamento (stopping power) resulta na probabilidade de ocorrência de cada tipo de interação, que representa a perda média de energia por unidade de caminho da partícula em um determinado meio e é simbolizada por $\frac{d E}{d x}$ ou $S$, com unidade $[\mathrm{MeV} / \mathrm{cm}]$. 
As perdas de energia são calculadas para cada interação, partícula e para o meio. Para os elétrons as perdas de energia cinética da partícula ocorre pelos processos de colisão (suave ou dura) devido à ionização e excitação do meio. A produção de Bremsstrahlung e a aniquilação em voo correspondem à perda de energia das partículas que contribuem para a produção de radiação eletromagnética (fótons de raios X e gama) (Okuno, 2010).

O poder de freamento tem valores positivos e, apesar do símbolo, não é uma derivada da energia. É considerado como o limite da perda de energia da partícula para percursos " $d x$ " muito pequenos. As partículas apresentam sua própria trajetória no meio, desta maneira, o poder de freamento é um conceito estatístico em que a média é considerada sobre um conjunto grande de partículas idênticas e com a mesma energia. Porémé importante frisar que o poder de freamento muda com a energia da partícula e, portanto, muda ao longo da trajetória de cada partícula (Okuno, 2010).

\subsection{Aplicação dos Elétrons em Radioterapia}

Feixes de elétrons de energia alta $(>5 \mathrm{MeV})$ tem largo emprego na área médica, principalmente no tratamento de diversos tipos de câncer, ou na irradiação de toda a pele - TSI. A aplicação de elétrons em terapia exige grande exatidão na dose absorvida pelo tumor, pois uma variação de $\pm 5 \%$ é determinante no risco de recidivas ou seqüelas (Kalmán, 2001; Osman, 1976). Os elétrons com altas energias têm sido utilizados na medicina desde o início de 1950 (Khan, 1994).

$\mathrm{Na}$ modalidade de radioterapia, a aplicação de elétrons de energias altas tem tido uma grande importância e muitas vezes fornece a única opção para tratamentos de certos tumores superficiais, com $5 \mathrm{~cm}$ de profundidade (Metcalfe, 2007).

As características da curva de PDP proporcionam uma concentração de dose no volume alvo, ou seja, a PDP aumenta com a energia do feixe e depende da lei do inverso do quadrado da distância e da atenuação exponencial devido à interação da radiação com o meio, considerando o poder de penetração. A liberação de elétrons acontece quando os elétrons penetram no meio atenuador e o feixe de radiação começa a ionizá-lo. Esses elétrons depositam energia ao longo do caminho percorrido, onde a distância em relação à superfície a troca de energia é máxima. Está região é conhecida como build up. Ao longo dessa região a PDP aumenta até atingir a um valor máximo, ou seja, 100\%, onde é seu limite (Khan, 1994). 


\subsection{Acelerador Linear}

Os aceleradores lineares atualmente são os equipamentos mais utilizados nos setores de radioterapia. São empregados em vários tratamentos que englobam as mais modernas modalidades especiais nos tratamentos radioterápicos, como a irradiação total da pele com elétrons e a radioterapia com arco de elétrons (Metcalfe et.al, 2007).

As acelerações dos elétrons acontecem linearmente por uma onda eletromagnética, em partículas, por uma onda de radiofrequência. Os elétrons são injetados no lado do tubo onde a velocidade da onda é mínima e são carregados por ela, aumentando a sua velocidade na mesma proporção que a da onda. Quando estes elétrons acelerados deixam o guia de onda, colidem com um alvo metálico (geralmente tungstênio) e produzem raios X; ou, o alvo pode ser removido e teremos um feixe de elétrons de alta energia (Scaff, 1997).

Vários tipos de LINACs são utilizados nos departamentos terapêuticos, como os que fornecem apenas raios $\mathrm{X}$ de 4 ou $6 \mathrm{MeV}$, outros produzem elétrons de diferentes energias e raios $\mathrm{X}$ no mesmo equipamento. Estas diferenças retratam o aumento da sofisticação de uma das cinco gerações de LINAC moderno. Um equipamento típico gera fótons de duas energias (6 e18 MeV) e elétrons de várias energias nominais (6, 9, 12, 16 e $22 \mathrm{MeV}$ ) (IAEA, 2005).

\subsection{Dosimetria em Radioterapia}

A verificação da dose no paciente tem sido recomendada para a melhoria da qualidade do tratamento radioterápico do paciente por vários organizações como a AAPM (American Association of Physicists in Medicine) e a ESTRO (Europian Society for Radiotherapy and Oncology).

A dosimetria in vivo tem se tornado uma parte importante no programa de garantia de qualidade (GQ) nos departamentos de radioterapia e tem provado ser muito útil na determinação da dose aplicadada a um determinado paciente, bem como na detecção de vários tipos de erros no processo de aplicação da dose (ESTRO, 2001; ICRU, 1976). O principal objetivo da dosimetria é designar, com maior precisão e exatidão a dose absorvida pelo tumor, garantindo dessa forma que a dose entregue ao paciente é a prescrita.

A Comissão internacional de Unidades e Medidas (ICRU) recomenda para o tratamento radioterápico a necessidade de exatidão de 5\% na liberação da dose no tumor, quanto a incerteza total do tratamento (ICRU 24, 1976). 
Vários tipos de dosímetros vêm sendo empregados em feixes de elétrons de energias altas. Na área médica os mais utilizados são as câmaras de ionização (Berger, 1976; Kase, 1982; Ehrlich, 1976; Rudén, 1976), os dosímetros termoluminescentes (Ehrlich, 1976; Soares, 1982; Lubbert, 1985; Campos, 1990), e os dosímetros Fricke (Fregene, 1976).

\subsection{Protocolo de Dosimetria}

A estipulação da exequibilidade de cura do tumor, tratamentos paliativos e a eficácia radiobiológicas preconizam que as incertezas dosimétricas sejam admissíveis e menor do que as incertezas relacionadas com a proporção volume tumor e sua resposta. É a partir deste seguimento que se introduz os protocolos para encetar os parâmetros para a dosimetria de feixes de elétrons e fótons de alta energia (AAPM, 1983), tendo como principal finalidade, determinar, com maior acurácia e exatidão, a dose absorvida pelo tumor. Pode ser determinado através da calibração do feixe de radiação e da realização da dosimetria de rotina para o controle de garantia de qualidade, tanto do equipamento radioterápico, como para o tratamento que o paciente é submetido (Metcalfe et al, 2007).

Uma nova abordagem foi proposta para calibração dos feixes de radiação de elétrons de energias máximas entre 5 e $50 \mathrm{MeV}$ e de feixes de fótons do ${ }^{60} \mathrm{Co}$, de tensões de aceleração entre 2 e $50 \mathrm{MeV}$, tendo como substrato a determinação da dose na água e sendo assentido a utilização de objetos simuladores plásticos na dosimetria de rotina para controle de qualidade.

O Task Group N N$^{0} 21$ (AAPM, 1983) também faz menção sobre o êxito do tratamento radioterápico, onde provém da precisão prescrita da dose a qual não pode oscilar mais do que $\pm 5 \%$ sobre o valor apropriado.

O protocolo Task Group (TG-51) do Comitê de Radioterapia da Associação Americana de Físicos em Medicina (AAPM), visa a calibração dos feixes de radiação de elétrons de energias máximas entre 4 e $50 \mathrm{MeV}$ e de feixes de fótons com energias entre a do ${ }^{60} \mathrm{Co}$ e $50 \mathrm{MeV}$. As dosimetrias de referência são executadas em um objeto simulador de água. As medidas são efetuadas com uma câmara de ionização, sendo imprescindível o cálculo da dose absorvida para fatores de correção na água (Almond et al, 1999).

A AAPM publicou um novo protocolo de práticas, o TRS-398, (IAEA, 2000) com uma abordagem sistemática para a calibração dos feixes administrados no tratamento radioterápico, onde integra os feixes de elétrons com energia de incidência entre 3 e $50 \mathrm{MeV}$, utilizando câmara de ionização sendo calibradas com dose absorvida na água, tendo como parâmetros o laboratório de padrões primários. 


\subsection{Dosimetria Termoluminescente}

A termoluminescência é um fenômeno conhecido desde 1663, por Robert Boyle, onde foi notificada a Sociedade Real, em Londres, por ter observado a emissão de luz por um diamante, quando este fora aquecido no escuro (Mackeever, 1995). Subsequentemente outros cientistas como Henri Becquerel iniciaram alguns trabalhos com a termoluminescência. Outros estudos obtidos por Marie Curie em 1904 constatou que as propriedades termoluminescentes dos cristais podiam ser restauradas, após a exposição dos mesmos à radiação do elemento rádio. Outros trabalhos experimentais com o fenômeno TL foram desenvolvidos por Urbach entre 1930 e 1940 (Mackeever, 1995; Horowitz, 1984). O primeiro modelo que permitiu cálculos quantitativos da cinética TL foi desenvolvido por Randall e Wilkins em 1945. Outros modelos foram desenvolvidos baseados no modelo de Randall e Wilkins, na tentativa de adequar melhor a teoria aos resultados experimentais (Cameron, 1968).

O fenômeno TL foi proposto como um instrumento adequado para a dosimetria de radiação por Farrington Daniels em 1950, sucedendo as primeiras aplicações da TL em dosimetria com o Fluoreto de Lítio, para mensurar a radiação após um teste com uma bomba.

Os trabalhos efetuados por Daniels foram interrompidos em 1955. No ano de 1960 na Universidade de Winconsin, J.R. Cameron restabeleceu as pesquisas nessa área contando com a contribuição de Daniels e Johnson, um estudante formado em geologia (Cameron et al, 1968).

\subsection{Termoluminescência}

A técnica da termoluminescência pode ser constatada no decurso da estimulação de semicondutores ou isolantes cristalinos, os quais foram anteriormente excitados, por terem sido expostos a radiação ionizante. A excitação eleva o cristal a um estado metaestável, caracterizado por elétrons e buracos separadamente armadilhados nos defeitos do cristal. Durante o decurso da leitura o aquecimento estimula a liberação desses elétrons e buracos dos centros de armadilhamento, sucedendo em uma recombinação dos pares elétrons-buracos e excitação dos centros de luminescência no cristal. O método respalda-se da emissão de fótons quando esses centros de luminescência excitados decaem ao estado fundamental (Mackeever et al.,1995; Olko, 2010; Yukihara e Mckeever, 2011).

O fenômeno TL é possível devido à estrutura de níveis de energia do cristal (detector): as bandas de valência e condução são as principais bandas de energia e entre elas 
existe uma faixa larga de estados energéticos "não permitidos" aos elétrons, conhecid a como banda proibida. Esses níveis de energia ocorrem devido aos defeitos do cristal. Quando o detector é exposto à radiação ionizante, elétrons da banda de valência são excitados e são conduzidos à banda de condução, deixando um "buraco" (ausência de elétron) na banda de valência. Ambos, elétrons e buracos, são livres para se mover nas respectivas bandas até serem capturados pelas armadilhas, que são estados metaestáveis de energia localizados na banda proibida, ou ocorrer recombinação. A quantidade de carga armadilhada é proporcional à dose absorvida (Yukihara e Mckeever, 2008).

Com o aquecimento, os elétrons armadilhados são liberados para a banda de condução e assim permite-se que haja uma recombinação com os "buracos", emitindo luminescência - a TL. Portanto, a emissão de luminescência é proporcional à dose absorvida pelo detector.

Ulteriormente à irradiação há um período de latência caracterizado por uma concentração metaestável de elétrons e buracos armadilhados. A probabilidade de fuga induzida termicamente das cargas armadilhadas é desprezível à temperatura ambiente se os poços de potencial associados aos centros de armadilhamento são suficientemente profundos. A energia absorvida pelo cristal durante o processo de excitação, que é a dose absorvida de radiação, está relacionada com a concentração relativamente estável de elétrons e buracos armadilhados; isso denota a informação latente sobre o campo de radiação (Yukihara e Makeever, 2011).

\subsection{Dosímetros Termoluminescentes}

Os dosímetros termoluminescentes (TLD) desempenham um papel importante em radioterapia para a dosimetria da radiação ionizante (Mckinlay, 1981; Mansfield, 1976). Este tipo de dosímetro apresenta vantagens que os torna uma ferramenta útil, em particular, para medidas em simuladores antropomórficos (K nöös, 1986; Gooden, 1972) e para dosimetria in vivo em pacientes (Kronetal, 1994; Daniels, 1953).

Em radioterapia, a maioria das medidas utilizando dosímetros termoluminescentes tem sido feitas empregando o fluoreto de lítio (LiF), geralmente o TLD-100, comercializado pela Harshaw, que já têm uma longa história neste tipo de aplicação (Campos, 1986). Mais recentemente, tem sido caracterizados e utilizados os micro dosímetros de LiF, que são detectores semelhantes aos TLD-100, porém com dimensões de $1 \mathrm{x} 1 \mathrm{x} 1 \mathrm{~mm}^{3}$. As dimensões mínimas permitem a sua utilização com algumas vantagens, principalmente na monitoração in vivo (Bravim, 2014). 
Novos materiais dosimétricos vêm sendo avaliados para possível aplicação na área de dosimetria clínica. Um material termoluminescente, o $\mathrm{CaSO}_{4}: \mathrm{Dy}$, tem sido intensamente empregado em medidas de dose em nível de radioproteção (Campos, 1987; Campos, 1983; Kumar, 2016) devido à sua alta sensibilidade. Este material, apresenta um extenso intervalo de linearidade da resposta com a radiação, que vai de $\mu \mathrm{Gy}$ a Gy (Campos, 1987) tem sido bastante avaliado para aplicações relacionadas à radioterapia, principalmente envolvendo feixes de elétrons (Nunes, 2008). $\mathrm{O} \mathrm{CaSO}_{4}$ :Dy é fabricado e comercializado pelo Laboratório de Materiais Dosimétricos da Gerência de Metrologia das Radiações/IPEN (Bravim, 2015).

Para garantir a qualidade do tratamento nos departamentos de radioterapia e manter as incertezas dosimétricas em $\pm 5 \%$ conforme recomenda a Comissão Internacional de Unidades e Medidas (ICRU) (Report 24, 1976) os parâmetros dosimétricos a serem analisados para a utilização dos dosímetros TL ou OSL na dosimetria clínica são:

- Estabilidade do Sinal

- Reprodutibilidade

- Repetibilidade

- Linearidade

- Limites mínimo e máximo de detecção

- Instabilidade do Sinal

- Decaimento térmico e óptico

- Reutilização dos dosímetros

- Dependência energética da resposta

\subsubsection{Propriedades Dosimétricas}

\subsubsection{Curva de Emissão}

A curva de emissão evidencia a variação da resposta TL em função da temperatura de aquecimento durante a leitura ou do tempo de aquisição (Metcalfe et al, 2007). A curva do material TL em função da temperatura apresenta picos e cada pico de emissão está relacionado a uma determinada armadilha, que pode ser tanto de elétrons como de buracos. A elaboração de um pico de emissão TL está associada à viabilidade de escape do buraco ou elétron, condizente à armadilha. A luz emitida se torna pouco intensa, quando a temperatura do material é menor do que a do pico reputado, desta maneira poucos portadores de cargas 
(elétrons e buracos) são liberados. Quando há um aquecimento do material, a possibilidade de escape aumenta ocasionando um aumento da emissão TL, que se torna máxima na temperatura do pico. Há uma redução dos portadores de carga armadilhados, quando a intensidade da luz minimiza (Oberhofer e Scharmann, 1981; Campos, 1998).

\subsubsection{Variação da Resposta TL com a Dose}

A curva de dose resposta é assentida como a relação da dose de radiação absorvida pelo detector e a intensidade da resposta TL. Para o material dosimétrico o ideal seria que ele apresentasse uma dose-resposta linear em um amplo intervalo de dose. Os dosímetros denotam um limite inferior de detecção (LID) abaixo do qual esses dosímetros não conseguem diferenciar as doses com que foram irradiados. O comportamento da curva se apresenta linear a partir do LID até uma região onde a quantidade de luz emitida cresce mais rápido e essa região é denominada de supralinear. Para dose com valores mais altos, a resposta TL pode saturar reduzindo desta maneira a sensibilidade do dosímetro (Mackeever et al, 1995).

\subsubsection{Sensibilidade}

A sensibilidade de um dosímetro TL pode ser expressa, em geral, como a resposta TL por unidade da dose na amostra (Mackeever, 1995; Furetta, 2003). A sensibilidade relativa, na execução da prática, compara-se a resposta TL do material com a resposta TL do LiF (TLD-100) que é apreciado com a sensibilidade igual 1. Sendo definida na Eq. 2.

$$
S_{D T L} \frac{R_{T L}}{D}\left[\frac{\mu C}{G y}\right]
$$

Onde:

S (D) é a sensibilidade relativa do material TL;

$\mathrm{R}_{\mathrm{TL}} \mathrm{e}$ a resposta $\mathrm{TL}$ do material;

D é a dose de radiação a que o material TL é submetida. 


\subsubsection{Estabilidade e Reprodutibilidade}

A estabilidade é uma variação ou não da resposta do dosímetro entre o tempo que este foi exposto à irradiação e no instante da sua leitura. É um processo que pode ser influenciado por condições ambientais como umidade e temperatura. Outra particularidade para qualquer material dosimétrico é a reprodutibilidade que esta relacionada a acurácia. A acurácia demonstra a dispersão dos valores obtidos, e um bom material dosimétrico deve ser reprodutível para as mesmas condições de análise. Para se obter a reprodutibilidade para uma determinada dose, pode ser efetuado o cálculo do desvio-padrão de uma série de repetições da mesma análise (Oberhofer e Scharmann, 1981). Com a obtenção de um menor desvio-padrão, maior será a acurácia, tendo uma maior reprodutibilidade.

A exatidão é o quão um valor experimental está próximo do valor verdadeiro. A diferença obtida do valor experimental do valor verdadeiro é designada de erro. Quanto menor for o erro, maior será a exatidão, então uma medida pode ser precisa mais não necessariamente exata.

\subsubsection{Limite Inferior de Detecção (LID)}

O limite inferior de detecção, ( $L I D)$ é a dose mínima medida a partir da dose zero, sendo expressa na Eq. 3 (Oberhofer e Scharmann, 1981).

$$
L I D=\left[T L(0)+\left(3 \cdot \sigma_{0}\right)\right] \cdot f_{c a l}
$$

Onde: $\sigma_{0}=$ Desvio-padrão da medida dos detectores não expostos à radiação;

$\mathrm{TL}(0)=$ leitura termoluminescente de dosímetros não irradiados $f_{\text {cal }}=$ Fator de calibração.

\subsubsection{Decaimento Térmico do Sinal}

O decaimento térmico é uma liberação de luz por consequência da liberação espontânea dos elétrons de suas armadilhas, tendo uma redução da resposta TL. Esta probabilidade de ocorrência é tanto maior quanto menor a diferença de energia entre a banda de condução e a armadilha. Esse decréscimo poder ocorrer por diversas causas, mas a principal é o decaimento da resposta TL (Mackeveer et al, 1995; Campos, 1998). 


\subsubsection{Tratamento Térmico}

O tratamento térmico tem por intuito restabelecer ao dosímetro as condições existentes antes da sua primeira exposição à irradiação. Este procedimento consiste em remover os sinais residuais de exposições que foram realizadas anteriormente, tornando-os aptos para a sua reutilização sem perda de suas propriedades dosimétricas (Cameron, 1968; Campos, 1998). Outro fator pode ser corrigido com o aquecimento é a sensibilidade, por isso, é necessário que esses materiais sejam submetidos a aquecimentos idênticos.

O tratamento térmico também influência na estrutura da curva de emissão TL. Desta maneira é necessário um forno com uma capacidade de manter a temperatura pré-estabelecida em um intervalo de tempo longo, já que a reprodutibilidade TL esta relacionada com a reprodutibilidade das taxas de aquecimento e resfriamento do fósforo (Oberhofer e Scharmann, 1981).

\subsubsection{Armazenamento e Manuseio}

A melhor forma de se manusear os dosímetros é com o auxílio de pinças, evitando que haja contaminação nos detectores, caso ocorra demandará primeiramente a limpeza desses detectores levando em consideração o método mais adequado para cada tipo de fósforo.

Apesar da radiação ultravioleta não alterar de maneira significativa a avaliação das doses características de tratamentos radioterápicos, indica-se evitar a exposição dos dosímetros à luz UV (Oberhofer e Scharmann, 1981).

\subsection{2 $\mathrm{CaSO}_{4}: \mathrm{Dy}$}

O Sulfato de Cálcio dopado com Disprósio é um material pouco explorado nos setores terapêuticos, tendo emprego em medidas de dose em radioproteção e no monitoramento das radiações beta e fótons (Nunes, 2008).

$\mathrm{O} \mathrm{CaSO}_{4}$ :Dy Fig. 4 é um TLD desenvolvido e produzido pelo LMD-IPEN, comercializado em forma de pó e pastilha de $6 \mathrm{~mm}$ de diâmetro com 0,2 e $0,8 \mathrm{~mm}$ de espessura, com massa de 10 a $50 \mathrm{mg}$ respectivamente. Este material apresenta dependência energética com a taxa de dose e com a temperatura de utilização e armazenamento que são pequenas no intervalo de doses utilizado em radioterapia. Suas propriedades dosimétricas são apresentadas na Tab 2. 


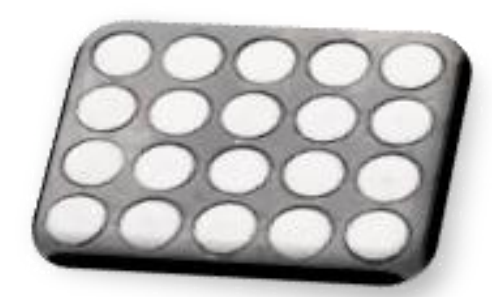

Figura 4. Pastilhas dosimétricas de Sulfato de Cálcio

Tabela 2. Propriedades dosimétricas do Sulfato de Cálcio. Campos e Lima, 1986.

\begin{tabular}{lc}
\hline Propriedades & CaSO $_{4}: \mathbf{D y}$ \\
\hline Material ativador & Dy \\
Número atômico efetivo $(\mathrm{Z})$ & 15,3 \\
Densidade $\left[\mathrm{g} \cdot \mathrm{cm}^{-3}\right]$ & 4,93 \\
$\begin{array}{l}\text { Decaimento térmico do pico } \\
\text { principal à temperatura ambiente }\end{array}$ & $5 \%$ ao ano \\
Tratamento térmico pré-irradiação & $300^{\circ} / 3 \mathrm{~h}$ \\
\hline
\end{tabular}

\subsubsection{Curva de Emissão}

Na Fig. 5 é demonstrados dois diferentes níveis de energia, aos quais estão associados a armadilhas, o primeiro de $145^{\circ} \mathrm{C}$ e o segundo de $250^{\circ} \mathrm{C}$. São dois picos de emissão que podem ser observados na curva de emissão do $\mathrm{CaSO}_{4}: \mathrm{Dy}$.

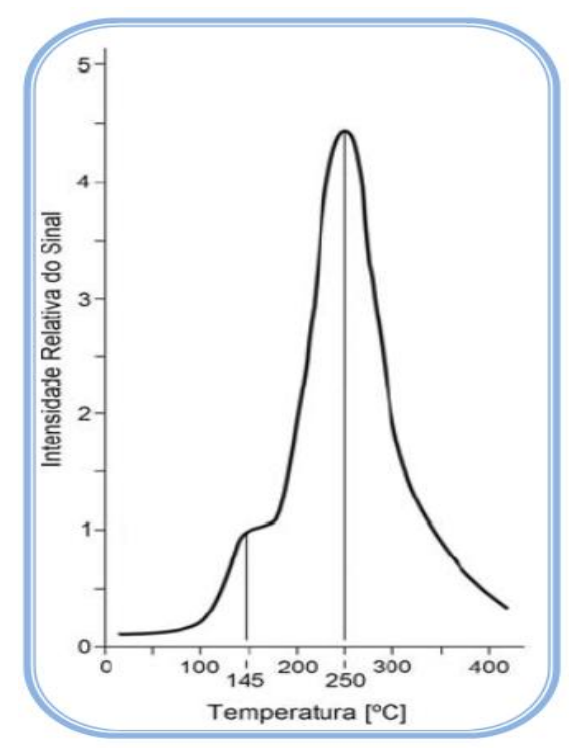

Figura 5. Curva de emissão do $\mathrm{CaSO}_{4}$ :Dy. Adaptado de Campos e Lima, 1986. 


\subsubsection{Curva Dose-Resposta}

$\mathrm{O}$ intervalo de linearidade do $\mathrm{CaSO}_{4}$ :Dy é de $\mu \mathrm{Gy}$ à $10 \mathrm{~Gy}$, sendo obtida uma saturação a aproximadamente $10^{4}$ Gy (Oberhofer e Scharmann, 1981).

É recomendado na dosímetria clínica que os TLDs possam ser utilizados apenas em região linear, porém, a aplicação na região supralinear é possível se a sua leitura for corrigida por uma curva de calibração verificada periodicamente com o TLDs e a leitora a serem utilizados (IAEA, 2005).

\subsubsection{Sensibilidade}

Um dos fatores que influenciam a sensibilidade do $\mathrm{CaSO}_{4}:$ Dy é o histórico de tratamentos térmicos do detector, principalmente, das taxas de aquecimento durante a leitura e de resfriamento após o ciclo a alta temperatura do tratamento térmico (Oberhofer e Scharmann, 1981).

$\mathrm{O} \mathrm{CaSO}_{4}$ :Dy apresenta uma perda de aproximadamente $2 \%$ a cada $10 \mathrm{~Gy}$ de radiação absorvida e a sua reprodutibilidade chega até 1,95\% para 20 ciclos de leitura com as mesmas cond ições (Cameron et al, 1968; Campos e Lima, 1986).

\subsubsection{Decaimento Térmico do Sinal TL}

O decaimento térmico do sinal TL é denominado como a redução do sinal TL devido à liberação espontânea dos elétrons de suas armadilhas, cuja possibilidade de ocorrência é tanto maior quanto menor a diferença de energia entre a banda de condução e a armadilha, com a conseqüente emissão de luz.

Se o $\mathrm{CaSO}_{4}$ :Dy for armazenado em uma blindagem de chumbo à temperatura ambiente, o mesmo apresentará um decaimento térmico do sinal de aproximadamente $5 \%$ ao ano (Campos e Lima, 1986).

\subsubsection{LiF:Mg,Ti}

O Fluoreto de Lítio é o material mais utilizado na radioterapia, foi desenvolvido pela Harshaw Chermical Company, Inc., USA em colaboração com Cameron. O LiF:Mg,Ti é comercializado como TLD-100, sua forma mais utilizada é a de amostras, com 3,1 x 3,1 mm² de área e com espessura que varia entre $0,14 \quad \mathrm{~mm}$ a $0,90 \mathrm{~mm}$ (Oberhofer e Scharmann, 1981; Mackeever et al, 1995).

O TLD-100 tem um número atômico efetivo próximo ao do tecido humano, a dependência de sua resposta com a energia, a taxa de doses e as temperaturas de utilização e 
armazenamento são pequenas no intervalo de doses da radioterapia e é possível alcançar na prática clínica uma acurácia melhor que $\pm 5 \%$ com as medidas efetuadas com o TLD-100, sendo muito recomendado nas aplicações médicas (Nunes, 2008).

Os micro dosímetros de LiF vem ganhado bastante importância nos departamentos de radioterapia. Esses detectores permitem medidas in vivo com grandes vantagens devido às suas dimensões mínimas de 1 x1 x1 mm².

\subsubsection{Curva de Emissão}

Na curva de emissão do LiF:Mg,Ti situam-se seis diferentes picos de emissão a uma temperatura de $250^{\circ} \mathrm{C}$, que estão concernentes a diferentes armadilhas. Os picos IV e V, são utilizados para avaliação da leitura da dose no LiF:Mg,Ti, para propósito dosimétrico Fig. 6.

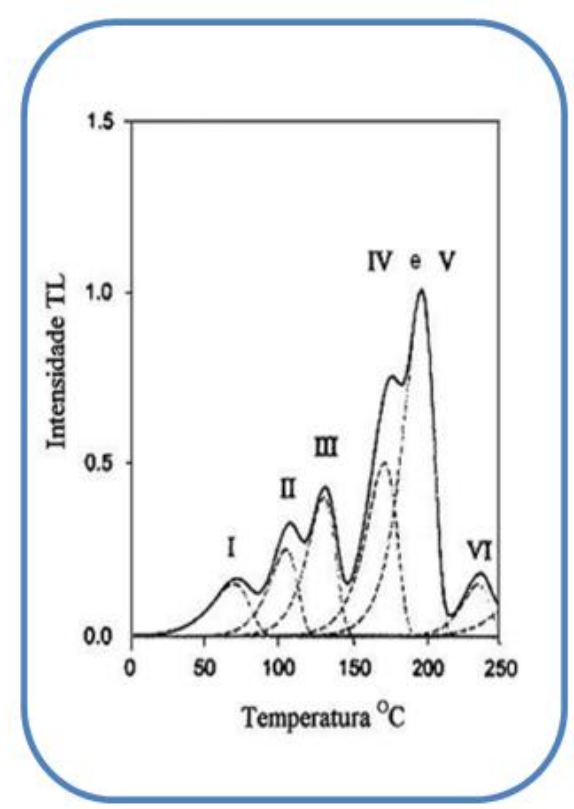

Figura 6. Curva de emissão TL do LiF:Mg,Ti. Adaptado de Metcalfe et al, 2007.

Tabela 3. Características dos picos dosimétricos do LiF:Mg,Ti. Metcalfe et al, 2007.

\begin{tabular}{cccc}
\hline Pico & $\begin{array}{c}\text { Diferenças } \\
\text { energéticas } \\
\text { aproximadas }[\mathbf{e V}]\end{array}$ & $\begin{array}{c}\text { Temperatura } \\
\left.\text { da le itora[ }^{\mathbf{0}} \mathbf{C}\right]\end{array}$ & $\begin{array}{c}\text { Meia-vida a } \\
\text { te mpe ratura } \\
\text { ambiente }\end{array}$ \\
\hline 1 & 1,02 & 70 & 10 minutos \\
2 & 1,07 & 105 & 20 horas \\
3 & 1,05 & 130 & 6 meses \\
4 & 1,53 & 170 & 10 anos \\
5 & 2,21 & 195 & 80 anos \\
\hline
\end{tabular}




\subsubsection{Curva Dose - Resposta}

O pico de emissão a valiado pode influenciar a supralinearidade e diversos picos na curva podem apresentar comportamento supralinear diferenciado. Este comportamento supralinear depende da sua composição química, além de variar com alguns fatores como: taxas de resfriamento, temperaturas de aquecimentos e o histórico dos tratamentos térmicos.

O TLD-100 possui um intervalo de linearidade de $\mu$ Gy à 10 Gy e o sinal de saturação ocorre em uma dose de aproximadamente $10^{3} \mathrm{~Gy}$ (Metcalfe et al, 2007).

\subsubsection{Sensibilidade}

O TLD-100 demonstra uma perda na sensibilidade em torno de 1,5\% a cada $10 \mathrm{~Gy}$ de radiação absorvida. A sua reprodutibilidade é de 1,1\% para um mesmo valor de dose, com uma variação de até 5\% para cada etapa dos ciclos de leitura (Cameron et al, 1968; Eggermont et al, 1971).

\subsubsection{Decaimento Térmico}

O LiF:Mg,Ti demonstra decaimento térmico da resposta TL em temperatura ambiente de 5 a $10 \%$ por ano. Os distintos tratamentos térmicos pré e pós-irradiação pode eliminar a componente do sinal TL originada pelos picos de meias-vidas curtas, com energias e temperaturas de leitura menores, sendo indesejável para a avaliação da dose no material (Metcalfe et al, 2007).

\subsubsection{Luminescência Opticamente Estimulada}

A luminescência opticamente estimulada foi sugerida pela primeira vez por Antonov-Romanovskii (et al.) no ano de 1950, como uma ferramenta de dosimetria individual. Mesmo obtendo uma alta sensibilidade, o principal obstáculo identificado naquela época foi a alta perda do sinal (fading) a temperaturas ambientes nos materiais de sulfeto utilizados, MgS, CaS e SrS dopados com os íons de terras raras Sm e Eu. Este acontecimento fez com que o foco das pesquisas se direcionasse para as técnicas de TLD (Mackeever, 2001; Sousa, 2009).

Na década de 1980 a OSL tornou-se apreciada com uso na arqueologia e datação a geológica pela técnica de dosimetria retrospectiva (Akselrod et al., 2007).

A OSL é um sinal emitido por um isolante ou semicondutor quando este é exposto à luz, após ter sido irradiado. A intensidade do sinal OSL é proporcional à dose de radiação absorvida pelo detector. O processo é similar ao da termoluminescência, mas difere quanto à 
estimulação: ao invés da estimulação térmica, na OSL os defeitos no detector são estimulados por meios ópticos.

Como já foi mencionado anteriormente, a informação armazenada na pastilha OSL pode ser obtida por estimulação óptica. No exemplo, um fóton com um comprimento de onda $\lambda_{\text {stim }}$ (luz verde) estimula o elétron da banda de condução. Uma vez na banda de condução, o elétron está livre para se mover pela rede do cristal e pode alcançar o buraco (que encontra-se armadilhado). O processo de recombinação do par elétron-buraco cria um defeito no estado excitado, o qual relaxa ao estado fundamental pela emissão de um fóton de comprimento de onda $\lambda_{\mathrm{OSL}}$ (luz azul), esquema demonstrativo na figura 7. (Matsushima, 2015).

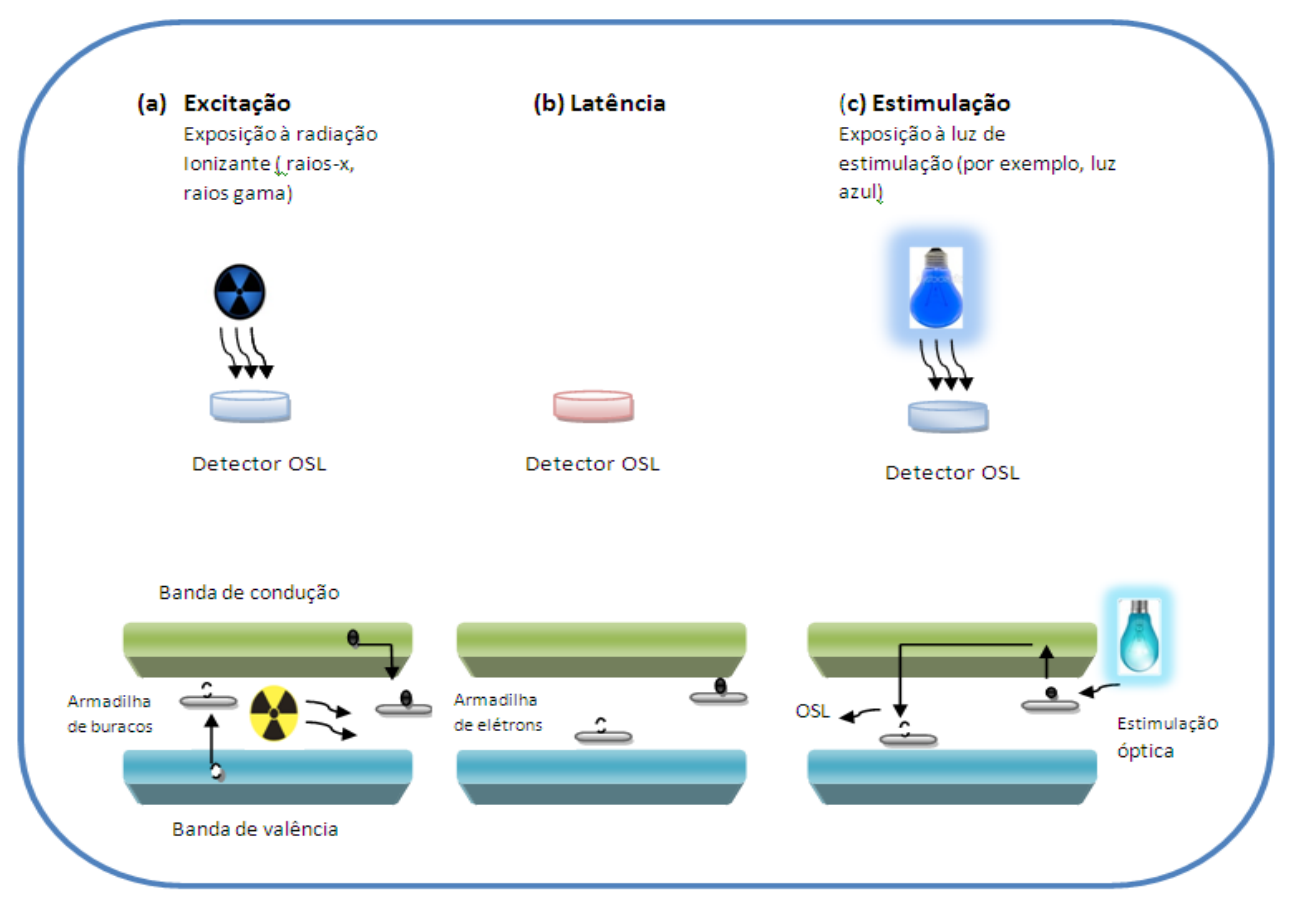

Figura 7. Teoria das bandas da Lu minescência Optica mente Estimu lada. (Adaptado de Matsushima, 2015).

\subsubsection{1 $\mathrm{Al}_{2} \mathrm{O}_{3}: \mathrm{C}$}

O Óxido de Alumínio crescido em baixa pressão na atmosfera de Carbono $\left(\mathrm{Al}_{2} \mathrm{O}_{3}: \mathrm{C}\right)$, de maneira geral, tem fornecido bons resultados como detector luminescente (Tillander et al, 2000; Yukihara e Mackeever, 2001; Yusof, 2017)). Esses dosímetros possuem vantagens sobre os TLDs pela sua alta sensibilidade, extensa linearidade em resposta à dose (exposições da ordem de $1 \mu$ Gy a 10 Gy) (Akselrod et al, 2007; Bos, 2017) maior rapidez de leitura, possibilidade de múltiplas releituras e a não necessidade de realizar o tratamento térmico das amostras (Mackeever, 2001; Viamonte et al, 2008; Kalita, 2017). 
Além disso, os processos eletrônicos e características dos cristais dosimétricos utilizados são relativamente similares ao método TL. A diferença significativa está no método de leitura: a avaliação dos detectores OSLé realizada por luz Laser ou LED ao invés de calor (Akselrod et al, 2007; Viamonte et al, 2008), como na TL. Não havendo necessidade de aquecimento, os cristais OSL podem ser envoltos em plástico, e, dessa maneira, são produzidos monitores mais robustos e eficientes (Mackeever, 2001; Mackeever, 2008) .

Pesquisas fazendo uso de dosímetros $\mathrm{OSL} \mathrm{Al}_{2} \mathrm{O}_{3}: \mathrm{C}$ na análise de feixes de energias altas em radioterapia vem sendo realizadas, desde seu uso para análise de parâmetros do feixe (ICRU 44) a técnicas de dosimetria de pacientes e medidas in vivo (Mackeever, 2001; Viamonte et al, 2008).

\subsection{Objetos Simuladores}

Objetos simuladores equivalentes à água, construídos com diferentes materiais, para utilização em diferentes áreas de atividade tem sido objeto de estudo (Tillander et al, 2000; Yukihara e Mackeever, 2001). A Comis são Internacional de Unidades e Medidas (ICRU), em suas publicações ICRU 44 e ICRU 48 discutem a construção de objetos simuladores e materiais substitutos do tecido para dosimetria das radiações. A publicação ICRU 48 recomenda o uso de simuladores com dimensões de $30 \times 30 \times 15 \mathrm{~cm}^{3}$ constituído de materiais equivalentes ao tecido recomendados na publicação 44, com uma referência ao PMMA (polimetilmetacrilato) preenchido com água (Kalef-Ezra, 2000). Esses objetos simuladores são constituídos por vários tipos de plásticos que possuem densidade eletrônica (número de elétrons por grama) e número atômico efetivo semelhante ao da água. Mesmo a água sendo o objeto simulador padrão para dosimetria de feixes de elétrons e fótons, diferentes materiais sólidos são utilizados para a realização de medidas dosimétricas como: PMMA, água sólida WT1 e água sólida RMI-457 (IAEA, 2005). 


\section{METODOLOGIA}

\subsection{Materiais}

- 44 TLDs de $\mathrm{CaSO}_{4}$ :Dy produzidos pelo IPEN de $6 \mathrm{~mm}$ de diâmetro, 0,8 $\mathrm{mm}$ de espessura e massa de $50 \mathrm{mg}$;

- 45 TLDs de LiF:Mg,Ti produzidos pela Harshaw de 3,15 mm de diâmetro, 0,9 mm de espessura e massa de $2 \mathrm{mg}$;

- 44 TLDs de $\mu \mathrm{LiF}: M g$,Ti produzidos pela Harshaw de 1,0 mm de diâmetro, 1,0 mm espessura e massa de $1 \mathrm{mg}$;

- 72 TLDs de $\mathrm{Al}_{2} \mathrm{O}_{3}: \mathrm{C}$ produzidos pela Rexon TLD Systems \& Components Inc. (EUA) fornecidos pela empresa brasileira Pro-Rad de $5 \mathrm{~mm}$ de diâmetro e $0,9 \mathrm{~mm}$ de espessura e massa de $72 \mathrm{mg}$.

Os dosímetros luminescentes são demonstrados na figura 8.

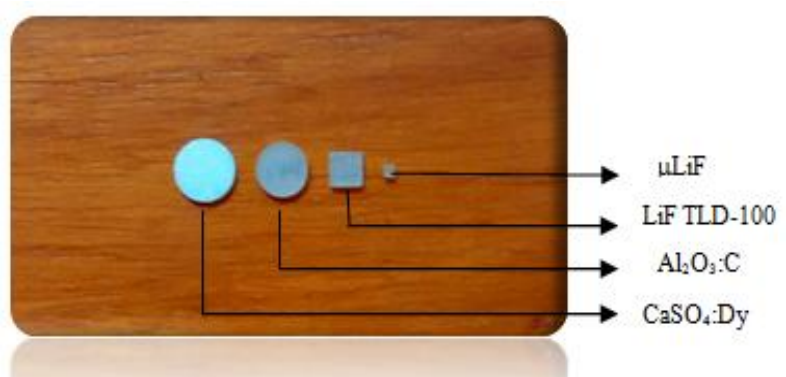

Figura 8. Dosímetros Lu minescentes

Os detectores foram selecionados de acordo com a sensibilidade e repetibilidade à radiação gama do ${ }^{137} \mathrm{Cs}$. A sensibilidade individual de cada fósforo apresentou uma variação máxima de $\pm \mathbf{5} \%$, para cada tipo de detector.

\subsection{Equipamentos}

\subsubsection{Sistemas de Irradiação}

- Fonte de radiação gama de ${ }^{137} \mathrm{Cs}$, geometria $4 \pi$ de atividade de $38,11 \mathrm{GBq}$ em 17 de Abril de 2014 do Laboratório de Dosimetria Termoluminescente (LDT/IPEN);

- Fonte de radiação gama de ${ }^{60}$ Co de atividade de 0,339 TBq em Setembro de 1999 do Laboratório de Calibração de Instrumentos (LCI/IPEN);

- Acelerador Clinac 23 EX ("High Dose Rate"- HDR = 1000/minuto) da Varian ("RapidArc") pertencente ao Hospital Israelita Albert Einstein (HIAE). 


\subsubsection{Simuladores}

- Objeto simulador antropomórfico AldersonRando® pertencente ao Hospital Israelita Albert Einstein (HIAE).

\subsubsection{Sistemas de Tratamento Térmico}

- Forno tipo mufla da marca Vulcan®, modelo 3-550 PD;

- Estufa cirúrgica da marca Fanen®, modelo 315-IEA 11200.

\subsubsection{Sistema de Tratamento Óptico}

- Lâmpadas de diodo emissor de luz (LED) azul da marca Ourolux®, de 1,3 watts de potência (composta por $30 \mathrm{LEDs}$ ).

\subsubsection{Sistemas de Leitura}

- Leitora TL/OSL da marca RISO ${ }^{\mathrm{TM}}$, modelo TL/OSL-DA-20;

- Leitora TL da marca Harshaw ${ }^{\mathrm{TM}}$, modelo 4500.

\subsubsection{Colimadores}

- Colimador para o $\mathrm{CaSO}_{4}: \mathrm{Dy}, 10 \mathrm{~mm}$ de diâmetro e abertura central com aproximadamente $1 \mathrm{~mm}$;

- Colimador para $\mathrm{o} \quad \mathrm{Al}_{2} \mathrm{O}_{3}: \mathrm{C}, 45 \mathrm{~mm}$ de diâmetro e abertura central com aproximadamente $2 \mathrm{~mm}$.

\subsubsection{Acessório de Posicionamento e Degradador Utilizado para o Tratamento -} TSI

- Plataforma giratória;

- Placa de acrílico com dimensões de (250 X 130) $\mathrm{cm}^{2}$. 


\subsection{Metodologia e Análises Realizadas}

\subsubsection{Preparação Para Uso dos Dosímetros}

Os dosímetros TL foram submetidos a tratamentos térmicos distintos. Os dosímetros $\mathrm{LiF}: \mathrm{Mg}$, Ti e $\mu \mathrm{LiF}: \mathrm{Mg}$,Ti receberam o tratamento térmico em duas etapas respectivas: em primeira instância eles foram dispostos no forno tipo mufla Vulcan, à uma temperatura de $400^{0}$ com um tempo de 1 hora, no término deste procedimento os dosímetros foram colocados por 2 horas na estufa Fanen à uma temperatura de $100^{\circ}$, sendo demonstrado na figura 9.

Os dosímetros $\mathrm{CaSO}_{4}: \mathrm{Dy}$, foram tratados no forno tipo mufla Vulcan, à uma temperatura de $300^{0}$ com um tempo de 3 horas (Bravim, 2015).

$\mathrm{O}$ tratamento óptico foi utilizado para os dosímetros de $\mathrm{Al}_{2} \mathrm{O}_{3}: \mathrm{C}$, onde estes ficaram expostos a lâmpadas de diodo emissor de luz (LED) azul, por um tempo determinado de 24 hora (Matsushima, 2015).

Um estudo de tempo de tratamento óptico foi realizado, analisando a resposta residual das amostras para diferentes doses, de acordo com diferentes tempos de exposição à luz LED, variando de 1 minuto até 24 horas.

a)

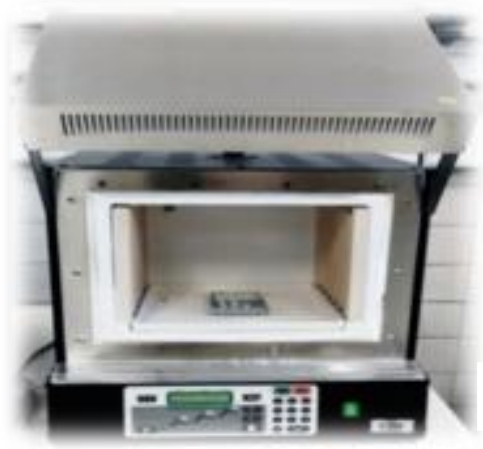

b)

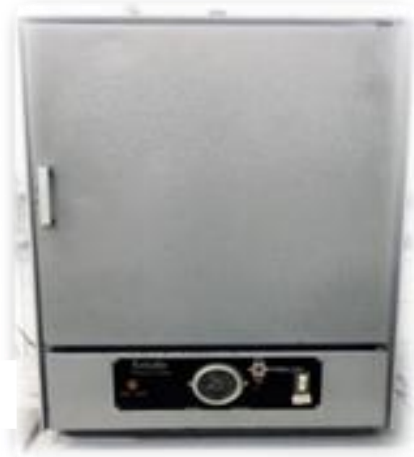

c)

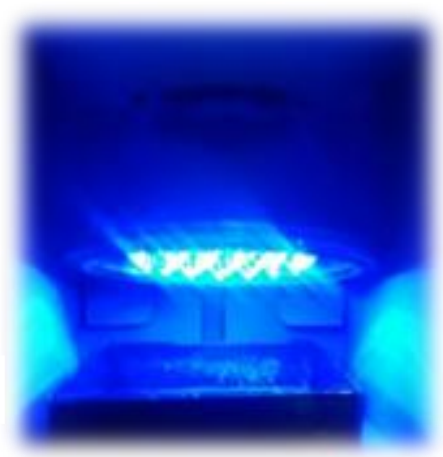

Figura 9. (a) Forno tipo mufla da marca Vulcan ${ }^{\circledR}$, (b) Estufa cirúrgica da marca Fanen ${ }^{\circledR}$ e (c) Lâmpada de diodo emissor de luz (LED) azul da marca Ourolux®.

\subsubsection{Testes de Estabilidade da Leitora TL}

Testes foram realizados para averiguação da estabilidade da leitora Harshaw ${ }^{\mathrm{TM}}, 4500$ (Fig. 10), cuja finalidade era verificar se a leitora apresentava algum tipo de variação. Os testes aos quais a leitora foi submetida resultou no teste de luz padrão (Test Light) e o da razão sinal/ruído (PMT Noise). Antecedendo o início de cada ciclo de leitura dos respectivos TLDs, foi realizado as leituras de luz padrão e sinal/ruído. Essas leituras também foram 
obtidas no final de cada ciclo. No conjunto de 10 leituras a variância não poderia ultrapassar $5 \%$.

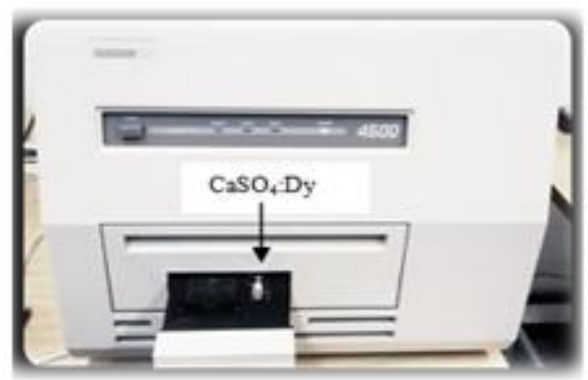

Figura 10. Leitora TL da marca Harshaw 4500.

\subsubsection{Testes de Estabilidade da Leitora OSL}

A leitora (RISO reader), demonstrada na figura 11 foi submetida a teste de funcionamento, como a contagem de fundo da fotomultiplicadora e o funcionamento do LED azul de estimulação. Testes de desempenho são realizados pela equipe de manutenção do fabricante periodicamente.

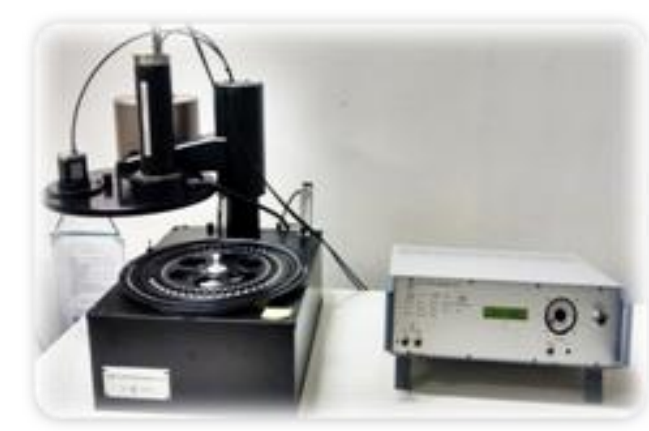

Figura 11. Leitora TL/OSL da marca RISOTM.

\subsubsection{Colimadores}

\subsubsection{Colimador para Leitura do $\mathrm{CaSO}_{4}: \mathrm{Dy}$}

$\mathrm{Na}$ Fig. 12 é demonstrado o colimador selecionado para as leituras do $\mathrm{CaSO}_{4}: \mathrm{Dy}$ com o propósito de restringir a intensidade do sinal transmitido pelos dosímetros TL (Villani, 2017).

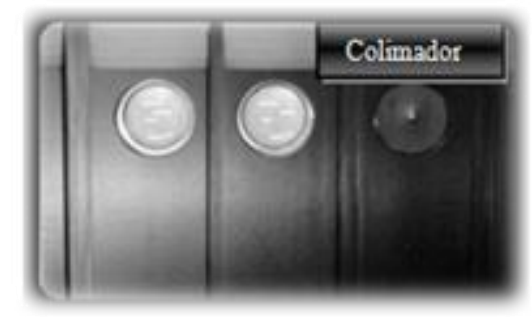

Figura 12. Bandeja da leitora Harshaw 4500 com colimador. 


\subsubsection{Colimador Para Leitura do $\mathrm{Al}_{2} \mathrm{O}_{3}: \mathrm{C}$}

Com o intuito de reduzir o sinal do Óxido de Alumínio em virtude da sua alta sensibilidade, verificou-se a necessidade de utilizar um colimador para proteger o tubo fotomultiplicador de atingir a saturação e possibilitar um intervalo de dosimetria mais amplo. Eles apresentam $45 \mathrm{~mm}$ de diâmetro e suas aberturas centrais são de aproximadamente $10 \mathrm{~mm}, 5 \mathrm{~mm}, 2 \mathrm{~mm}$ e $1 \mathrm{~mm}$ respectivamente (Fig. 13)

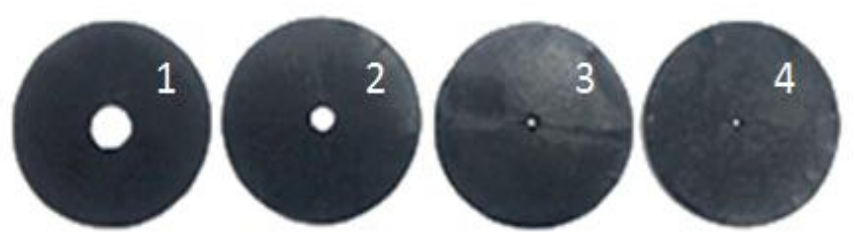

Figura 13. Colimadores utilizados na leitora OSL dos dosímetros $\mathrm{Al}_{2} \mathrm{O}_{3}: \mathrm{C}$ TLD-500.

$\mathrm{O}$ colimador selecionado para as realizações das leituras do $\mathrm{Al}_{2} \mathrm{O}_{3}: \mathrm{C}$, é o que possui uma abertura central de $2 \mathrm{~mm}$ (terceiro colimador) demonstrado na figura acima, utilizado em trabalho anterior (Bravim, 2015).

\subsubsection{Seleção dos Dosímetros e Testes de Desempenho}

Os dosímetros TL e OSL foram inicialmente separados em lotes de acordo com a sensibilidade, dentro de $\pm 5 \%$ em relação à radiação gama do ${ }^{137} \mathrm{Cs}$ (Fig. 14). Para isto, foram efetuadas quatro irradiações para reduzir o efeito da variação estatística. Os TLDs foram colocados entre placas de acrílico com uma espessura de $3 \mathrm{~mm}$, com o intuito de manter o equilíbrio eletrônico na irradiação. $\mathrm{O}$ aro (distância da fonte) utilizado para as irradiações foi de $30 \mathrm{~cm}$ com uma dose de $2 \mathrm{mGy}$. Os dosimetros OSL foram involucrados em papel alumínio por causa do "bleaching", tendo o mesmo procedimento que os TLDs, com uma distinção na aplicação da dose, onde para os OSL, a dose foi de 10 mGy.

a)

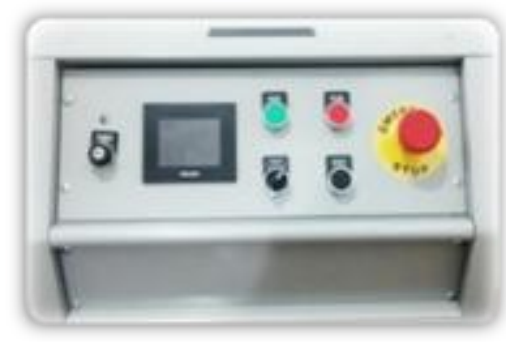

b)

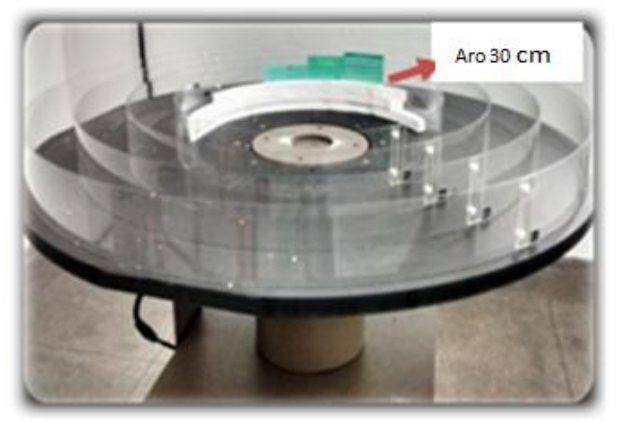

Figura 14. (a) Painel de Controle do ${ }^{137} \mathrm{Cs}$, (b) Fonte de ${ }^{137} \mathrm{Cs}$. 


\subsubsection{Caracterização dos Sistemas Dosimétricos}

Para caracterização, as curvas de resposta em função da dose para ${ }^{60} \mathrm{Co}$ foram obtidas utilizando o irradiador do LCI/IPEN no intervalo de doses de $0,03 \mathrm{~Gy}$ a $10 \mathrm{~Gy}$, livre no ar e em condições de equilíbrio eletrônico. Para utilização clínica, os dosímetros foram irradiados em feixe de elétrons de $6 \mathrm{MeV}$ do acelerador linear Clinac 23 EX (Fig. 15) no intervalo de doses de 28,7 cGy a 382,8 cGy, utilizando “Bolus”em profundidade de máxima dose $(1,0 \mathrm{~cm})$. O arranjo (setup) de irradiação de campo $(10 \times 10) \mathrm{cm}^{2}$ a uma distância focosuperfície $(\mathrm{SSD})$ de $100 \mathrm{~cm}$.

a)

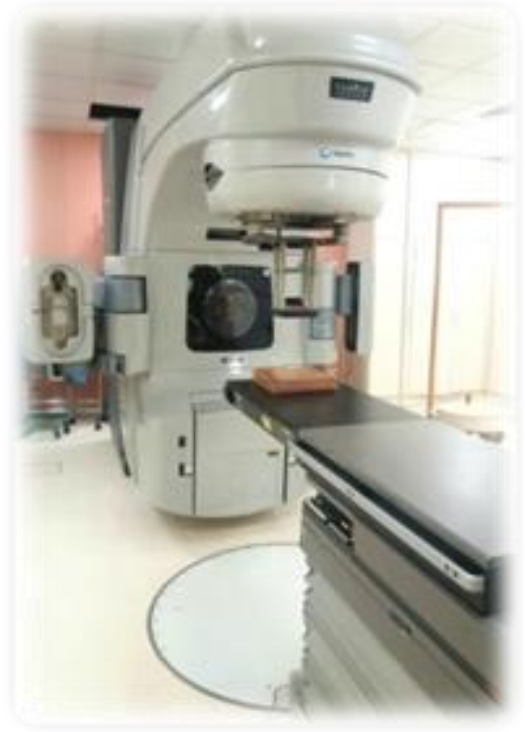

Figura 15. (a) Acelerador Clinac 23 EX ("High Dose Rate"-HDR=1000/minuto) da Varian ("RapidArc") - HIAE e (b) "Bolus" para preparação da curva de dose resposta.

\subsubsection{Uso do "Bolus"}

O "bolus" (Fig. 16) é um material que deve ser averiguado comparando a distribuição de dose com a profundidade no "bolus" com a água. Alguns materiais são comercialmente disponíveis para o uso como "bolus"(Lucite, Poliestireno, Superstuff, Superflab e Cera de parafina) (Khan, 2010).

Idealmente, este material deve ser equivalente ao tecido em "stopping power" e em poder de espalhamento. Nos tratamentos radioterápicos, as irradiações com feixes de elétrons pode-se colocar uma placa de material com um baixo número atômico (Lucite ou Poliestireno) podendo-se reduzir desta maneira a energia do feixe.

O "bolus" é altamente empregado em radioterapia com feixes de elétrons com a finalidade de: 
- Aumentar a dose na superfície;

- Achatar uma superfície irregular;

- Reduzir a penetração dos elétrons em algumas partes do campo (Matsushima, 2015).

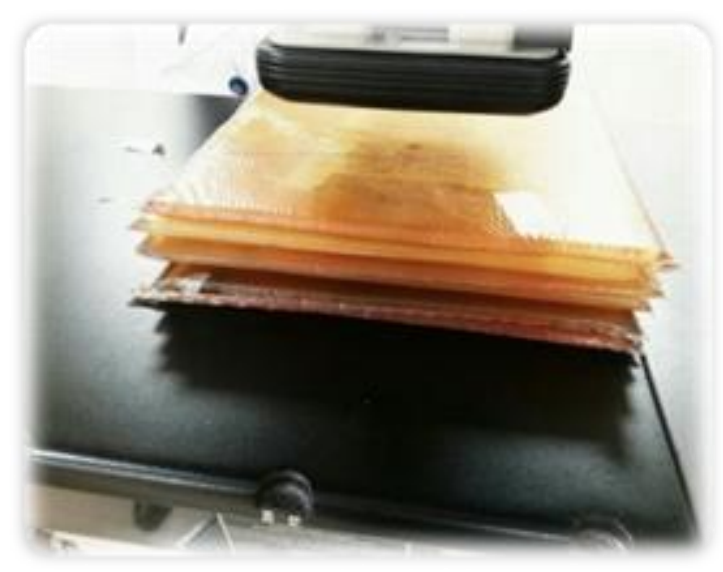

Figura 16. "Bolus"

\subsubsection{Sensibilidade Indi vidual dos Dosímetros Luminescentes}

Visando obter o mínimo de variação estatística, foi determinada a sensibilidade individual de cada dosímetro utilizado no trabalho. Através da sensibilidade foi adquirido o coeficiente de calibração individual, utilizado em todas as aplicações clínicas.

Para obter a sensibilidade foram feitas duas irradiações de 150 MU e 250 MU, energia de $6 \mathrm{MeV}$, uma profundidade de 1,3 $\mathrm{cm}$ (considerando a espessura das placas de acrílico de $3 \mathrm{~mm})$ com um campo de $(20 \times 20) \mathrm{cm}^{2}$ e uma distância de $100 \mathrm{~cm}$. Todos os dosímetros encontravam-se em condições de equilibrio eletrônico. Foi efetuado um planejamento CT utilizando o programa Elétron Monte Carlo Eclipse 13-6 da Varian Medical Systen. (Todos os valores de sensibilidade e o coeficiente de calibração são apresentados nos anexos 1 a 4$)$.

Na Fig. 17 é demonstrado o arranjo das amostras para determinação da sensibilidade dos dosímetros luminescentes. O planejamento e imagem do CT é demonstrado na figura 18. 


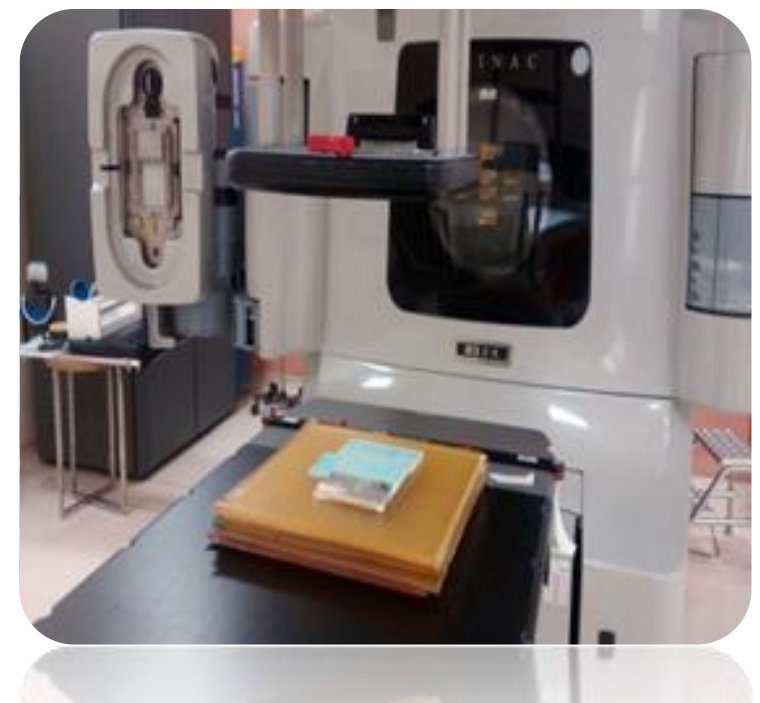

Figura 17. Arran jo experimental das amostras para determinação da sensibilidade dos dosímetros lu minescentes.

a)

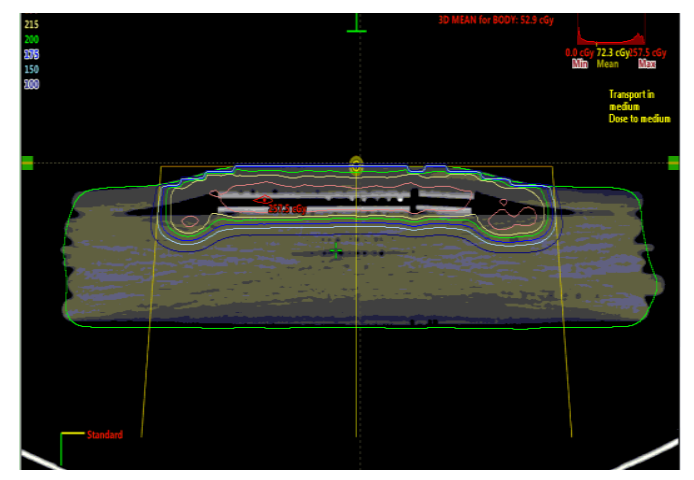

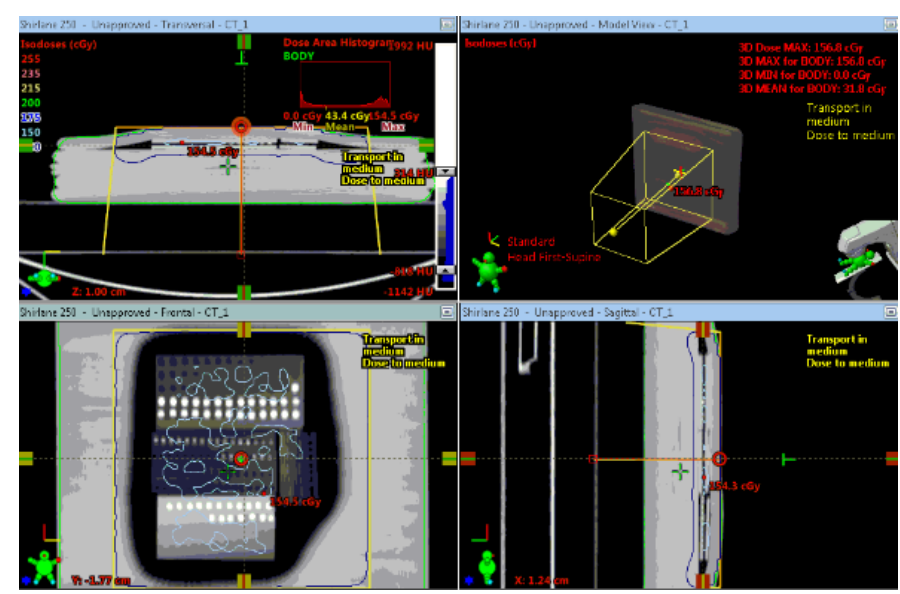

Figura 18. (a) Planejamento CT e (b) imagens CT do programa Elétron Monte Carlo Eclipse 13 -6 da Varian Medical Systen.

\subsubsection{Simulador Antropomórfico AldersonRando®}

O simulador AldersonRando® (Fig. 19) simula um homem padrão com 1,75 m e $73,5 \mathrm{~kg}$ sendo constituido por várias placas sobrepostas que permitem acoplar os dosímetros. O AldersonRando ${ }^{\circledR}$ é composto de um esqueleto humano natural dentro de um material que é radiobiologicamente equivalente ao tecido. A formulação do objeto simulador é constituído de uretano com um número efetivo e densidade de massa muscular com tecido adiposo (RSD, Alderson Phantoms). 


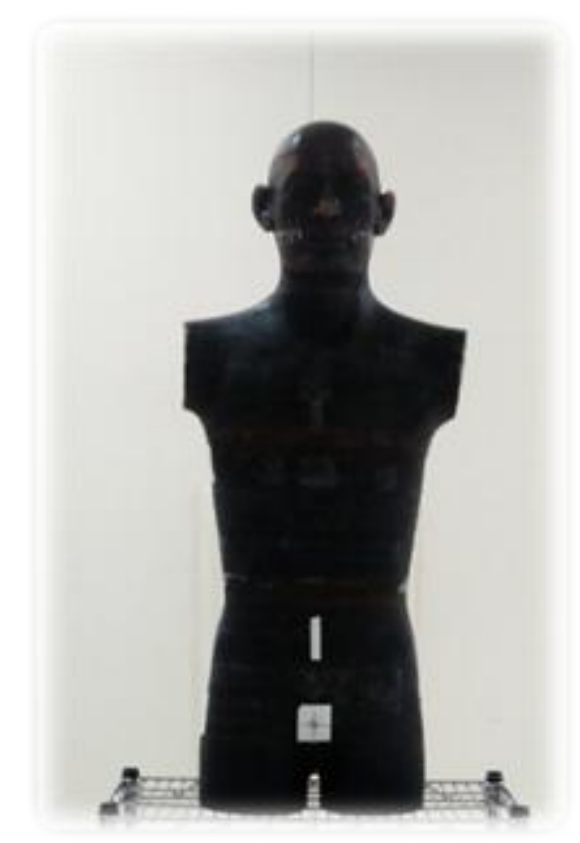

Figura 19. Simu lador AldersonRando®.

\subsubsection{Aplicações Clínicas}

\subsubsection{Homogeneidades do Campo para Irradiação TSI}

A finalidade do tratamento TSI é distribuir a dose em toda a extensão da superfície da pele do paciente de maneira homogênea. Para isto foram efetuadas irradiações para verificar a homogeneidade do campo.

Nesse estudo o campo foi inclinado $\pm 17^{0}$ com irradiação de campo duplo em relação ao eixo horizontal, tendo como referência a linha da cintura $\left(\mathrm{Z}_{\mathrm{Ref}}\right)$. Uma placa de PMMA de $0,5 \mathrm{~cm}$ foi utilizada entre o feixe de radiação primário e os dosímetros $\mathrm{CaSO}_{4}: \mathrm{Dy}$, $\mathrm{LiF}: \mathrm{Mg}, \mathrm{Ti}, \mu \mathrm{LiF}: \mathrm{Mg}, \mathrm{Ti}$ e $\mathrm{Al}_{2} \mathrm{O}_{3}: \mathrm{C}$ com uma distância de $50 \mathrm{~cm}$ do $\mathrm{Z}_{\text {Ref. }} \mathrm{O}$ tamanho do campo de irradiação foi de $(36 \times 36) \mathrm{cm}^{2}$, com uma distância de $4 \mathrm{~m}$ (distância do isocentro ao $Z_{\text {Ref }}$ de $3 \mathrm{~m}$ ). A energia aplicada foi de $6 \mathrm{MeV}$ com 470 Unidade Monitora (MU).

$\mathrm{Na}$ figura 20 é demonstrado o degradador ou placa de acrílico e a plataforma giratória. 
a)

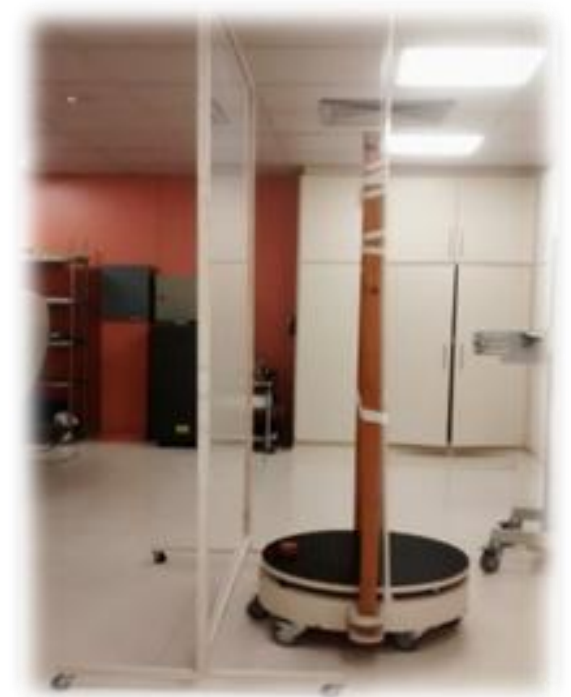

b)

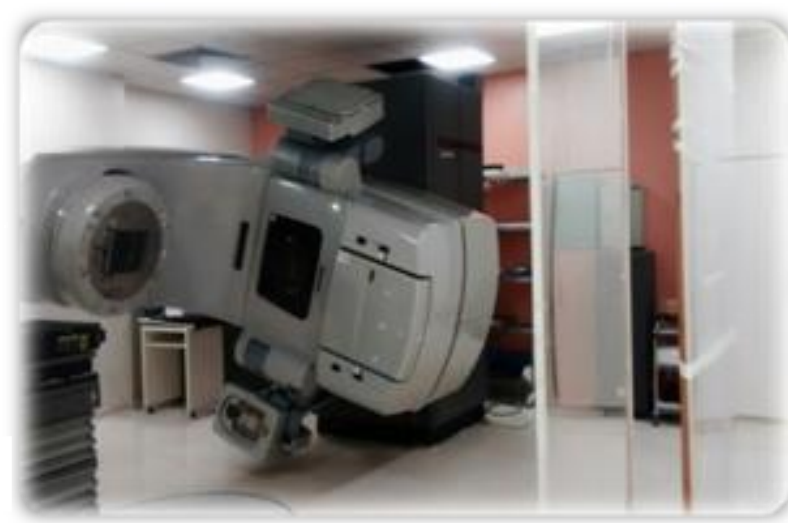

Figura 20. (a) e (b) Posicionamento do degradador e da plataforma giratória para homogeneidade do campo.

\subsubsection{Dose no Ponto de Calibração $\left(Z_{\text {Ref }}\right)$}

$\mathrm{Na}$ técnica TSI o paciente é tratado com dois campos duais, ou seja, o campo é composto por dois elementos do feixe, tendo como ponto de calibração a linha da cintura $\left(Z_{\text {Ref }}\right)$, para cima e para baixo, obtendo desta forma uma melhor prestância dos feixes. Para este estudo, foi empregado um objeto simulador antropomórfico AldersonRando® (Fig. 21), sendo posicionado a $60^{\circ}$ para cada campo dual. Os dosímetros foram divididos em cinco grupos e um grupo para controle. Os respectivos detectores foram situados nas regiões: anterior, posterior, lateral direita, oblíqua anterior direita e oblíqua posterior direita.

a)

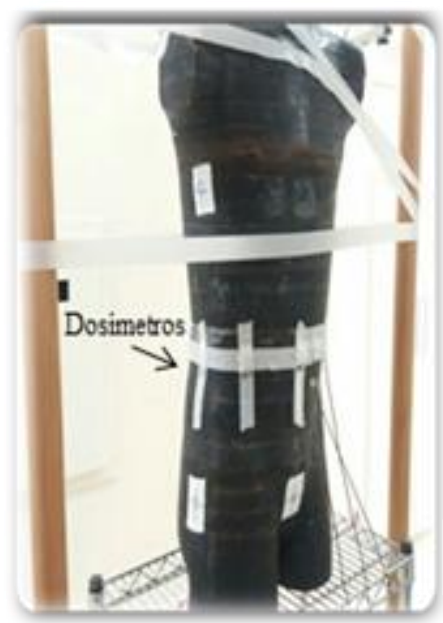

b)

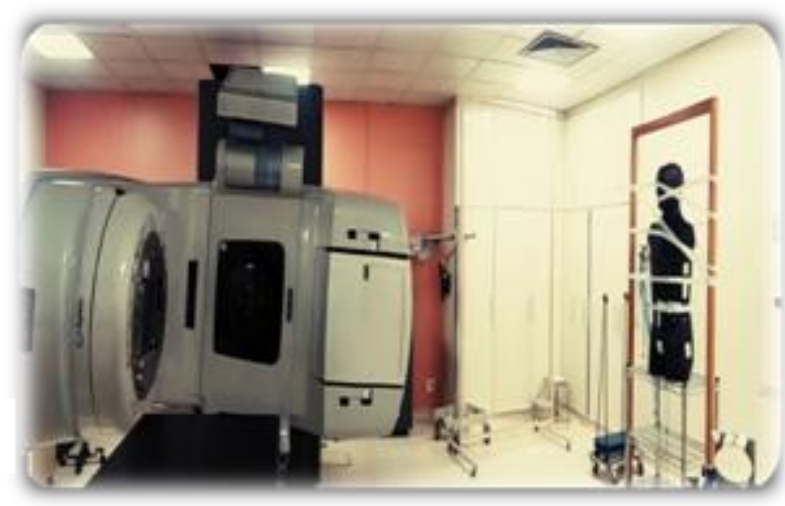

Figura 21. (a) Posicionamento dos dosímetros luminescentes, (b) Posicionamento do AldersonRando ${ }^{\circledR}$ para tratamento TSI. 


\subsubsection{Planejamento TSI - Irradiação Total da Pele}

Na técnica de Stanford o paciente é tratado por um ciclo de dois dias com três campos duais por dia (Fig. 22), ou seja, no primeiro dia o paciente é tratado na posição anterior e as oblícuas posteriores direita e esquerda. No segundo dia o paciente é tratado na posição posterior e as oblícuas anteriores direita e esquerda.

Quando o paciente é situado nas seis posições com uma irradiação de campo duplo em cada posição, a dose é considerada menos uniforme, devido a curvatura do corpo do paciente, os ângulos de incidências de elétrons que são variados e as orientações dos feixes. Os campos duais são usados para minimizar a contaminação de raios $\mathrm{X}$ do eixo central e a não uniformidade devida à lei do inverso do quadrado da distância (Report 23, 1987).

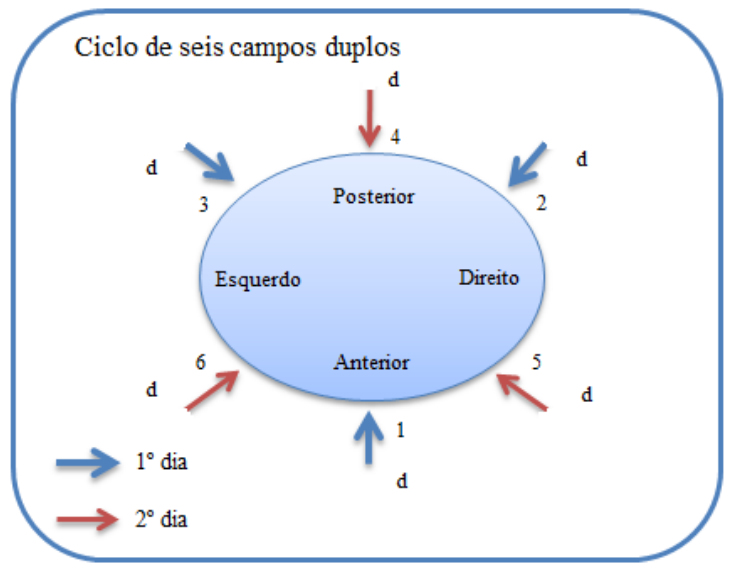

Figura 22. Esquema de monstrativo sequencial de dois dias alternados dos angulos de orientações para seis campos duplos (Report 23).

As seis obliquidades do paciente resultam em uma variação da dose que tem uma periodicidade de $60^{\circ}$. Esta variação é de cerca de $\pm 10 \%$ na superfície deixando cair $\pm 5 \%$ a uma profundidade de $3 \mathrm{~mm}$, significando que na técnica de seis campos duais a uma deposição da dose máxima muito mais superficialmente.

O degradador contribui para um grande campo de dispersão dos elétrons emergentes, isso melhora a uniformidade da dose, particularmente em superfícies oblíquas do corpo. A placa de acrílico é interposta no feixe de elétrons sendo necessário para superficializar a dose do feixe de $6 \mathrm{MeV}$.

O procedimento de irradiação para TSI adotou condições reais de tratamento, sendo utilizado um simulador antropomórfico, onde foi disposto em uma plataforma giratória. Os dosímetros TL e OSL foram situados em várias regiões anatômicas, com o intuito de verificar 
a distribuição da dose de entrada na pele. As doses foram adquiridas em dias alternados possibilitando um estudo maior em regiões subdosadas e sobredosadas.

Em todas as aplicações clínicas o dosímetro de LiF:Mg,Ti foi empregado como dosímetro padrão, os outros dosímetros utilizados foram relacionados com os resultados obtidos pelo LiF:Mg,Ti.

\subsubsection{Cálculo de Unidade Monitora (MU)}

A unidade monitora é um parâmetro inserido no console do acelerador linear onde indica a quantidade de radiação a ser emitida. Vários fatores que se dispõe no momento do planejamento devem ser considerados para que um valor de MU seja indicado para o acelerador linear e a dose correta de radiação seja entregue.

Para a determinação da unidade monitora todos os parâmetros essenciais e os resultados das medições de dose absorvida foram utilizados. Um conjunto de medições foi realizada utilizando um simulador antropomórfico AldersonRando®, onde foram posicionados os dosímetros luminescentes no $\mathrm{Z}_{\mathrm{Ref}}$ com uma dose de 210 cGy para todos os campos de irradiações. Os cálculos foram realizados por meio da equação 4 (Platoni, 2012; Cox, 1990).

$$
M U=\frac{{\mathrm{D} 6 \mathrm{CD}_{(\mathrm{Pr})}}_{\mathrm{D}_{\mathrm{CSH}} \cdot \mathrm{FC}_{\mathrm{CD}} \cdot \mathrm{FC}_{6 \mathrm{CD}}}}{{ }}
$$

Onde: $M U=$ Unidade Monitora para um único feixe horizontal;

$\mathrm{D}_{6 \mathrm{CD}}(\mathrm{Pr})=$ Dose prescrita para o $\mathrm{Z}_{\mathrm{ref}}$, por 6 campos duplos;

$\mathrm{D}_{\mathrm{CSH}}=$ Dose entregue em $\mathrm{Z}_{\text {ref }}$, por um campo simples horizontal;

$\mathrm{FC}_{\mathrm{CD} / \mathrm{CSH}}=$ Fator de correção. Relação de um campos duplo simples por um campo simples horizontal;

$\mathrm{FC}_{6 \mathrm{CD} / \mathrm{CD}}=$ Fator de correção. Relação de seis campos duplos por um campo duplo simples.

A simulação para obtenção da unidade monitora é demonstrado na figura 23. 


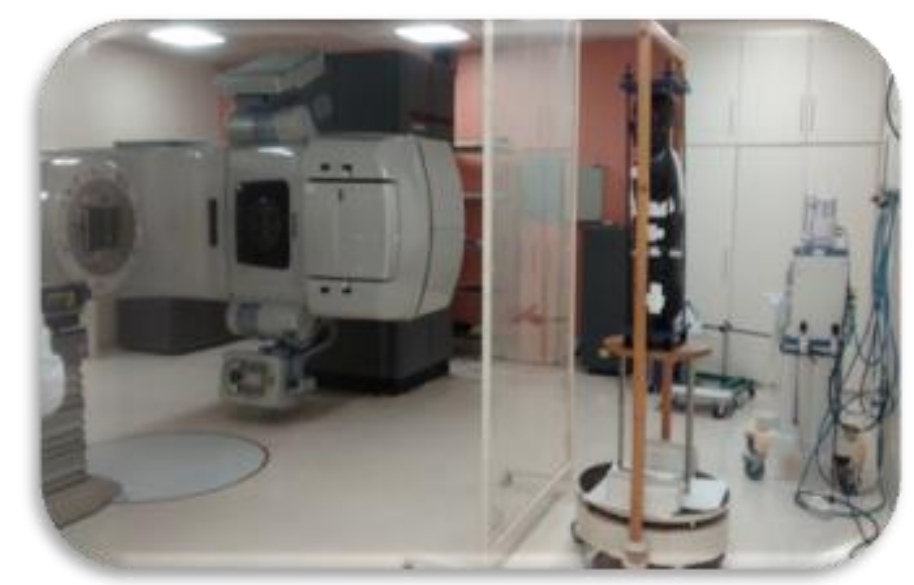

Figura 23. Simu lação do tratamento TSI com seis campos duplos para obtenção da unidade monitora.

\subsubsection{Análises de Incertezas}

A incerteza do resultado de uma medição reflete a falta de conhecimento exato do valor mensurando. O resultado de uma medição, após correção dos efeitos sistemáticos reconhecidos, é ainda e tão somente uma estimativa do valor do mensurando oriunda da incerteza proveniente dos efeitos aleatórios e da correção imperfeita do resultado para efeitos sistemáticos (GUM, 1995).

Na prática, existem muitas fontes possíveis de incerteza em medição, incluindo:

- Definição incompleta do mensurando;

- Realização imperfeita da definição do mensurando;

- Amostragem não representativa - a amostra medida pode não representar o mensurando definido;

- Conhecimento inadequado dos efeitos das condições ambientais sobre a medição ou medição imperfeita das condições ambientais;

- Erro de tendência pessoal na leitura de instrumentos analógicos;

- Resolução finita do instrumento ou limiar de mobilidade;

- Valores inexatos dos padrões de medição e materiais de referência;

- Valores inexatos de constantes e de outros parâmetros obtidos de fontes externas e usados no algoritmo de redução de dados;

- Aproximações e suposições incorporadas ao método e procedimento de medição;

- Variações nas observações repetidas do mensurando sob condições aparentemente idênticas (GUM, 1995). 
As incertezas nos resultados estão associadas a duas categorias, tipo A e tipo B. As incertezas do tipo A são estimados por análises estatísticas, ou seja, devido à dispersão do valor dos resultados obtidos em torno do valorverdadeiro, como o desvio padrão da média. As incertezas do tipo B são incertezas devido ao conjunto de medições que apresenta valores igualmente espaçados do valor verdadeiro, tendo sua estimativa por outros métodos (nãoestatísticos), sendo procedente de erros instrumentais, ambientais e observacionais. A incerteza total das medidas é obtida atra vés da Eq.5 (Vuolo, 1992).

$$
\sigma_{\text {total }}^{2}=\sigma_{\text {estat ístico }}^{2}+\sigma_{\text {sistem ático }}^{2}
$$

Emque:

$\sigma_{\text {Total }}$ : Incerteza total;

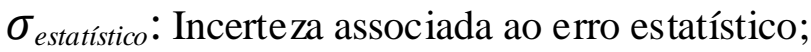

$\sigma_{\text {sistemático }}$ : Incerteza associada ao erro sistemático.

As incertezas associadas as aplicações clínicas foram efetuadas pelo desvio padrão da média Eq. 6.

$$
\sigma_{(\bar{y})}=\frac{\sigma_{\left(y_{i}\right)}}{\sqrt{n}}
$$

Onde: $\sigma_{\left(y_{i}\right)}=$ Desvio padrão das medidas;

$\sqrt{n}=$ Raíz do número de contagens. 


\section{RESULTADOS E DISCUSSÕES}

No presente trabalho todos os resultados de caracterização dosimétrica para feixe de elétrons e estudos clínicos foram obtidos utilizando a sensibilidade individual de cada dosímetro (Coeficiente de Calibração). As unidades de medida foram todas utilizadas em "cGy", devido às aplicações clínicas, levando em consideração a numeração decimal e a unidade monitora, possibilitando uma melhor compreensão na área médica.

\subsection{Teste de Estabilidade da Leitora TL Harshaw 4500}

$\mathrm{Na}$ figura 24 é demonstardo os valores obtidos para a luz de referência (Reference Light), e a razão sinal ruído (PMT Noise).

a)

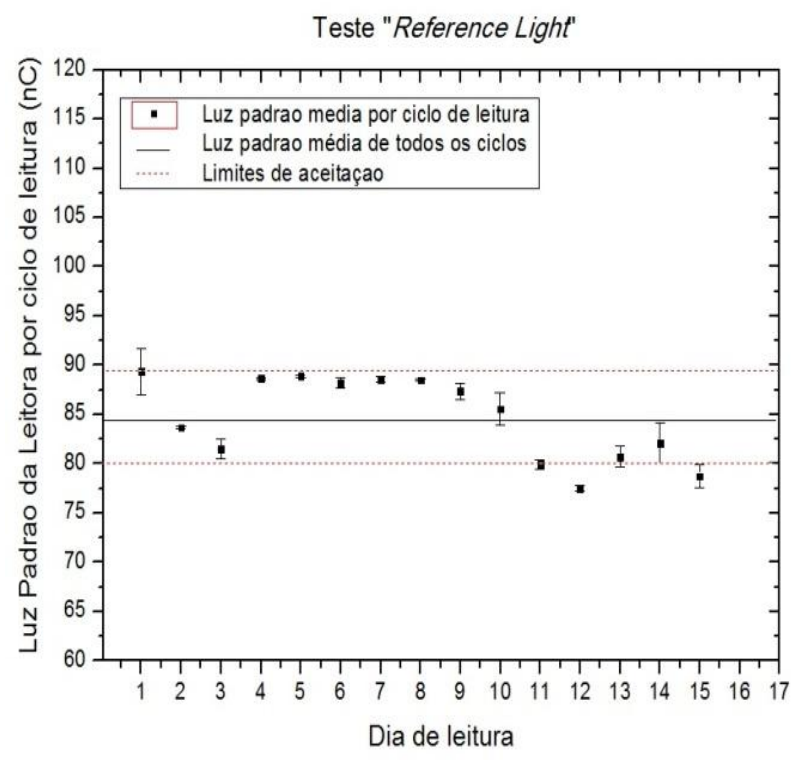

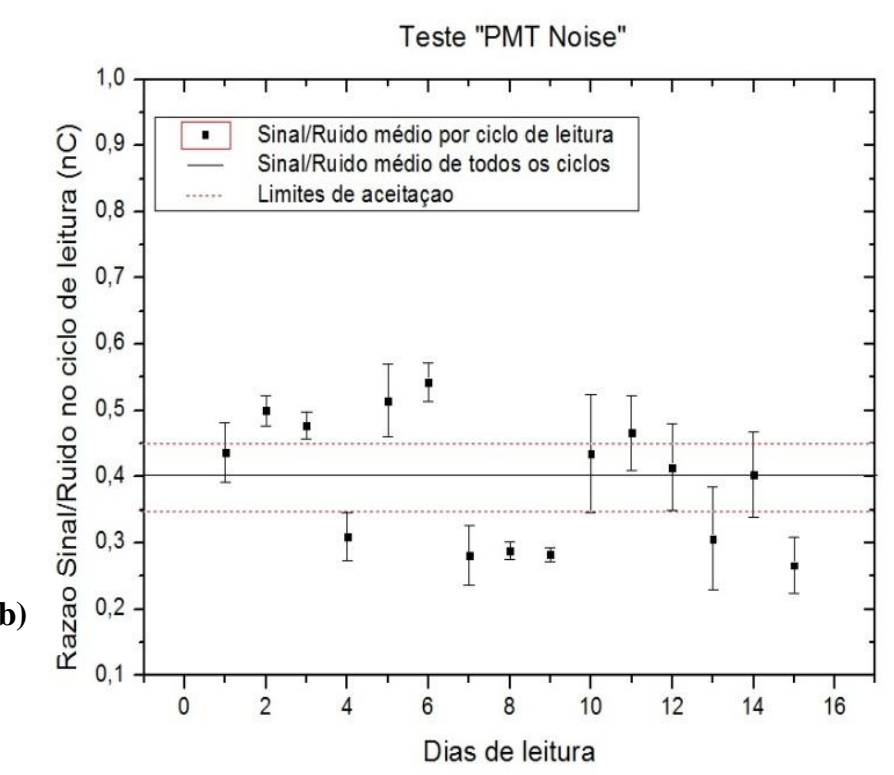

Figura 24. Teste da luz de referência. Valores médios dos conjuntos de leituras e limites de aceitação.Resultados para o teste de ruído.

Os valores da média da luz de referência encontram-se dentro dos limites de aceitação $\pm 5 \%$. Os resultados das medições demonstram que a leitora TL utilizada apresentou boa estabilidade quanto aos testes de luz padrão de referência. A razão sinal/ruído demonstrou uma instabilidade, mais se encontra nos limites de aceitação. 


\subsection{Teste de Estabilidade da Leitora RISØ TL/OSL}

No decorrer do uso da leitora RIS $\varnothing$ TL/OSL não foram encontrados problemas em seu funcionamento. Testes como o funcionamento do LED azul de estimulação e a contagem de fundo foram averiguados apresentando resultados dentro do esperado.

\subsection{Seleção dos Dosímetros}

A seleção foi elaborada de maneira minuciosa para obtenção de lotes mais homogêneos e com sensibilidades relativamente próximas, a fim de assegurar medidas precisas e confiáveis os lotes foram obtidos utilizando o cálculo da média ponderada pela incerteza Eq. 7 e 8 (Taylor, 2012).

$$
\begin{gathered}
\bar{x}=\frac{\sum_{i=1}^{n}\left(\frac{x_{i}}{\sigma_{i}^{2}}\right)}{\sum_{i=1}^{n}\left(\frac{1}{\sigma_{i}^{2}}\right)} \\
\sigma_{\bar{x}}=\sqrt{\frac{1}{\sum_{i=1}^{n}\left(\frac{1}{\sigma_{i}^{2}}\right)}}
\end{gathered}
$$

Onde: $x_{i}=$ Valor das medidas;

$\sigma=$ Incertezas.

Os lotes apresentaram incerteza relativamente baixas e adequadas para utilização na dosimetria de feixes clínicos de elétrons.

- $\mathrm{LiF}: \mathrm{Mg}, \mathrm{Ti}-36$ dosímetros com incerteza do lote de $\pm 0,1 \%$;

- $\mu \mathrm{LiF}: \mathrm{Mg}, \mathrm{Ti}-18$ dosímetros com incerteza do lote de $\pm 0,5 \%$;

- $\mathrm{CaSO}_{4}: \mathrm{Dy}-30$ dosímetros com incerteza do lote de $\pm 0,2 \%$;

- $\mathrm{Al}_{2} \mathrm{O}_{3}: \mathrm{C}-18$ dosímetros com incerteza do lote de $\pm 0,2 \%$.

As figuras 25 e 26, demonstram o histograma da média de quatro leituras para os dosímetros luminescentes. 

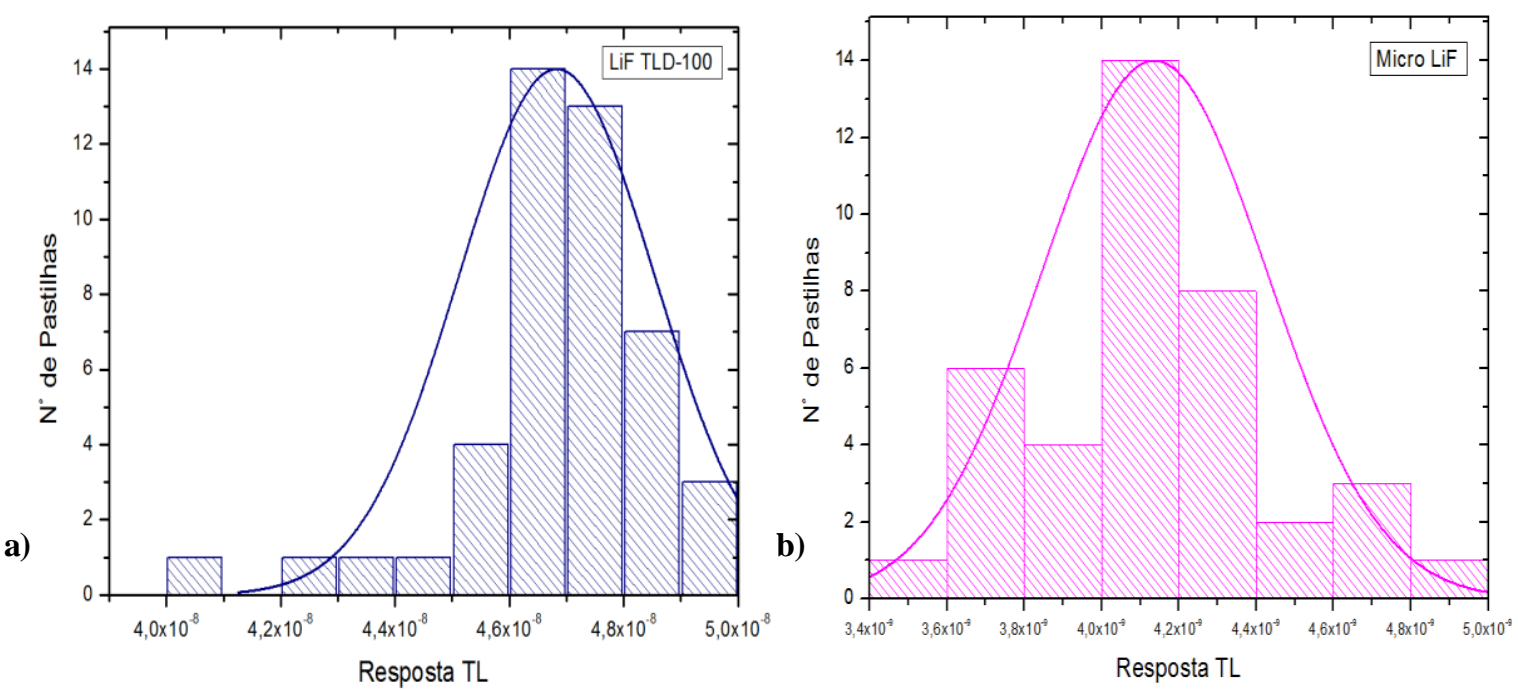

Figura 25. His tograma da média de quatro leituras dos dosímetros TL (a) LiF:Mg,Ti TLD-100 e (b) $\mu$ LiFpara separação do lote.

c)

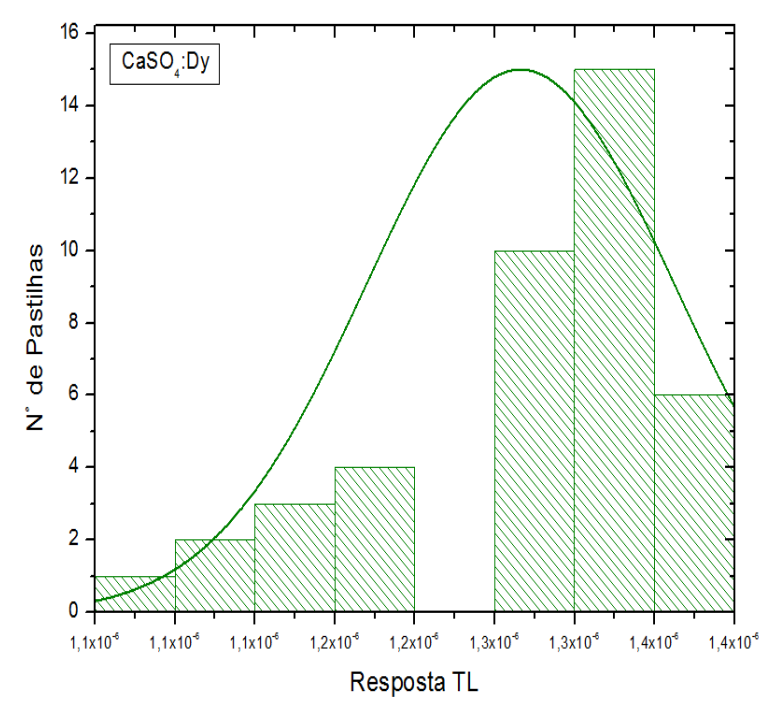

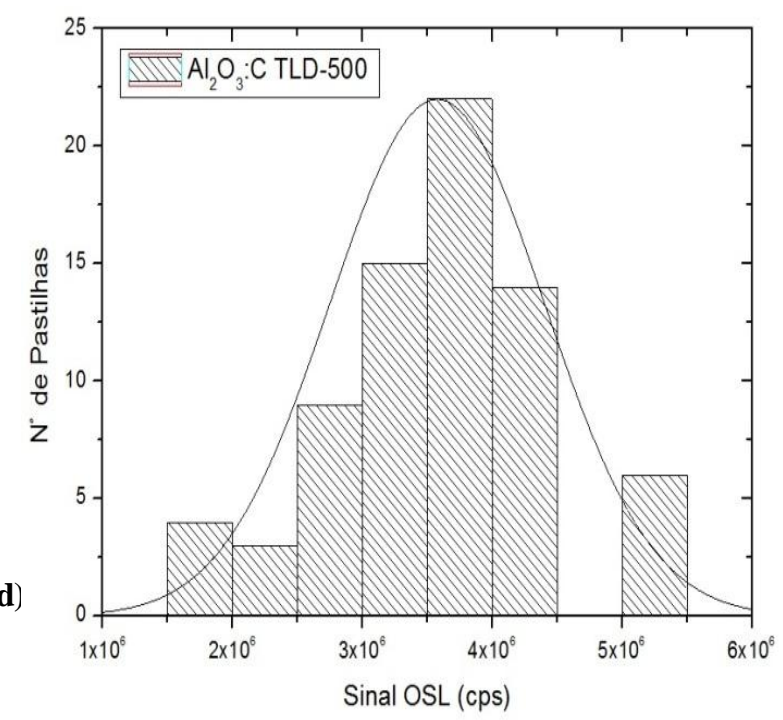

Figura 26. Histograma da média de quatro leituras dos dosímetros TL e OSL (c) $\mathrm{CaSO}_{4}: \mathrm{Dy}$ e (d) $\mathrm{Al}_{2} \mathrm{O}_{3}:$ C para separação do lote.

\subsection{Caracterização das Leituras OSL dos TLD-500 na Leitora RISØ ${ }^{\mathrm{TM}}$ TL/OSL- DA-20}

\subsubsection{Caracterização dos Colimadores da Leitora}

Para caracterização das melhores condições de leitura, parâmetros como tempo de estimulação, potência do arranjo de LEDs e tamanho do orifício de colimação foram variados. 
Os fatores de correção obtidos para os respectivos colimadores estão representados na (Tab. 4). Os fatores foram calculados conforme a Eq. 9.

$$
f_{\text {col }}=\frac{\bar{R}_{0}}{\bar{R}_{c o l}}
$$

Onde: $\bar{R}_{0}$ é a resposta média dos dosímetros sem colimadores;

$\bar{R}_{c o l}$ : é a resposta média dos dosímetros com colimador.

Tabela 4. Fatores de correção obtidos para cada um dos colimadores de sinal.

\begin{tabular}{ccc}
\hline Colimador & $\begin{array}{c}\text { Leitura } \\
\text { (contagens) }\end{array}$ & Fatores $\left(f_{\text {col }}\right)$ \\
\hline Sem colimador & $3,66 \times 10^{\circ}$ & 17,60 \\
Colimador 1 & $2,08 \times 10^{\circ}$ & 45,62 \\
Colimador 2 & $8,02 \times 10^{4}$ & 287,19 \\
Colimador 3 & $1,27 \times 10^{4}$ & 444,11 \\
Colimador 4 & $8,24 \times 10^{3}$ & \\
\hline
\end{tabular}

As curvas de decaimento OSL obtidas para os quatro colimadores analisados estão demonstradas na figura 27. As irradiações foram realizadas para uma dose de 10 mGy e os resultados apresentados são a média de três espectros.

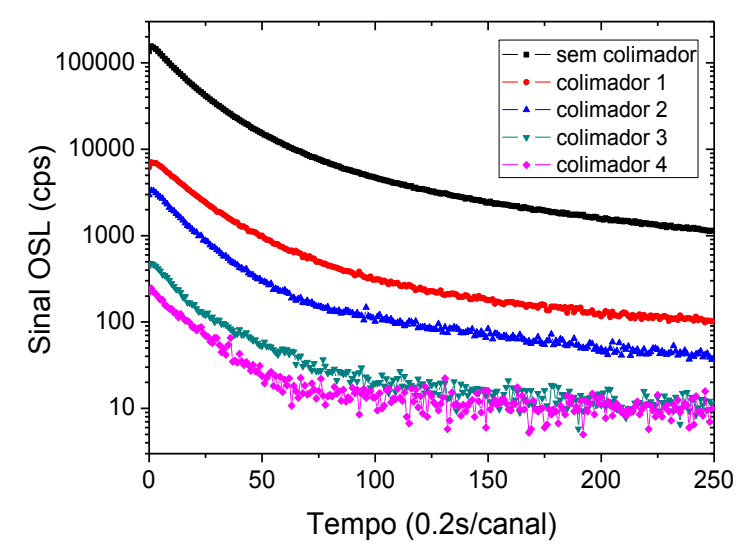

Figura 27. Curvas de decaimento OSL obtidas para aquisição dos fatores de correção de cada um dos colimadores.

Com a utilização do colimador 1, pode-se observar a diminuição de uma ordem de grandeza na curva de decaimento OSL, quando comparado com a curva sem colimação. Para os colimadores 3 e 4, o resultado foi a diminuição de três ordens de grandeza. 


\subsubsection{Caracterização da Potência do Arranjo de LEDs Azuis}

A leitora RIS $\emptyset$ TL/OSL possibilita o ajuste na potência de estimulo Óptico. As figuras 28 e 29 demonstram os resultados obtidos para a variação de 90 a $1 \%$ da potência do arranjo de LEDs azuis. As leituras foram realizadas sem colimadores para uma dose de 10 mGy. Os resultados obtidos são média de três espectros.

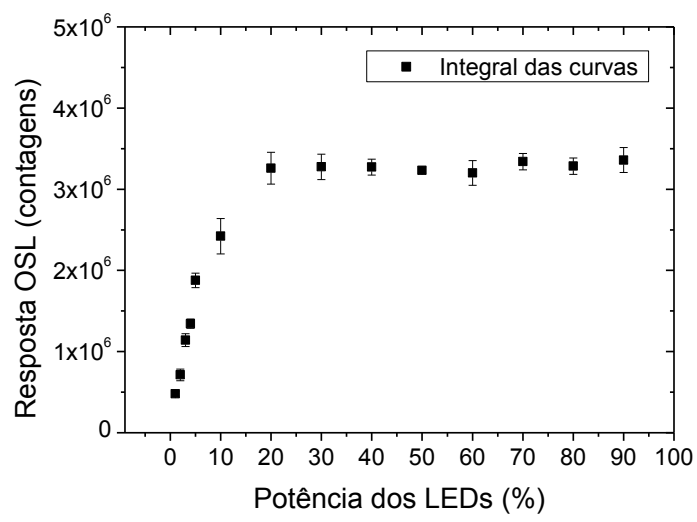

Figura 28. Co mportamento das integrais das curvas de decaimento OSL variando a potência do arranjo de LEDs azuis.
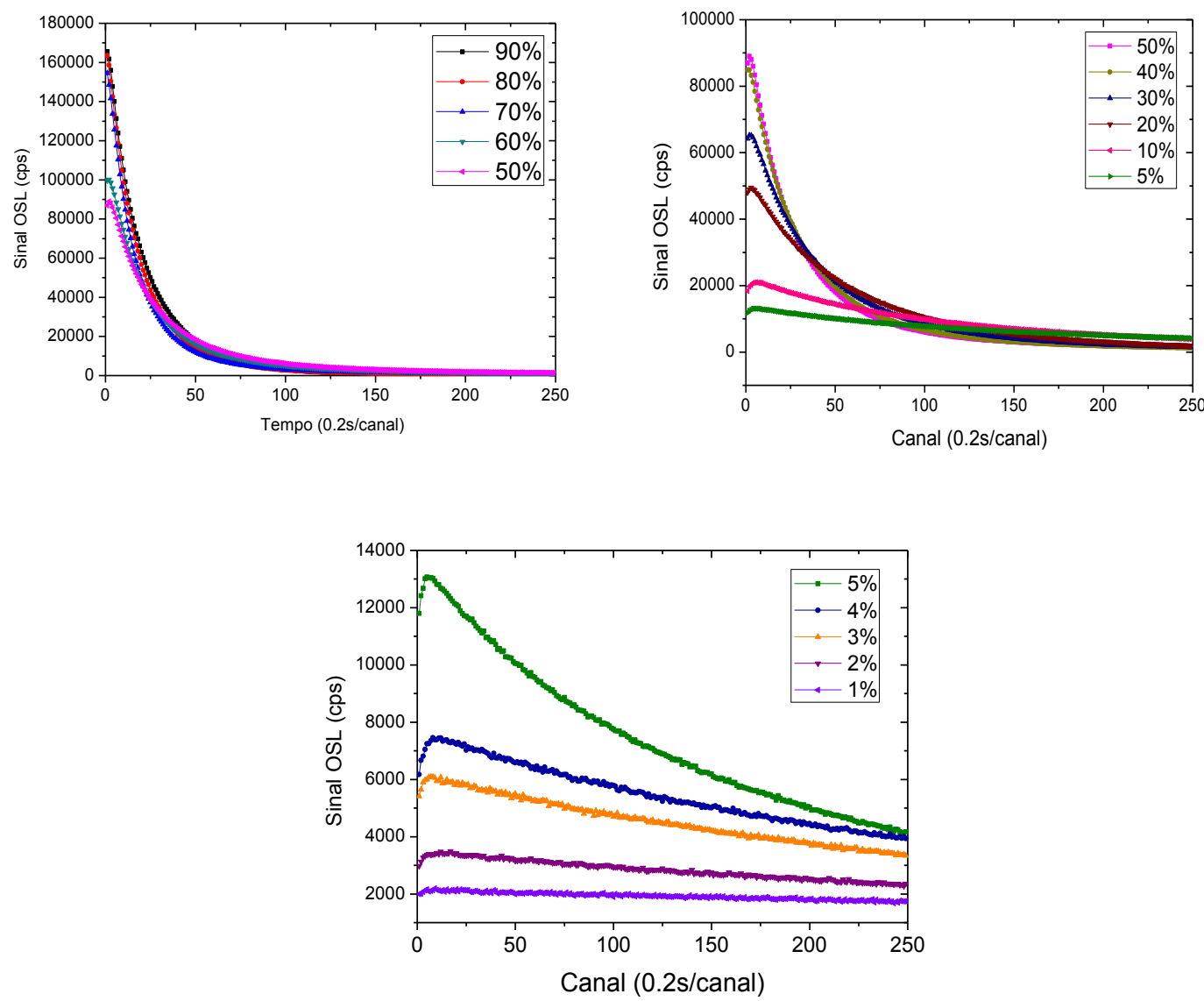

Figura 29. Curvas de decaimento OSL obtidas pela variação da potência do arranjo de LEDs azuis. 
Por meio da análise das figuras 28 e 29 fica evidenciado que, entre 90 e $20 \%$, independente da potência utilizada, os valores das integrais das curvas de decaimento OSL permanecem na mesma variação estatística e, verifica-se, portanto, o desarmadilhamento do mesmo número de cargas. O perfil decrescente de valor de contagem integrada de 15 a $1 \%$ mostra que, nessa faixa, quanto menor a potência do estímulo, menor a recombinação das cargas nos dosímetros.

\subsubsection{Caracterização do Tempo de Estímulo Óptico}

Outro parâmetro que pode ser ajustado na leitora é o tempo do estímulo óptico. $\mathrm{Na}$ (figura 30) estão demonstrados os resultados dos espectros (a) e das integrais das curvas (b) obtidas para a variação de 50 a 5 do estimulo óptico. As irradiações foram realizadas para uma dose de $10 \mathrm{mGy}$, sem os colimadores e os resultados demonstrados são a média de três espectros.
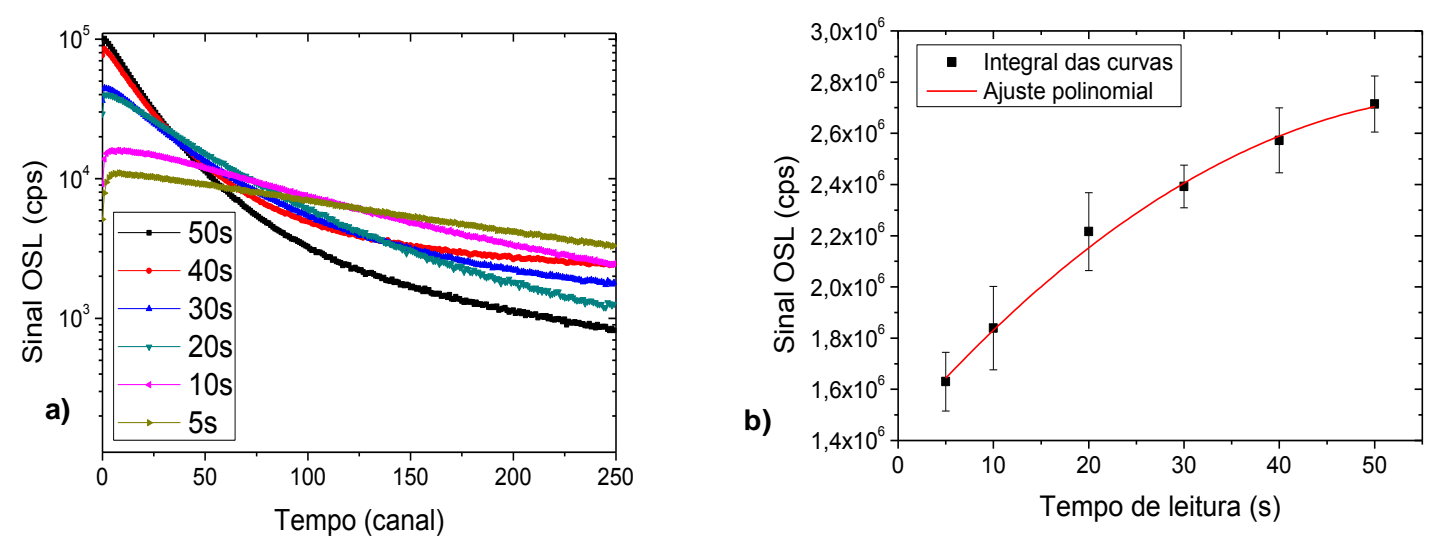

Figura 30. Comportamento das curvas de decaimento OSL (a) das integrais das curvas de decaimento OSL, (b) em função davariação do tempo de estímu lo óptico.

Analisando a figura 30 (b) pode-se evidenciar o comportamento polinomial dos valores das integrais e, que, quanto menor o tempo de estímulo, menor o desarmadilhamento das cargas no dosímetro. A partir dos resultados anteriormente descritos, pode-se afirmar que autilização de $1 \%$ de potência do arranjo de LEDs azuis, e 5 segundos de estimulo de leitura são suficientes para caracterização dosimétrica do sistema. 


\subsubsection{Estudo da Correlação entre o "Bleaching" do Sinal OSL e Efetividade do Tempo de Iluminação para Diferentes Doses em Dosimetria de Fótons.}

O tratamento óptico para reutilização das amostras foi determinado variando de 1 a 390 minutos o tempo de exposição dos dosímetros a uma lâmpada de 1,3 watts de potência, composta por 30 LEDs azuis Ourolux®. As doses avaliadas foram as mesmas utilizadas para obtenção da curva dose-resposta, e as leituras foram realizadas utilizando os mesmos parâmetros ( $1 \%$ de potência do arranjo de LEDs, e 5 segundos de leitura). Os resultados estão demonstrados na figura 31 .

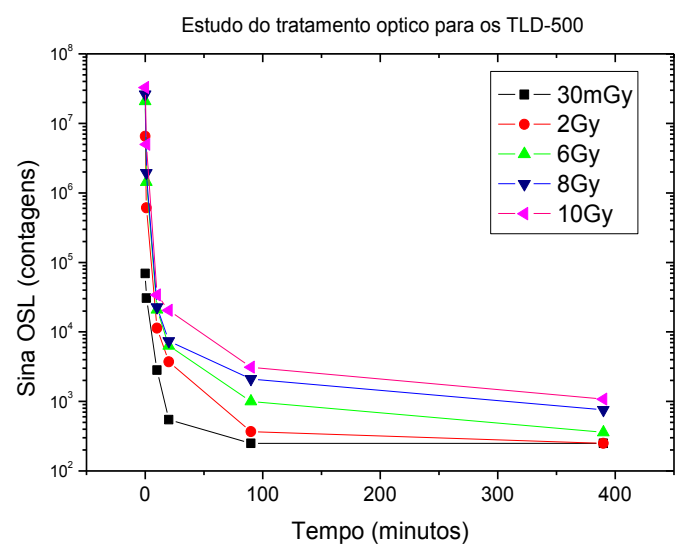

Figura 31. Comportamento das integrais das curvas OSL de acordo como tempo de tratamento óptico.

Pode ser verificado que para a dose de $0,03 \mathrm{~Gy}, 1$ h e 30 minutos foram suficientes para limpar por completo as amostras irradiadas. Para doses nível terapia (2 Gy) são necessárias $5 \mathrm{~h}$.

\subsection{Caracterização dos Sistemas Dosimétricos}

Nas figuras 32 a 35 são apresentadas as curvas de resposta em função da dose dos quatros dosímetros para irradiação no ar em fonte de radiação gama do ${ }^{60} \mathrm{Co}$ e para feixes clínicos de elétrons de $6 \mathrm{MeV}$. Os pontos apresentados na curva representam a média das leituras. $\mathrm{O}$ desvio padrão da média é representado pelas barras de erro, sendo importante frisar a subtração da leitura de "Brackground" (BG) de cada pastilha empregada.

As curvas de resposta em função da dose para feixes de fótons do ${ }^{60} \mathrm{Co}$ apresentaram um comportamento linear no intervalo de dose estudado. Nota-se que para a dose de 10 Gy as respostas tendem a sair da linearidade, onde pode ser observado um comportamento supralinear para os quatros detectores. 

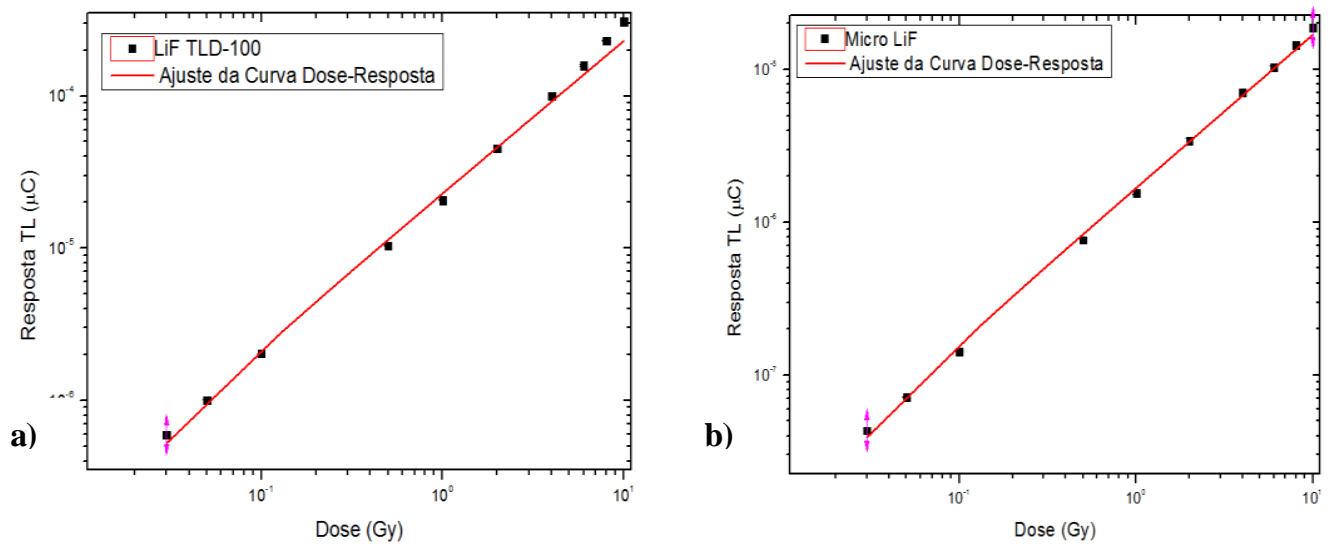

Figura 32. Curvas de resposta TLem funcão da dose dos dosímetros LiF:Mg,Ti (a) e (b) $\mu \mathrm{LiF}: \mathrm{Mg}, \mathrm{Ti}$ para radiação gama do ${ }^{60} \mathrm{Co}$ livres no ar e em equilíbrio eletrônico.

c)

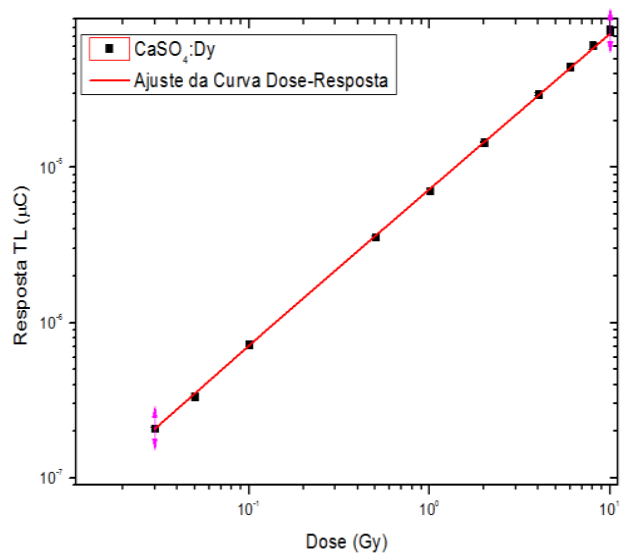

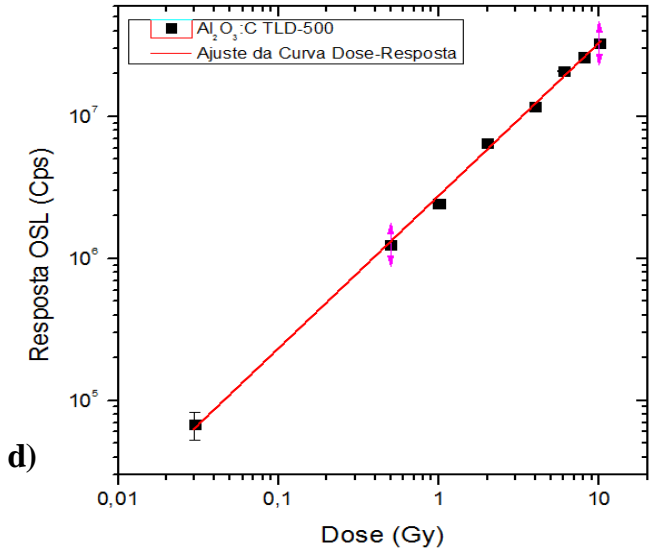

Figura 33. Curvas de resposta TL em função da dose dos dosímetros $\mathrm{CaSO}_{4}$ :Dy (c) e (d) OSL dos dosímetros $\mathrm{Al}_{2} \mathrm{O}_{3}: \mathrm{C}$ para radiação gama do ${ }^{60} \mathrm{Co}$ livres no ar e em equilíbrio eletrônico.
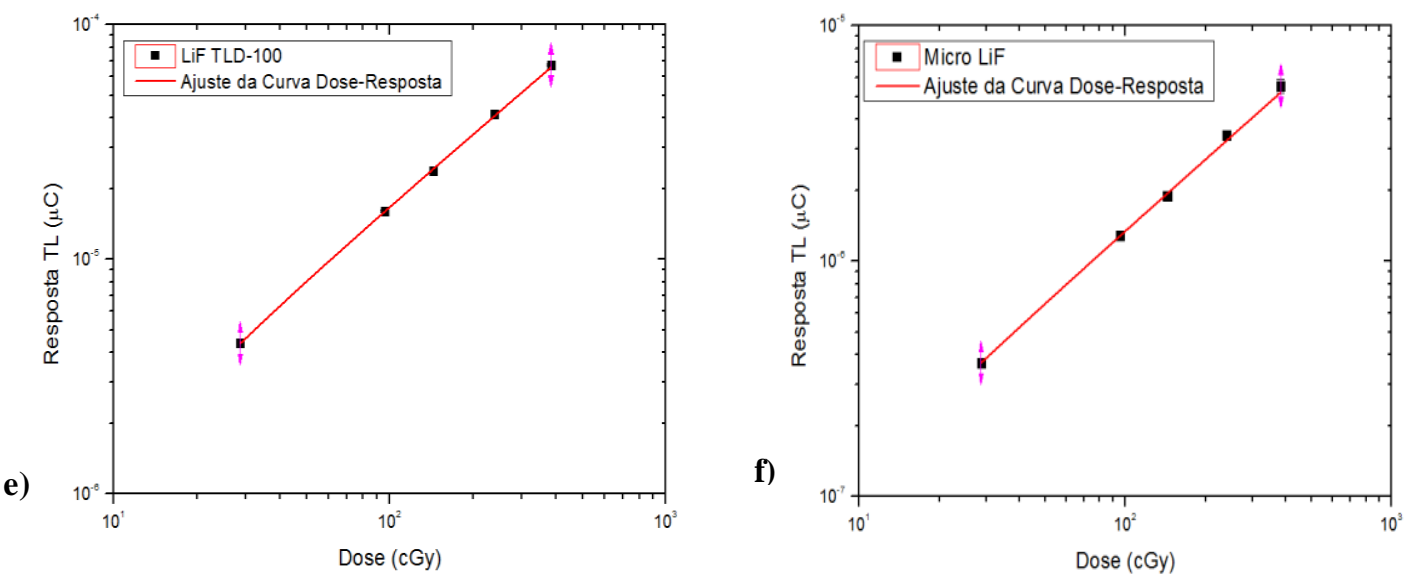

Figura 34. Curvas de resposta TL em função da dose dos dosímetros LiF:Mg,Ti (e) e (f) $\mu \mathrm{LiF}: \mathrm{Mg}$,Ti para elétrons de $6 \mathrm{MeV}$. 

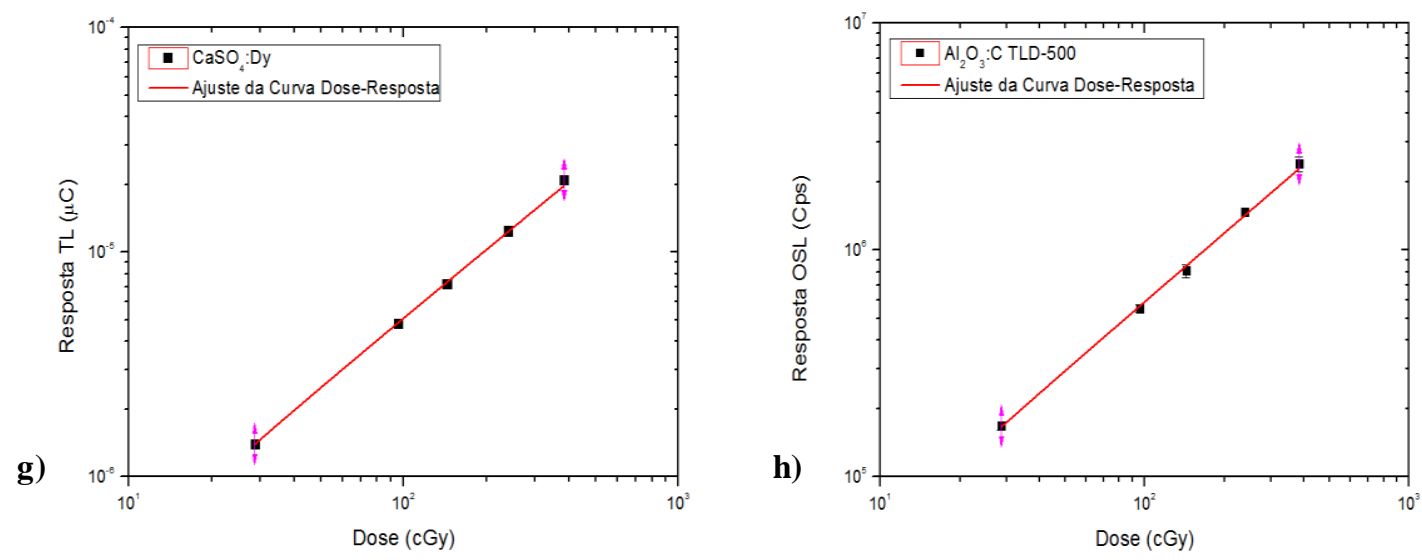

Figura 35. Curvas de resposta TLem função da dose dos dosímetros $\mathrm{CaSO}_{4}: \mathrm{Dy}(\mathrm{g})$ e (h) OSL dos dosímetros $\mathrm{Al}_{2} \mathrm{O}_{3}: \mathrm{C}$ para elétrons de $6 \mathrm{MeV}$.

\subsection{Limite Inferior de Detecção}

A tabela 5 apresenta os resultados dos LID dos quatro dosímetros para radiação de feixes clínicos de elétrons de $6 \mathrm{MeV}$, e estão de acordo com os valores obtidos na literatura. Os valores foram obtidos pela Eq. 3 (Oberhofer, M.; Scharmann, 1981).

Tabela 5. Valores dos Limites Inferiores de Detecção (LID) dos dosímetros TL e OSL para os feixes clínicos de elétrons com energia de $6 \mathrm{MeV}$.

\begin{tabular}{|c|c|c|c|}
\hline $\mathrm{LiF}: \mathrm{Mg}, \mathrm{Ti}$ & $\begin{array}{l}\text { Resposta TL } \\
(\mathrm{nC})\end{array}$ & $\begin{array}{l}\text { LID } \\
\text { (cGy) }\end{array}$ & $\begin{array}{c}\sigma(\mathrm{DPM}) \\
(\mathrm{cGy})\end{array}$ \\
\hline Dosímetro 1 & 8,313 & 0,075 & 0,034 \\
\hline Dosímetro 2 & 13,96 & 0,112 & 0,042 \\
\hline Dosímetro 3 & 10,76 & 0,093 & 0,030 \\
\hline$\mu \mathrm{LiF}: \mathrm{Mg}, \mathrm{Ti}$ & 4,863 & 0,45 & 0,007 \\
\hline $\mathrm{CaSO}_{4}: \mathrm{Dy}$ & & & \\
\hline Dosímetro 4 & 4,147 & 0,075 & 0,035 \\
\hline Dosímetro 5 & 4,128 & 0,080 & 0,019 \\
\hline Dosímetro 6 & 4,077 & 0,074 & 0,036 \\
\hline $\mathrm{Al}_{2} \mathrm{O}_{3}: \mathrm{C}$ & $\begin{array}{l}\text { Resposta OSL } \\
\text { (cont) }\end{array}$ & $\begin{array}{l}\text { LID } \\
\text { (cGy) }\end{array}$ & $\begin{array}{c}\sigma(\mathrm{DPM}) \\
(\mathrm{cGy})\end{array}$ \\
\hline Dosímetro 7 & 2509,00 & 0,423 & 0,016 \\
\hline Dosímetro 8 & 2606,00 & 0,370 & 0,105 \\
\hline Dosímetro 9 & 2355,00 & 0,373 & 0,058 \\
\hline
\end{tabular}




\subsection{Sensibilidade Média dos Dosímetros Luminescentes}

Os valores de sensibilidade média em função da dose $(\mu \mathrm{C} / c \mathrm{~Gy})$ dos dosímetros, $\mathrm{LiF}: \mathrm{Mg}, \mathrm{Ti}, \mu \mathrm{LiF}: \mathrm{Mg}, \mathrm{Ti}, \mathrm{CaSO}_{4}: \mathrm{Dy}$ e $\mathrm{Al}_{2} \mathrm{O}_{3}: \mathrm{C}$ para feixes clínicos de elétrons de $6 \mathrm{MeV}$, calculados usando a equação 10, são demonstrados na Fig. 36.

$$
S_{i}=\frac{R}{D}
$$

Onde: $R=$ Resposta TL ou OSL;

$\mathrm{D}=$ Dose.

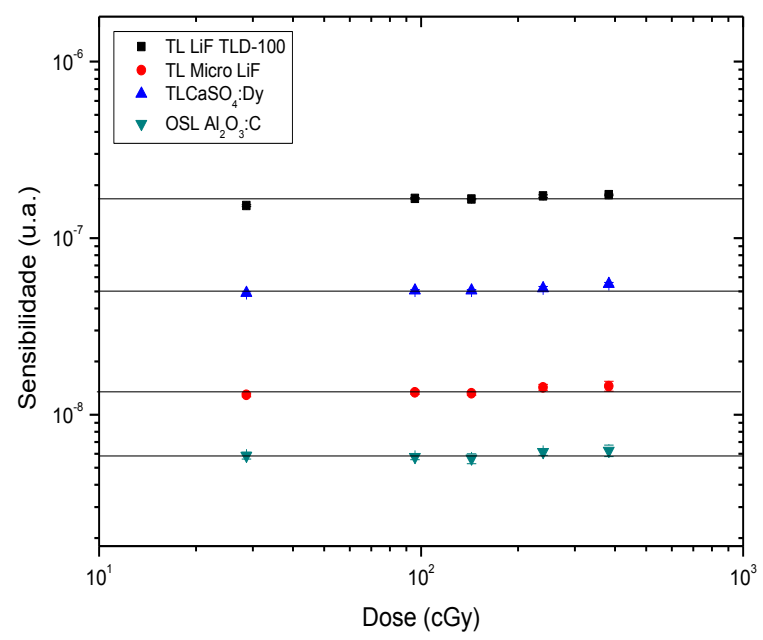

Figura 36. Sensibilidade méd ia em função da dose dos dosímetros TLe OSL para feixes clínicos de elétrons de $6 \mathrm{MeV}$.

Como pode ser observado na figura 36, os quatros tipos de detectores apresentam os valores constantes dentro do intervalo de dose estudado, que foram de 28,7 cGy a 382,8 cGy.

\subsection{Sensibilidade Intrínseca Indi vidual dos Fósforos}

A sensibilidade intrínseca dos fósforos ( $\mu \mathrm{C} / \mathrm{cGy} \cdot \mathrm{mg}$ ) pode ser definida como (Furetta, 2008):

$$
S_{i}=\frac{R}{D . m}
$$

Onde: $R=$ Resposta TL ou OSL;

$\mathrm{D}=$ Dose;

$\mathrm{m}=$ massa do fósforo 
Foi calculada para cada fósforo a sensibilidade intrínseca individual para todos os dosímetros utilizados no presente trabalho. Os valores obtidos são apresentados nas tabelas 6, 7,8 e 9 .

Tabela 6. Sensibilidade Intrínseca Individual ( $\mathrm{LiF}: \mathrm{Mg}, \mathrm{Ti})$

Tabela 7. Sensibilidade Intrínseca Individual $\left(\mathrm{CaSO}_{4}: \mathrm{Dy}\right)$

\begin{tabular}{|c|c|c|c|}
\hline LiF:Mg,Ti & $\begin{array}{c}\text { Sensibilidade } \\
\text { Média } \\
(\mu \mathrm{C} / \mathrm{cGy})\end{array}$ & $\begin{array}{c}\text { Massa } \\
(\mathrm{mg})\end{array}$ & $\begin{array}{c}\text { Sensibilidade } \\
\text { intrínseca } \\
(\mu \mathrm{C} / \mathrm{c} \text { Gy.mg })\end{array}$ \\
\hline 1 & 0,173 & 24,6 & 0,007 \\
\hline 2 & 0,164 & 24,3 & 0,007 \\
\hline 3 & 0,164 & 24,6 & 0,007 \\
\hline 4 & 0,172 & 24,6 & 0,007 \\
\hline 5 & 0,167 & 24,6 & 0,007 \\
\hline 6 & 0,164 & 24,2 & 0,007 \\
\hline 7 & 0,176 & 24,3 & 0,007 \\
\hline 8 & 0,168 & 24,8 & 0,007 \\
\hline 10 & 0,166 & 24,4 & 0,007 \\
\hline 11 & 0,169 & 24,3 & 0,007 \\
\hline 12 & 0,166 & 24,7 & 0,007 \\
\hline 14 & 0,158 & 24,9 & 0,006 \\
\hline 15 & 0,174 & 24,8 & 0,007 \\
\hline 17 & 0,172 & 23,9 & 0,007 \\
\hline 18 & 0,149 & 24,1 & 0,006 \\
\hline 19 & 0,166 & 24,3 & 0,007 \\
\hline 20 & 0,164 & 24,3 & 0,007 \\
\hline 21 & 0,165 & 24,5 & 0,007 \\
\hline 22 & 0,169 & 24,3 & 0,007 \\
\hline 23 & 0,172 & 24,7 & 0,007 \\
\hline 24 & 0,172 & 23,8 & 0,007 \\
\hline 25 & 0,168 & 24,3 & 0,007 \\
\hline 28 & 0,163 & 24,8 & 0,007 \\
\hline 29 & 0,163 & 24,6 & 0,007 \\
\hline 30 & 0,160 & 24,0 & 0,007 \\
\hline 31 & 0,166 & 24,6 & 0,007 \\
\hline 33 & 0,170 & 24,8 & 0,007 \\
\hline 34 & 0,167 & 24,3 & 0,007 \\
\hline 36 & 0,162 & 24,6 & 0,007 \\
\hline 37 & 0,163 & 24,6 & 0,007 \\
\hline 39 & 0,171 & 24,5 & 0,007 \\
\hline 40 & 0,168 & 24,0 & 0,007 \\
\hline 41 & 0,161 & 24,3 & 0,007 \\
\hline 43 & 0,171 & 24,3 & 0,007 \\
\hline 44 & 0,173 & 24,6 & 0,007 \\
\hline 45 & 0,170 & 24,4 & 0,007 \\
\hline
\end{tabular}

\begin{tabular}{|c|c|c|c|}
\hline $\mathrm{CaSO}_{4}: \mathrm{Dy}$ & $\begin{array}{c}\text { Sensibilidade } \\
\text { Média } \\
(\mu \mathrm{C} / \mathrm{c} \text { Gy }) \\
\end{array}$ & $\begin{array}{c}\text { Massa } \\
(\mathrm{mg})\end{array}$ & $\begin{array}{c}\text { Sensibilidade } \\
\text { intrínseca } \\
(\mu \mathrm{C} / \mathrm{c} \text { Gy.mg })\end{array}$ \\
\hline 21 & 0,055 & 50,7 & 0,0011 \\
\hline 23 & 0,058 & 51,9 & 0,0011 \\
\hline 25 & 0,050 & 51,6 & 0,0010 \\
\hline 27 & 0,056 & 51,4 & 0,0011 \\
\hline 211 & 0,053 & 51,3 & 0,0010 \\
\hline 212 & 0,052 & 50,5 & 0,0010 \\
\hline 213 & 0,056 & 50,8 & 0,0011 \\
\hline 214 & 0,052 & 50,6 & 0,0010 \\
\hline 215 & 0,051 & 50,7 & 0,0010 \\
\hline 216 & 0,053 & 51,0 & 0,0010 \\
\hline 223 & 0,054 & 51,7 & 0,0010 \\
\hline 225 & 0,048 & 50,0 & 0,0010 \\
\hline 227 & 0,053 & 51,7 & 0,0010 \\
\hline 230 & 0,057 & 50,0 & 0,0011 \\
\hline 234 & 0,052 & 50,4 & 0,0010 \\
\hline 237 & 0,055 & 51,1 & 0,0011 \\
\hline 243 & 0,053 & 50,7 & 0,0011 \\
\hline 250 & 0,052 & 52,2 & 0,0010 \\
\hline 252 & 0,056 & 50,3 & 0,0011 \\
\hline 257 & 0,055 & 52,2 & 0,0011 \\
\hline 263 & 0,054 & 51,1 & 0,0010 \\
\hline 272 & 0,055 & 51,8 & 0,0011 \\
\hline 277 & 0,055 & 52,5 & 0,0011 \\
\hline 279 & 0,055 & 52,7 & 0,0010 \\
\hline 280 & 0,055 & 50,6 & 0,0011 \\
\hline 281 & 0,048 & 51,2 & 0,0009 \\
\hline 283 & 0,058 & 51,8 & 0,0011 \\
\hline 285 & 0,052 & 51,6 & 0,0010 \\
\hline 292 & 0,055 & 51,9 & 0,0011 \\
\hline 298 & 0,054 & 51,2 & 0,0011 \\
\hline
\end{tabular}


Tabela 8. Sensibilidade Intrínsica Individual $(\mu \mathrm{LiF})$

\begin{tabular}{cccc}
\hline$\mu \mathrm{LiF}: \mathrm{Mg}, \mathrm{Ti}$ & $\begin{array}{c}\text { Sensibilidade } \\
\text { Média } \\
(\mu \mathrm{C} / \mathrm{cGy})\end{array}$ & $\begin{array}{c}\text { Massa } \\
(\mathrm{mg})\end{array}$ & $\begin{array}{c}\text { Sensibilidade } \\
\text { intrínseca } \\
(\mu \mathrm{C} / \mathrm{c} \text { Gy.mg })\end{array}$ \\
\hline 1 & 0,011 & 3,5 & 0,003 \\
2 & 0,010 & 3,5 & 0,003 \\
3 & 0,012 & 3,4 & 0,003 \\
4 & 0,011 & 3,5 & 0,003 \\
5 & 0,012 & 3,5 & 0,003 \\
6 & 0,012 & 3,5 & 0,003 \\
7 & 0,012 & 3,5 & 0,003 \\
8 & 0,011 & 3,5 & 0,003 \\
9 & 0,011 & 3,5 & 0,003 \\
10 & 0,011 & 3,5 & 0,003 \\
11 & 0,012 & 3,5 & 0,003 \\
12 & 0,011 & 3,5 & 0,003 \\
13 & 0,011 & 3,5 & 0,003 \\
14 & 0,012 & 3,5 & 0,003 \\
15 & 0,011 & 3,8 & 0,003 \\
16 & 0,011 & 3,5 & 0,003 \\
17 & 0,011 & 3,6 & 0,003 \\
18 & 0,011 & 3,6 & 0,003 \\
\hline
\end{tabular}

Tabela 9. Sensibilidade Intrínseca Individual $\left(\mathrm{Al}_{2} \mathrm{O}_{3}: \mathrm{C}\right)$

\begin{tabular}{cccc}
\hline $\mathrm{Al}_{2} \mathrm{O}_{3}: \mathrm{C}$ & $\begin{array}{c}\text { Sensibilidade } \\
\text { Média } \\
(\mu \mathrm{C} / \mathrm{cGy})\end{array}$ & $\begin{array}{c}\text { Massa } \\
(\mathrm{mg})\end{array}$ & $\begin{array}{c}\text { Sensibilidade } \\
\text { intrínseca } \\
(\mu \mathrm{C} / \mathrm{cGy} \cdot \mathrm{mg})\end{array}$ \\
\hline 17 & 6450,80 & 71,5 & 90,22 \\
62 & 7648,42 & 72,8 & 105,06 \\
65 & 5090,59 & 70,0 & 72,72 \\
67 & 6650,30 & 68,7 & 96,80 \\
71 & 4471,55 & 71,2 & 62,80 \\
73 & 6750,84 & 72,5 & 93,11 \\
85 & 6386,45 & 73,1 & 87,37 \\
90 & 6639,39 & 69,1 & 96,08 \\
97 & 4255,22 & 67,3 & 63,23 \\
103 & 7418,25 & 75,8 & 97,87 \\
114 & 4384,99 & 74,4 & 58,94 \\
125 & 6811,95 & 67,7 & 100,62 \\
127 & 6260,47 & 71,5 & 87,56 \\
128 & 6989,25 & 70,0 & 99,85 \\
140 & 5336,28 & 78,6 & 67,89 \\
149 & 5598,27 & 72,1 & 77,65 \\
150 & 4762,75 & 72,5 & 65,69 \\
156 & 6647,53 & 65,5 & 101,49 \\
\hline & & & \\
\hline
\end{tabular}

\subsection{Dependência Energética da Resposta TL e OSL}

$\mathrm{Na}$ (Fig. 37) pode ser observada a dependência energética da resposta TL e OSL dos dosímetros de $\mathrm{CaSO}_{4}: \mathrm{Dy}, \mathrm{LiF}: \mathrm{Mg}, \mathrm{Ti}, \mu \mathrm{LiF}: \mathrm{Mg}, \mathrm{Ti}$ e $\mathrm{Al}_{2} \mathrm{O}_{3}: \mathrm{C}$ para feixes clínicos de elétrons.

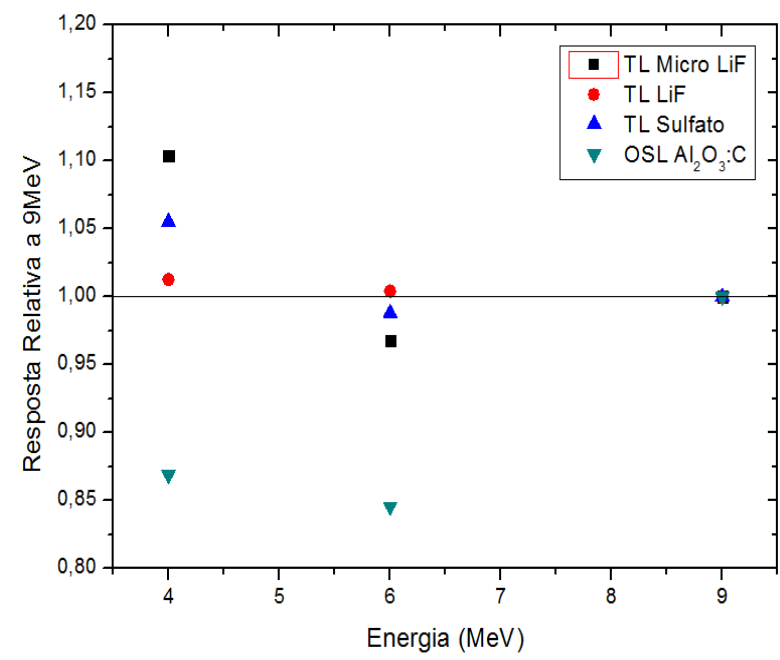

Figura 37. Dependência energética da resposta dos Dosímetros TLe OSL. 
Como pode ser observado na figura 37, os detectores $\mu \mathrm{LiF}$ e $\mathrm{Al}_{2} \mathrm{O}_{3}: \mathrm{C}$ apresentam dependência energética relevante. A hipótese mais provável são as dimensões e espessuras dos respectivos detectores.

\subsection{Dependência Angular}

$\mathrm{Na}$ figura 38 foram analisadas a dependência angular das respostas TL e OSL de cada dosímetro. Os ângulos estudados foram de $0^{0}$ à $40^{\circ}$, demonstrando uma maior dependência para os ângulos de $30^{\circ}$ e $40^{\circ}$ sendo observado na figura 39.

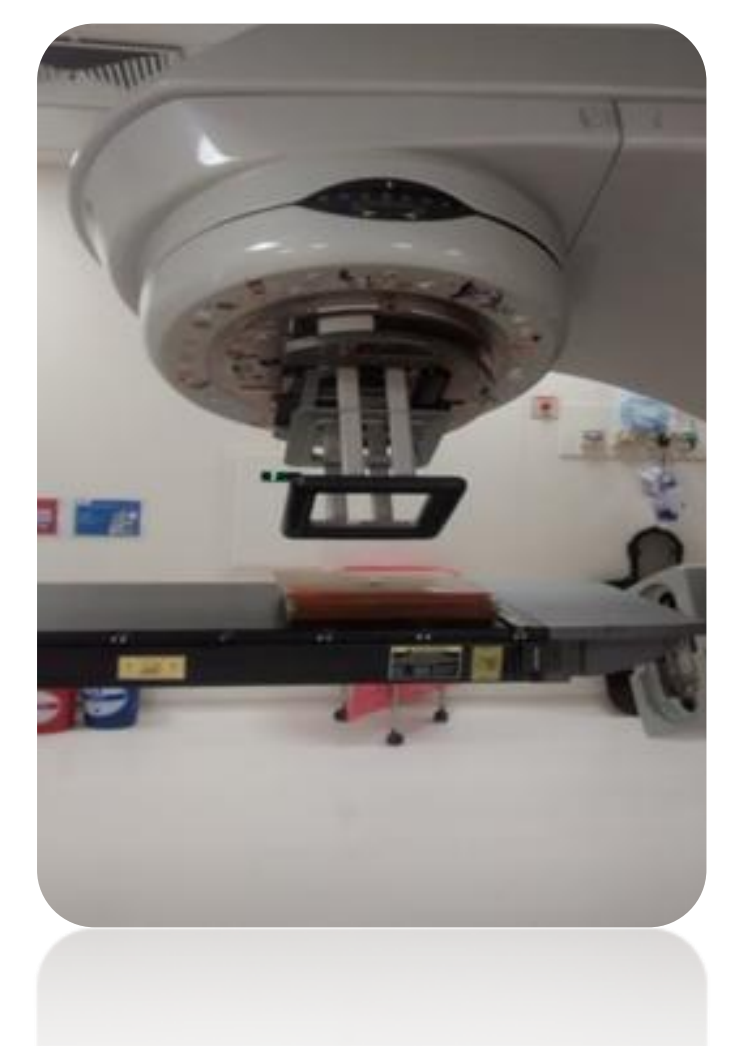

Figura 38. Arran jo experimental para determinação da dependência angular dos materiais estudados. 

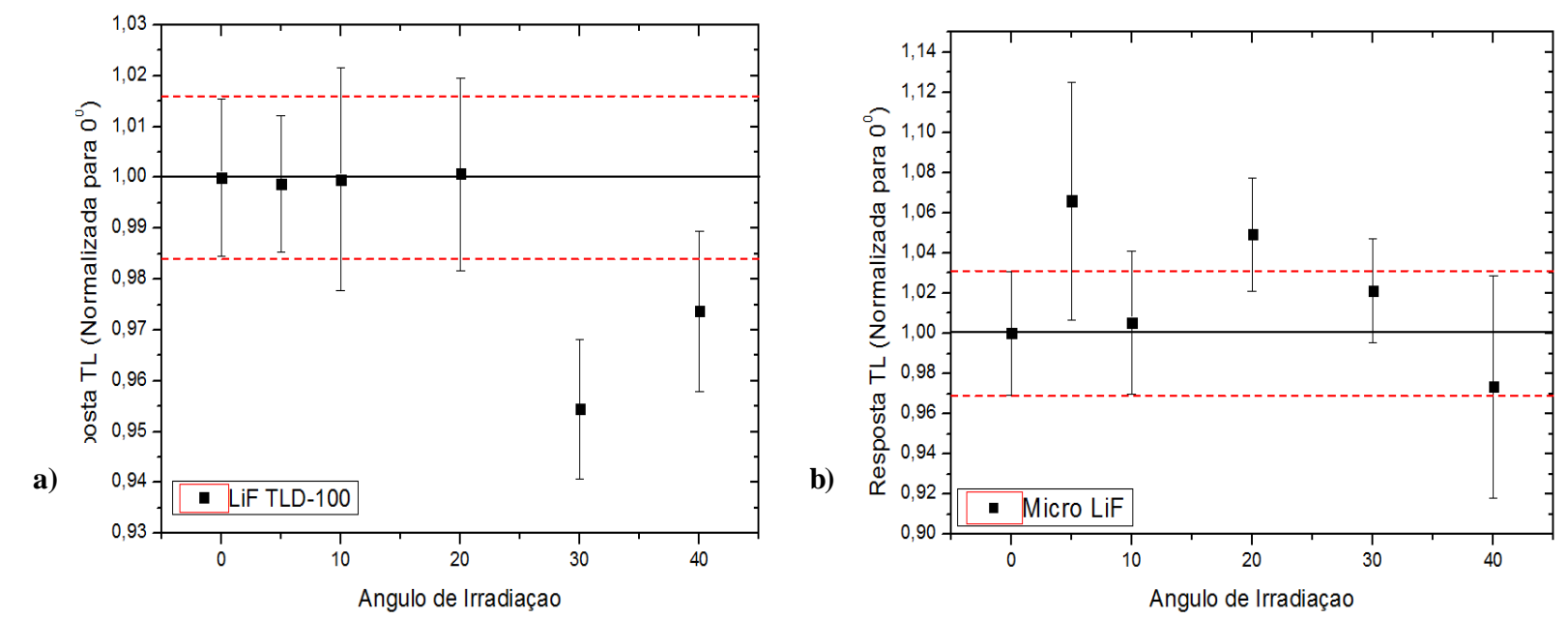

c)
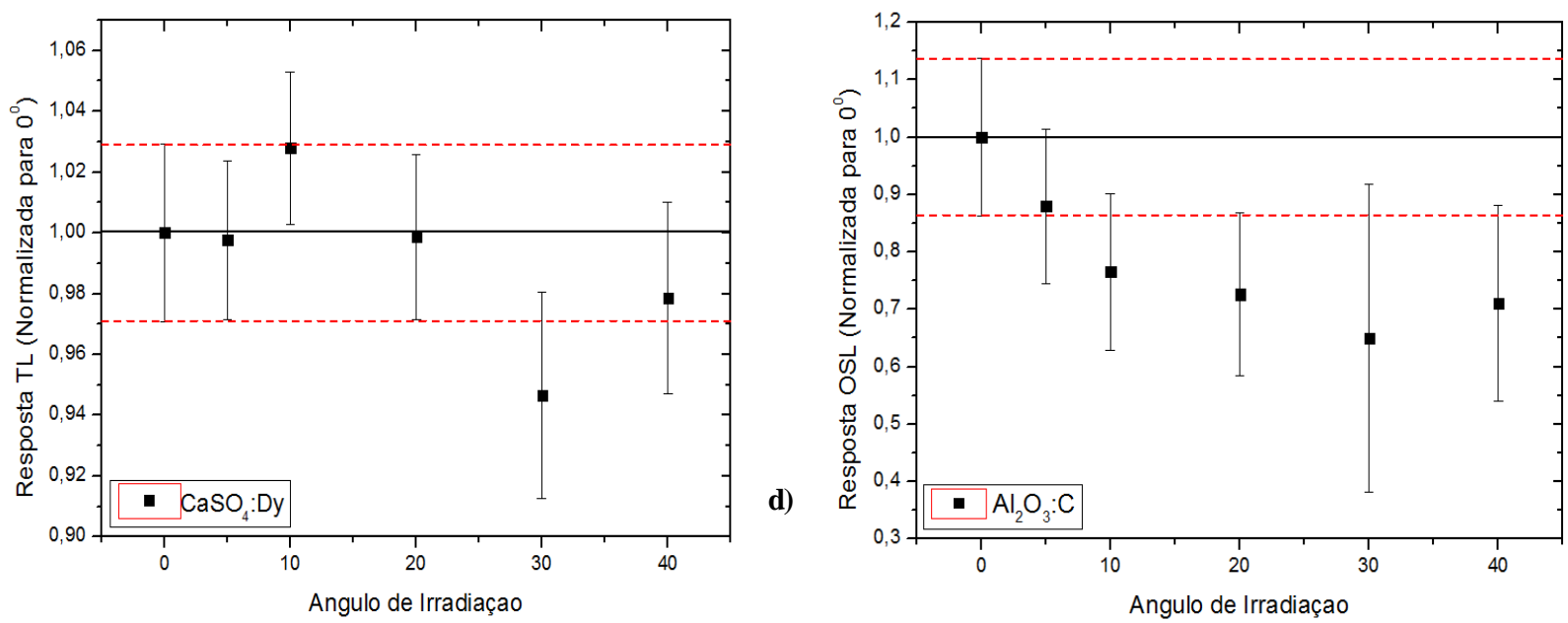

Figura 39. Dependência Angular da resposta dos dosímetros: (a) LiF TLD-100, (b) Micro LiF, (c) $\mathrm{CaSO}_{4}: \mathrm{Dy}$ e (d) $\mathrm{Al}_{2} \mathrm{O}_{3}: \mathrm{C}$

\subsection{Aplicações Clínicas}

\subsubsection{Homogeneidades do Campo para Irradiação TSI}

Considerando as características do campo, a deposição da dose máxima deve ser entregue em alguns milímetros da superfície da pele (5 - $15 \mathrm{~mm})$. O campo de tratamento deve ter dimensões de modo a abranger totalmente o paciente. $O$ campo deve ter uniformidades verticais de $\pm 8 \%$ e uniformidades horizontais de $\pm 4 \%$ em relação a área central de $(160 \times 60) \mathrm{cm}^{2}$ do plano de tratamento (Platoni, 2012). 
Para os dosímetros $\mathrm{LiF}: \mathrm{Mg}, \mathrm{Ti}, \mu \mathrm{LiF}: \mathrm{Mg}$, $\mathrm{Ti}$ e $\mathrm{CaSO}_{4}: \mathrm{Dy}$ os resultados obtidos se encontraram com uniformidades dentro do desejável em relação ao plano de tratamento de maneira a serem utilizados para aplicação clínica.

Para os dosímetros óxido de alumínio os resultados não se encontraram adequado para a aplicação clínica, as uniformidades tanto verticais como horizontais apresentaram maior do que o esperado.

Nas tabelas 10 a 13 é apresentado os respectivos valores obtidos para cada dosímetro avaliado.

Tabela 10. Ho mogeneidade do campo para inclinações de $\pm 17^{\circ}$ com irradiação de campo duplo ( $\mathrm{LiF}: \mathrm{Mg}, \mathrm{Ti}$ )

\begin{tabular}{cccc}
\hline Distância no eixo central & $\begin{array}{c}\text { Dose Avaliada } \\
\text { (cGy) }\end{array}$ & $\begin{array}{c}\sigma \text { (DPM) } \\
\text { (c Gy) }\end{array}$ & $\begin{array}{c}\text { Diferença Percentual } \\
\text { em relação ao } Z_{\text {Ref }}\end{array}$ \\
\hline$Z_{\text {Ref }}$ & 63,7 & 0,51 & \\
$50 \mathrm{~cm}$ Sup & 62,3 & 0,23 & 2,22 \\
$75 \mathrm{~cm}_{\text {Sup }}$ & 61,4 & 0,36 & 3,74 \\
$50 \mathrm{~cm}_{\text {Inf }}$ & 63,3 & 0,86 & 0,56 \\
$75 \mathrm{~cm}_{\text {Inf }}$ & 62,1 & 0,29 & 2,53 \\
\hline Distanciamento horizontal & Dose Avaliada & $\sigma(\mathrm{DPM})$ & Diferença Percentual \\
de $30 \mathrm{~cm}$ à direita do eixo & $(\mathrm{cGy})$ & $(\mathrm{cGy})$ & em relação ao $\mathrm{Z}_{\text {Ref }}$ \\
central & 61,3 & 0,35 & \\
\hline$Z_{\text {Ref }}$ & 58,2 & 0,89 & 5,35 \\
$50 \mathrm{~cm}_{\text {Sup }}$ & 56,7 & 0,31 & 7,99 \\
$75 \mathrm{~cm}_{\text {Sup }}$ & 57,9 & 0,26 & 5,92 \\
$50 \mathrm{~cm}_{\text {Inf }}$ & 57,9 & 0,23 & 5,79 \\
$75 \mathrm{~cm}_{\text {Inf }}$ & & &
\end{tabular}

Tabela 11. Ho mogeneidade do campo para inclinações de $\pm 17^{\circ}$ com irradiação de campo duplo ( $\mu \mathrm{LiF}: \mathrm{Mg}$,Ti)

\begin{tabular}{cccc}
\hline Distância no eixo central & $\begin{array}{c}\text { Dose Avaliada } \\
\text { (cGy) }\end{array}$ & $\begin{array}{c}\sigma(\mathrm{DPM}) \\
(\mathrm{cGy})\end{array}$ & $\begin{array}{c}\text { Diferença Percentual } \\
\text { em relação ao } Z_{\text {Ref }}\end{array}$ \\
\hline $\mathrm{Z}_{\text {Ref }}$ & 65,5 & 0,19 & \\
$50 \mathrm{c} \mathrm{m}_{\text {Sup }}$ & 69,2 & 2,14 & 5,70 \\
$75 \mathrm{~cm}_{\text {Sup }}$ & 67,7 & 0,20 & 3,44 \\
$50 \mathrm{~cm}_{\text {Inf }}$ & 67,6 & 0,84 & 3,27 \\
$75 \mathrm{~cm}_{\text {Inf }}$ & 66,3 & 0,91 & 1,31 \\
\hline Distanciamento horizontal & Dose Avaliada & $\sigma(\mathrm{DPM})$ & Diferença Percentual \\
de $30 \mathrm{~cm}$ à direita do eixo & $(\mathrm{cGy})$ & $(\mathrm{cGy})$ & em relação ao $\mathrm{Z}_{\text {Ref }}$ \\
\hline central & 66,6 & 1,41 & \\
\hline$Z_{\text {Ref }}$ & 61,3 & 0,39 & 8,57 \\
$50 \mathrm{~cm}$ Sup & 60,6 & 0,79 & 9,88 \\
$75 \mathrm{~cm}_{\text {Sup }}$ & 63,2 & 0,41 & 5,43 \\
$50 \mathrm{~cm}_{\text {Inf }}$ & 63,1 & 1,01 & 5,50 \\
$75 \mathrm{~cm}_{\text {Inf }}$ & & & \\
\hline
\end{tabular}


Tabela 12. Ho mogeneidade do campo para inclinações de $\pm 17^{\circ}$ com irradiação de campo duplo $\left(\mathrm{CaSO}_{4}: \mathrm{Dy}\right)$

\begin{tabular}{|c|c|c|c|}
\hline Distânciano eixo central & $\begin{array}{l}\text { Dose Avaliada } \\
\text { (cGy) }\end{array}$ & $\begin{array}{c}\sigma(\mathrm{DPM}) \\
(\mathrm{c} \text { Gy })\end{array}$ & $\begin{array}{c}\text { Diferença Percentual } \\
\text { em relação ao } Z_{\text {Ref }}\end{array}$ \\
\hline$Z_{\text {Ref }}$ & 62,3 & 0,15 & \\
\hline $50 \mathrm{~cm}$ Sup & 61,2 & 0,20 & 1,71 \\
\hline $75 \mathrm{~cm}_{\text {Sup }}$ & 59,3 & 0,40 & 5,07 \\
\hline $50 \mathrm{~cm}$ Inf & 60,2 & 0,80 & 3,41 \\
\hline $75 \mathrm{~cm}_{\text {Inf }}$ & 58,2 & 0,20 & 6,95 \\
\hline $\begin{array}{l}\text { Distancia mento horizontal } \\
\text { de } 30 \mathrm{~cm} \text { à dire ita do eixo } \\
\text { central }\end{array}$ & $\begin{array}{l}\text { Dose Avaliada } \\
\text { (cGy) }\end{array}$ & $\begin{array}{c}\sigma(\mathrm{DPM}) \\
(\mathrm{cGy})\end{array}$ & $\begin{array}{c}\text { Diferença Percentual } \\
\text { em relação ao } Z_{\text {Ref }}\end{array}$ \\
\hline $\mathrm{Z}_{\mathrm{Ref}}$ & 62,3 & 0,84 & \\
\hline $50 \mathrm{~cm}_{\text {Sup }}$ & 57,9 & 1,02 & 7,58 \\
\hline $75 \mathrm{~cm}_{\text {Sup }}$ & 57,7 & 1,27 & 7,97 \\
\hline $50 \mathrm{~cm}$ Inf & 57,8 & 0,98 & 7,87 \\
\hline $75 \mathrm{~cm}_{\text {Inf }}$ & 57,5 & 0,35 & 8,24 \\
\hline
\end{tabular}

Tabela 13. Ho mogeneidade do campo para inclinações de $\pm 17^{\circ}$ com irradiação de campo duplo $\left(\mathrm{Al}_{2} \mathrm{O}_{3}: \mathrm{C}\right)$

\begin{tabular}{|c|c|c|c|}
\hline Distânciano eixo central & $\begin{array}{c}\text { Dose Avaliada } \\
\text { (cGy) }\end{array}$ & $\begin{array}{l}\text { Incerteza } \\
\text { (cGy) }\end{array}$ & $\begin{array}{c}\text { Diferença Percentual } \\
\text { em re lação ao } Z_{\text {Ref }}\end{array}$ \\
\hline $\mathrm{Z}_{\text {Ref }}$ & 67,5 & 8,22 & \\
\hline $50 \mathrm{~cm}_{\text {Sup }}$ & 55,8 & 7,47 & 21,08 \\
\hline $75 \mathrm{~cm}_{\text {Sup }}$ & 65,0 & 8,06 & 3,93 \\
\hline $50 \mathrm{~cm}_{\text {Inf }}$ & 66,9 & 8,18 & 0,91 \\
\hline $75 \mathrm{~cm}_{\text {Inf }}$ & 62,0 & 7,87 & 8,89 \\
\hline $\begin{array}{c}\text { Distancia mento horizontal } \\
\text { de } 30 \mathrm{~cm} \text { à direita do eixo } \\
\text { central }\end{array}$ & $\begin{array}{c}\text { Dose Avaliada } \\
\text { (cGy) }\end{array}$ & $\begin{array}{l}\text { Incerteza } \\
\text { (cGy) }\end{array}$ & $\begin{array}{c}\text { Diferença Percentual } \\
\text { em relação ao } Z_{\text {Ref }}\end{array}$ \\
\hline$Z_{\text {Ref }}$ & 63,1 & 7,94 & \\
\hline $50 \mathrm{~cm}_{\text {Sup }}$ & 49,6 & 7,05 & 27,04 \\
\hline $75 \mathrm{~cm}_{\text {Sup }}$ & 57,9 & 7,61 & 8,86 \\
\hline $50 \mathrm{~cm}_{\text {Inf }}$ & 55,1 & 7,43 & 14,38 \\
\hline $75 \mathrm{~cm}_{\text {Inf }}$ & 59,7 & 7,73 & 5,58 \\
\hline
\end{tabular}

\footnotetext{
*A incerteza desta medida foi determinada pela raíz da dose indívidual.
} 


\subsubsection{Dose no Ponto de Calibração $\left(Z_{R e f}\right)$}

Nas tabelas 14 a 17 é apresentada a dose no ponto de referência para cada grupo de dosímetro TL e OSL.

A avaliação no ponto de calibração possibilitou um estudo mais preciso, os resultados foram comparados com a dose do abdômen anterior. A lateral direita demonstrou uma diferença percentual maior pois o feixe incidente não é direcionado para esta posição, obtendo desta maneira uma dose menor neste local. A região posterior também recebeu uma dose menor por causa da assimétria anatômica.

Os outros dosímetros avaliados foram comparados com os resultados obtidos pelo LiF:Mg,Ti. Alguns detectores apresentaram uma diferença percentual maior devido ao posicionamento dos mesmo cujas irradiações foram realizadas simultaneamente.

Tabela 14. Dose no $\mathrm{Z}_{\mathrm{Ref}}(\mathrm{LiF}: \mathrm{Mg}, \mathrm{Ti})$

\begin{tabular}{cccc}
\hline Posicionamento & $\begin{array}{c}\text { Dose Avaliada } \\
\text { (cGy) }\end{array}$ & $\begin{array}{c}\sigma(\mathrm{DPM}) \\
(\mathrm{cGy})\end{array}$ & $\begin{array}{c}\text { Difereça } \\
\text { Percentual em } \\
\text { relação ao } \mathrm{Z}_{\text {Ref }}\end{array}$ \\
\hline Anterior & 214,5 & 1,20 & \\
Posterior & 199,8 & 1,23 & 7,36 \\
OAD & 212,6 & 1,13 & 0,90 \\
OPD & 210,1 & 0,94 & 2,09 \\
LD & 196,7 & 1,04 & 9,09 \\
\hline
\end{tabular}

Tabela 15. Dose no $Z_{\text {Ref }}(\mu \mathrm{LiF}: M g, T i)$

\begin{tabular}{cccc}
\hline Posicionamento & $\begin{array}{c}\text { Dose Avaliada } \\
\text { (cGy) }\end{array}$ & $\begin{array}{c}\sigma(\mathrm{DPM}) \\
(\mathrm{cGy})\end{array}$ & $\begin{array}{c}\text { Difereça } \\
\text { Percentual em } \\
\text { relação ao LiF:Mg.Ti }\end{array}$ \\
\hline Anterior & 230,9 & 6,36 & 7,63 \\
Posterior & 213,1 & 3,80 & 6,62 \\
OAD & 219,4 & 13,61 & 3,19 \\
OPD & 241,9 & 1,50 & 15,10 \\
LD & 221,0 & 6,10 & 12,38 \\
\hline
\end{tabular}


Tabela 16. Dose no $\mathrm{Z}_{\mathrm{Ref}}\left(\mathrm{CaSO}_{4}: \mathrm{Dy}\right)$

\begin{tabular}{cccc}
\hline Posicionamento & $\begin{array}{c}\text { Dose Avaliada } \\
\text { (cGy) }\end{array}$ & $\begin{array}{c}\sigma(\mathrm{DPM}) \\
(\mathrm{cGy})\end{array}$ & $\begin{array}{c}\text { Difereça } \\
\text { Percentual em } \\
\text { Relação ao LiF:Mg,Ti }\end{array}$ \\
\hline Anterior & 204,9 & 1,14 & 4,69 \\
Posterior & 191,2 & 1,34 & 4,52 \\
OAD & 196,4 & 2,97 & 8,26 \\
OPD & 195,3 & 3,89 & 7,62 \\
LD & 186,9 & 1,67 & 5,23 \\
\hline
\end{tabular}

Tabela 17. Dose no $\mathrm{Z}_{\mathrm{Ref}}\left(\mathrm{Al}_{2} \mathrm{O}_{3}: \mathrm{C}\right)$

\begin{tabular}{cccc}
\hline Posicionamento & $\begin{array}{c}\text { Dose Avaliada } \\
\text { (cGy) }\end{array}$ & $\begin{array}{c}\text { Incerteza } \\
\text { (cGy) }\end{array}$ & $\begin{array}{c}\text { Difereça } \\
\text { Percentual em } \\
\text { relação ao LiF:Mg.Ti }\end{array}$ \\
\hline Anterior & 201,0 & 14,18 & 6,72 \\
Posterior & & & \\
OAD & 225,1 & 15,00 & 5,88 \\
OPD & 215,8 & 14,69 & 2,67 \\
LD & 206,9 & 14,38 & 5,21 \\
\hline *A incerteza desta medida foi determinada pela raíz da dose indívidual. &
\end{tabular}

\subsubsection{Planejamento TSI - Irradiação Total da Pele}

Muitos elétrons que penetram na superfície da pele são incidentes em grandes ângulos referente ao plano de tratamento, e a própria superfície da pele é muitas vezes significativa sendo curva e oblíqua à este plano. Como consequência a distribuição da dose na pele pode variar amplamente. Em algumas regiões como tórax, região posterior, lateral direita e coxa direita varia apenas em uma pequena porcentagem como previsto pela distribuição de dose no ar. No entanto, para muitas outras partes do corpo, as doses são medidas na pele mais que $20 \%$. Diferente para dose anterior do abdômen ( $\left.Z_{\text {Ref }}\right)$ (Report 23, 1987).

Algumas áreas recebem pelo menos $20 \%$ menos dose do que no ponto de referência, incluindo axilas, couro cabeludo, palma das mãos e região medial da coxa.

Nas tabelas 18 a 21 é possível evidenciar os pontos que obteve uma sobredosagem como é o caso dos pés e uma subdosagem como no escalpe, axilas e regiões abaixo dos pés.

Para as regiões que tiveram uma subdosagem no final do tratamento os pacientes são submetidos a um "boost" de localizadas para complemento da dose. 
Tabela 18. Posicionamentos de Irradiação para Tratamento TSI (LiF:Mg,Ti)

\begin{tabular}{lccc}
\hline Posicionamento & $\begin{array}{c}\text { Dose Avaliada } \\
\text { (cGy) }\end{array}$ & $\begin{array}{c}\sigma(\mathrm{DPM}) \\
\text { (cGy) }\end{array}$ & $\begin{array}{c}\text { Diferença Percentual } \\
\text { em relação ao Z Zef }\end{array}$ \\
\hline Abdômen & 205,0 & 0,98 & \\
Abdômen & 213,5 & 0,69 & \\
Abdômen & 212,9 & 0,78 & \\
Abdômen & 211,0 & 1,06 & \\
Tórax Centro & 205,3 & 1,18 & 4,02 \\
Tórax Dir. & 189,6 & 1,11 & 12,58 \\
Tórax Esq. & 193,2 & 1,70 & 10,51 \\
Posterior & 206,4 & 0,87 & 3,46 \\
Lateral Dir. & 196,6 & 1,82 & 8,60 \\
Coxa Direita & 204,4 & 2,15 & 4,48 \\
Períneo & 202,2 & 0,91 & 5,59 \\
Fronte & 200,9 & 0,72 & 6,26 \\
Escalpe & 155,8 & 2,78 & 37,02 \\
Axila Dir. & 86,2 & 2,43 & 147,65 \\
Mão Dir. & 179,2 & 1,16 & 19,18 \\
Mão Esq. & 181,1 & 1,03 & 17,87 \\
Mão Esq. & 190,7 & 0,75 & 11,95 \\
Pé Dir. & 266,2 & 1,22 & 24,66 \\
Pé Esq. & 277,3 & 3,13 & 29,85 \\
Pé Esq. & 272,2 & 1,32 & 27,48 \\
\hline
\end{tabular}

Tabela 19. Posicionamentos de Irradiação para Tratamento TSI ( $\mu \mathrm{LiF}: \mathrm{Mg}, \mathrm{Ti})$

\begin{tabular}{lccc}
\hline Posicionamento & $\begin{array}{c}\text { Dose Avaliada } \\
\text { (cGy) }\end{array}$ & $\begin{array}{c}\sigma \text { DPM } \\
(\mathrm{cGy})\end{array}$ & $\begin{array}{c}\text { Diferença Percentual } \\
\text { em relação ao } \\
\text { LiF:Mg.Ti }\end{array}$ \\
\hline Abdômen & 221,8 & 0,84 & 8,17 \\
Abdômen & 222,4 & 7,86 & 4,18 \\
Abdômen & 227,4 & 0,22 & 6,81 \\
Abdômen & 225,7 & 2,65 & 6,94 \\
Tórax Centro & 211,3 & 1,59 & 2,94 \\
Tórax Dir. & 199,6 & 1,02 & 5,24 \\
Tórax Esq. & 213,3 & 6,14 & 10,39 \\
Posterior & 207,2 & 2,78 & 0,39 \\
Lateral Dir. & 210,2 & 0,09 & 6,93 \\
Coxa Direita & 229,4 & 1,72 & 12,24 \\
Períneo & 217,3 & 2,17 & 7,49 \\
Fronte & 224,1 & 1,19 & 11,51 \\
Escalpe & 159,8 & 7,47 & 2,56 \\
Axila Dir. & 85,8 & 0,08 & 0,48 \\
Mão Dir. & 183,4 & 2,52 & 2,38 \\
Mão Esq. & 187,5 & 3,53 & 3,52 \\
Mão Esq. & 203,1 & 1,28 & 6,50 \\
Pé Dir. & 275,1 & 7,20 & 3,37 \\
Pé Esq. & 272,8 & 4,90 & 1,65 \\
Pé Esq. & 288,7 & 5,17 & 6,08 \\
\hline
\end{tabular}


Tabela 20. Posicionamentos de Irradiação para Tratamento TSI $\left(\mathrm{CaSO}_{4}: \mathrm{Dy}\right)$

\begin{tabular}{lccc}
\hline Posicionamento & $\begin{array}{c}\text { Dose Avaliada } \\
\text { (cGy) }\end{array}$ & $\begin{array}{c}\sigma \text { (DPM) } \\
\text { (cGy) }\end{array}$ & $\begin{array}{c}\text { Diferença Percentual } \\
\text { em relação ao } \\
\text { LiF:Mg.Ti }\end{array}$ \\
\hline Abdômen & 205,0 & 1,65 & 0,01 \\
Abdômen & 216,7 & 1,65 & 1,49 \\
Abdômen & 215,3 & 0,95 & 1,14 \\
Abdômen & 209,6 & 0,37 & 0,70 \\
Tórax Centro & 203,7 & 2,04 & 0,75 \\
Tórax Dir. & 193,4 & 0,83 & 1,97 \\
Tórax Esq. & 203,2 & 0,71 & 5,18 \\
Posterior & 212,7 & 1,93 & 3,07 \\
Lateral Dir. & 198,6 & 0,70 & 0,99 \\
Coxa Direita & 200,4 & 4,05 & 1,98 \\
Períneo & 195,7 & 2,40 & 3,35 \\
Fronte & 206,4 & 2,04 & 2,71 \\
Escalpe & 141,3 & 9,51 & 10,30 \\
Axila Dir. & 103,8 & 4,52 & 20,34 \\
Mão Dir. & 187,5 & 2,11 & 4,63 \\
Mão Esq. & 184,8 & 1,65 & 2,05 \\
Mão Esq. & 190,5 & 2,29 & 0,13 \\
Pé Dir. & 277,2 & 3,63 & 4,13 \\
Pé Esq. & 287,2 & 3,39 & 3,60 \\
Pé Esq. & 245,1 & 2,47 & 11,06 \\
\hline
\end{tabular}

Tabela 21. Posicionamentos de Irradiação para Tratamento TSI $\left(\mathrm{Al}_{2} \mathrm{O}_{3}: \mathrm{C}\right)$

\begin{tabular}{lccc}
\hline Posicionamento & $\begin{array}{c}\text { Dose Avaliada } \\
\text { (cGy) }\end{array}$ & $\begin{array}{c}\text { Incerteza } \\
\text { (cGy) }\end{array}$ & $\begin{array}{c}\text { Diferença Percentual } \\
\text { em relação ao } \\
\text { LiF:Mg.Ti }\end{array}$ \\
\hline Abdômen & 188,8 & 13,74 & 8,61 \\
Abdômen & 228,7 & 15,12 & 7,11 \\
Abdômen & 218,1 & 14,77 & 2,45 \\
Abdômen & 222,6 & 14,92 & 5,46 \\
Tórax Centro & 213,5 & 14,61 & 4,01 \\
Tórax Dir. & 200,8 & 14,17 & 5,86 \\
Tórax Esq. & 195,3 & 13,98 & 1,10 \\
Posterior & 204,5 & 14,30 & 0,90 \\
Lateral Dir. & & & \\
Coxa Direita & & & \\
Períneo & 207,1 & 14,39 & 2,41 \\
Fronte & 201,7 & 14,20 & 0,39 \\
Escalpe & 177,7 & 13,33 & 14,05 \\
Axila Dir. & 96,9 & 9,84 & 12,35 \\
Mão Dir. & 179,2 & 13,39 & 0,02 \\
Mão Esq. & 181,5 & 13,47 & 0,20 \\
Mão Esq. & 181,4 & 13,47 & 5,17 \\
Pé Dir. & & & \\
Pé Esq. & 277,5 & 16,66 & 0,10 \\
Pé Esq. & 269,6 & 16,42 & 0,95 \\
\hline incerteza desta medida foi determinada pela ráz dadose indívidulal &
\end{tabular}




\subsubsection{Cál culo de Unidade Monitora (MU)}

Utilizando a equação 4 em conjunto com os valores obtidos nas tabelas 22 e 23, foi concluído que se 210 cGy é entregue no $Z_{\text {Ref }}\left(D_{6 C D}=210 \mathrm{cGy}\right)$, a unidade monitora que deve ser selecionada no console do acelerador linear para cada campo deve ser de $470 \mathrm{MU}$.

Tabela 22. Valores de dose por $\mathrm{MU}$ no $\mathrm{Z}_{\mathrm{Ref}}$ e fatores de correção relativos ( $\left.\mathrm{LiF}: \mathrm{Mg}, \mathrm{Ti}\right)$

\begin{tabular}{ccccc}
\hline $\begin{array}{c}1 \mathrm{CSH}_{\text {(Zref) }} \\
(\mathrm{cGy} / \mathrm{MU})\end{array}$ & $\begin{array}{c}1 \mathrm{CDS}_{\text {(Zref) }} \\
(\mathrm{cGy} / \mathrm{MU})\end{array}$ & $\begin{array}{c}6 \mathrm{CD}_{\text {(Zref) }} \\
(\mathrm{cGy} / \mathrm{MU})\end{array}$ & $\mathrm{F}_{\text {correção (1CD/1CSH) }}$ & $\mathrm{F}_{\text {correção (6CD/1CD) }}$ \\
\hline 0,128 & 0,139 & 0,449 & 1,087 & 3,228 \\
\hline
\end{tabular}

Tabela 23. Valores de dose por $\mathrm{MU}$ no $\mathrm{Z}_{\mathrm{Ref}}$ e fatores de correção relativos $\left(\mathrm{CaSO}_{4}: \mathrm{Dy}\right)$

\begin{tabular}{ccccc}
\hline $\begin{array}{l}1 \mathrm{CSH}_{\text {(Zref) }} \\
(\mathrm{cGy} / \mathrm{MU})\end{array}$ & $\begin{array}{c}1 \mathrm{CDS}_{\text {(Zref) }} \\
(\mathrm{cGy} / \mathrm{MU})\end{array}$ & $\begin{array}{c}6 \mathrm{CD}_{\text {(Zref) }} \\
(\mathrm{cGy} / \mathrm{MU})\end{array}$ & $\mathrm{F}_{\text {correção (1CD/1CSH) }}$ & $\mathrm{F}_{\text {correção (6CD/1CD) }}$ \\
\hline 0,132 & 0,139 & 0,450 & 1,057 & 3,236 \\
\hline
\end{tabular}

Os resultados foram validados com os dosímetros de $\mathrm{LiF}: \mathrm{Mg}$, Ti sendo confirmados com os dosímetros de $\mathrm{CaSO}_{4}$ :Dy, apresentando resultados equivalentes aos dosímetros de $\mathrm{LiF}: \mathrm{Mg}, \mathrm{Ti}$. 


\section{CONCLUSÕES}

A dosimetria para TSI é complexa, devido à necessidade de medir e avaliar doses absorvida em superfícies ao longo de uma grande área no plano de tratamento. Os TLDs são muito úteis para avaliar a uniformidade da dose na pele, bem como avaliar áreas que receberam mais doses do que outras, por causa da geometria do corpo, erros de posicionamentos, movimentação do paciente, auto blindagem (sobreposições de estruturas, dobras cutâneas) e angulações do corpo para realizações do tratamento.

Os dosímetros de $\mathrm{LiF}: \mathrm{Mg}$,Ti e o $\mathrm{CaSO}_{4}: \mathrm{Dy}$ demonstraram bons resultados para o tratamento TSI. Alguns dosímetros apresentaram uma variação maior, sendo explicado pelas angulações e sobreposições, onde um grupo de dosímetros recebeu mais doses do que outros grupos.

Os $\mu \mathrm{LiF}: \mathrm{Mg}$,Ti, é necessário o uso cauteloso visando variações em alguns parâmetros analisados.

Os dosímetros $\mathrm{Al}_{2} \mathrm{O}_{3}: \mathrm{C}$, apresentaram uma maior variação e incertezas relevantes que os outros dosímetros utilizados. A hipótese para interpretação dos resultados é o tamanho, espessura e a variação de sua massa, onde os mesmos demonstraram respostas e desempenhos diferentes para feixes de fótons e elétrons. Desse modo, é aconselhável uma caracterização minuciosa para o respectivo feixe que será empregado.

Para a determinação da unidade monitora os dosímetros de LiF:Mg,Ti demonstraram excelentes resultados visando a precisão e exatidão.

De acordo com resultados obtidos neste trabalho o protocolo sugerido para tratar pacientes com a técnica de irradiação total da pele é com uma distância de 4 metros, com dois campos de elétrons angulados a $\left( \pm 17^{0}\right)$, com o intuito de compor um grande campo homogêneo de elétrons com dimensões equivalentes a $(250 \mathrm{X} 130) \mathrm{cm}^{2}$. A unidade monitora sugerida é de 470 (MU) para entregar 210 cGy em cada campo de irradiação.

Os índices de qualidades e vários aspectos de dosimetria clínica foram avaliados e definidos com precisão, para que possa se utilizar a técnica de maneira eficaz e proporcionar o melhor tratamento. Os resultados adquiridos concordam com os valores sugeridos pela AAPM Report 23. 


\section{REFERÊNCIAS BIBLIOGRÁFICAS}

AMERICAN ASSOCIATION OF PHYSICISTS IN MEDICINE. A protocol for the determination of absorbed dose from high-energy photon and electron beams. Med. Phys., v. 10, n.6, p. 741-771, 1983 (TG-21).

AMERICAN ASSOCIATION OF PHYSICISTS IN MEDICINE. A protocol for clinical reference dosimetry of high-energy photon and electron beams. Med Phys., v.26, n. ${ }^{0}$ 9, p. 1847-1870, 1999. (TG-51).

ALMOND, P. R., BIGGS, P. J.; COURSEY, B. M.; HANSON, W. F.; SAIFUL HUQ, M.; NATH, R.; ROGERS, D. W. O. AAPM's TG-51 protocol for clinical reference dosimetry of high-energy photon and electron beams. Med. Phys., v. 29, p. 1847-1870, 1999.

AHMED, SYED NAEEM. Physics \& Engineering of Radiation Detection.1ed.Elsevier, 2007.

AKSELROD, M. S. et al. Optically stimulated luminescence and its use in medical dosimetry. Radiation Measurements. v. 41, p. 78-99, 2007.

AAPM, "Total Skin Electron Therapy: Technique and Dosimetry”, AAPM Report N² 23, Dic 1987.

BAO, QINAN; HRYCUSHKO, BRIAN A.; DUGAS, JOSEPH P.; HAGER, FREDERICK H.; SOLBERG, TIMOTHY D.A technique for pediatric total skin electron irradiation.Radiation Oncology, v. 7, n. 1, p. 1, 2012.

BERGER, M. J., SELTER, S. M., DOMEN, S. R. AND LAMPERTI, P. J. "Electron Dosimetry with Ionization Chambers ”.NBS SP456, Proceed. Of NBS Symposium, P. 307-312 (1976).

BOS, A. J. J., A. J. M. WINKELMAN, AND C. W. E. VAN EIJK."Optically stimulated luminescence in $\mathrm{KMgF} 3$ : Ce3+ comparison of dosimetric characteristics with A12O3:C." IEEE Transactions on Nuclear Science, 48 (4) (2017).

BRAVIM, A. "Aplicação das técnicas de dosimetria termoluminescente (TL) e luminescência opticamente estimulada (OSL) na determinação de curvas de isodose em uma simulação de tratamento de câncer pela técnica de radioterapia em arco modulado volumétrico-VMAT”.Tese, Universidade de São Paulo, 2015.

BRAVIM, A. et al. "dosimetric evaluation of TL response, sensitivity and intrinsic efficiency of tl dosimeters in 4 mev clinical electron beam using liquid water phantom." (2015).

BRAVIM, A., and L. L. Campos. "Comparison of TL and OSL signal of LiF: Mg, Ti dosimeters to beta radiation." (2014).

CAMERON, J. R.; SUNTHARALINGAM, N.; KENNEY, G. N. Thermoluminescent dosimetry. Londres: The Colonial Press, 1968.

CAMPOS , L. L. Thermoluminescence of materials and its application on radiation dosimetry. Cerâmica, São Paulo, v. 44, n. 290, 1998.

CAMPOS, L.L.; LIMA, M.F. "Dosimetric Properties of $\mathrm{CaSO}_{4}$ :Dy + Teflon Pellets Produced at IPEN”.- Rad. Prot. Dosim. 14, 4 (1986 ) 333. 
CAMPOS, L.L.;LIMA, M.F. “Thermoluminescent $\mathrm{CaSO}_{4}$ :Dy + Teflon Pellets for Beta Radiation Detection”. Rad. Prot. Dosim. 18, 2 ( 1987 ) 95.

CAMPOS, L.L.“Preparationof $\mathrm{CaSO}_{4}$ :Dy TL Single Crystals ”.J.Lum. 28(1983) 481.

CAMPOS, L.L.; SOUZA C.N. "Proced.do Fifth Latin America Conference on Medical Phys ics". 7-12 Outubro - 1990 - Ribeirão Preto, SP, Brasil.

CHOWDHARY, M. et al. Total Skin Electron Beam Therapy in the Treatment of Mycosis Fungoides: A Review of Conventional and Low-Dose Regimens. Clinical Lymphoma Myeloma and Le ukemia, v. 16, n. 12 , p. 662-671, 2016.

COX, R. S., HECK R, J., FESSENDEN, P., KARZMARK, C. J., RUST, D. C., Development of to talskin electron therapy at two energies. Int. J. Radiat. Oncol. Biol. Phys. 1990; 18 (3): 659-69.

DANIELS, F, BOYD, CA. \& SAUNDERS, D.F. “Thermoluminescence as a research tool," Science 117:343 - 349, 1953.

EHRLICH, M. AND LAMPERTI, P. J. “Electron-Therapy Dosimetry". NBS456, Proceed of NBS Symposium, p. 365-370 (1976).

EGGERMONT, G.; JACOBS, R.; JANSSENS, A SEGAERT, O.; THIELENS, G. Dose relationship, energy response and rate dependence of $\mathrm{LiF}-100, \mathrm{LiF}-7$ and $\mathrm{CaSO}_{4}-\mathrm{Mn}$ from $8 \mathrm{Kev}$ to $30 \mathrm{MeV}$. In: $3^{\mathrm{RD}}$ INTERNATIONAL CONFERENCE ON LUMINESCENCE DOSIMETRY, October, 11-14, 1971, Riso. Proceedings... Riso: anish AEC Research Stablishment, 1971. P. 444-460.

ELSAYAD, K. et al. Total skin electron beam for primary cutaneous T-cell lymphoma. Inte rnational Journal of Radiation Oncology* Biology* Physics, v. 93, n. 5, p. 1077-1086, 2015.

FREGENE, A. O.; Fricke Dosimetry in Radiotherapy. Med. Phys. 3 (5), 360-363 (1976).

FURETTA, C. Handbook of thermoluminescence. London: World Scientific Publishing, 2003.

GOODEN, DS \& BRICKNER, TJ. "The routine use of thermoluminescence dosimetry for radiation therapy," Radiology 102: 685-9, 1972.

GUM, 1995. http://www.inmetro.gov.br/noticias/conteudo/iso_gum_versao_site.pdf. Acessado em 14/03/2017 às 16:44 hs.

HINDS, G. A. et al. Treatment of mycosis fungoides with total skin electron beam: response and relapse by ethnicity and sex. American journal of clinical oncology, v. 36, n. 5, p. 481-485, 2013.

HABITZREUTER, A. B., Implementação da irradiação de corpo interio em radioterapia. Diss., Universidade de São Paulo, 2010.

IBANEZ-ROSELLO, B. et al. SU-F-T-248: FMEA Risk Analysis Implementation (AAPM TG-100) in Total Skin Electron Irradiation Technique. Medical Physics, v. 43, n. 6, p. 3519-3519, 2016.

INTERNATIONAL COMISSION ON RADIATION UNITS AND MEASURMENTS, "Determination of Absorbed Dose in a Patent Irradiated by Beams of X or Gamma Rays in Radiotherapy Procedures", ICRU Report 24, ICRU Publications, Bethesda ND (1976). 
INTERNATIONAL ORGANIZATION FOR STANDARDIZATION (ISO - DIS 4037): X and gamma Reference radiation for Calibrating Dosimeters and Dose Rate Meters and for Determining Their Response as a Function of photon Energy - Part 3. ISO DIS 4037. Geneva, Switzerland: International Organization for Standardization, 1996.

JAWED, SARAH I., ET AL. "Primary cutaneous T-cell lymphoma (mycosis fungoides and Sezary syndrome): part II. Prognos is, management, and future directions." Journal of the American Academy of Dermatology 70.2 (2014): 223-e1.

KALEF-EZRA, J.; BAZIOGLOU, M.; THEODOROU, K.; KAPPAS, C. A Phantom for Dosimetric Characterization of Small Radiation Fields: Design and Use. Medical Dosimetry, v. 25, n. 1, p. 9-15, 2000.

KALMÁN, I. Report IAEA-SM-272/31, pg. 85. 2001.

KAMSTRUP, M.R., et al. "Low-dose (10-Gy) total skin electron beam therapy for cutaneous T-cell lymphoma: an open clinical study and pooled data analysis." International Journal of Radiation Oncology* Biology* Physics 92.1 (2015) :138-143.

KALITA, J. M., and M. L. CHITHAMBO. "The influence of dose on the kinetic parameters and dosimetric features of the main thermoluminescence glow peak in $\alpha-\mathrm{Al}_{2} \mathrm{O}_{3}: \mathrm{C}, \mathrm{Mg}$." Nuclear Instruments and Methods in Physics Research Section B: Beam Interactions with Materials and Atoms 394 (2017) :12-19.

KASE, K. R. ADLER, G. J. AND BJARNGARD, B. E. "Electron Dosimetry with Ionization Chambers"Med. Phys. 2 (1) 13-19 (1982).

KHAN, F. M.; The physics of radiation therapy. 4 ed. Baltimore, Maryland: Lippincott Williams \& Wilkins, 2010.

KHAN, F. M. The physics of radiation therapy. 2. Ed Baltimore, Maryland: Williams \& Wilkins, 1994.

KNÖÖS, T, AHLGREN, L \& NILSSON, M. "Comparison of measured and calculated absorbed doses from tangential irradiation of the breast, ”Radiother. Oncol. 7: 81-8, 1986.

KRON, ELLIOT, A., WONG, T., SHOWELL, G., CLUBB, B. \& METCALFE, P. “ X-ray surface dose measurements using TLD measurements," Medical Physics, 1994.

KUTCHER, G. J., COIA, L.; GILLIN, M. et al. Comprehensive QA for Radiation Oncology: Report of AAPM. Radiation Therapy Committee Task Group 40.Méd. Phys. 1993; 21:581-618.

KUMAR, M. et al. "Beta response of $\mathrm{CaSO}_{4}$ :Dy based thermoluminescent dosimeter badge and its angular dependence studies for personnel monitoring applications." Radiation Protection and Environment 39.3 (2016): 132.

LUBBERT, K. AND RAHIM, H.; Strahlentherapie 161 (2), 109-112 (1985).

MAHESH, K.; WENG, P. S.; FURETTA, C. Thermoluminescence in Solids and its applications. Ashford: Nuclear Technology Publishing, 1989.

MANSFIELD, CM \& SUNTHARALINGAM, N. "Thermoluminescence dosimetry in radiation oncology,” Appl. Radiol. 2: 43-8, 1976. 
MATSUSHIMA, L. C. Determinação das curvas de isodose e confirmação do planejamento em Radioterapia de Intensidade Modulada-IMRT convencional empregando as técnicas de termoluminescência, luminescência opticamente estimulada e detectores semicondutores. Diss. Universidade de São Paulo, 2015.

McKEEVER S. W. S. Optically stimulated luminescence dosimetry. Nuclear Instruments and Methods in Phys ics Research B. v. 184, p. 29-54, 2001.

McKEEVER S. W. S.;MOSCOVITCH, M. On the advantages and disadvantages of optically stimulated luminescence dosimetry and thermoluminescence dosimetry.Radiation Protection Dosimetry. v. 104, n. 3, p.263-270, 2003.

McKEEVER, S.W.S. MOSCOVITCH, M.; TOWNSEND, P.D. Thermoluminescence dosimetry materials: Properties and user. Ashford, Kent: Nuclear Technology Publishing, 1995.

McKINLAY, AF. Thermoluminescene dosimetry Medical Physics 5 (Bristol: Adam Hilger, (1981).

METCALFE, P.; KRON, T.; HOBAN, P.The physics of radiotherapy X-rays and electrons. Madison, WI: Medical Physics, 2007.

NEVELSKY, A. et al. Room scatter effects in Total Skin Electron Irradiation: Monte Carlo simulation study. Journal of Applied Clinical Medical Physics, v. 18, n. 1, p. 196-201, 2017.

NUNES, M.G., CAMPOS, L. L. Study of CaSO $\mathrm{C}_{4}$ Dy and LiF:Mg,Ti Detectors TL Response to Electron Radiation Using a SW Solid Water Phantom. Rad. Measur. 43 (2008) 459 - 462.

OBERHOFER, M.; SCHARMANN, A. Applied thermoluminescence dosimetry.Ispra, Itália: Adam Hilger Ltd (Commission of the European Communities), 1981.

OLKO, P. Advantages and disadvantages of luminescence dosimetry. Rad.Meas., v.45, p. 506-511, 2010.

OSMAN, G. "Dose Profiles in Tissue and in Air for Therapeutic Eletrons Beams", NBS SP456. Proceed of NBS Symposium, p. 313-326 (1976).

OKUNO, E.;YOSHIMURA, E. M. Física das radiações. São Paulo: Oficina de Textos, 2010.

PARK, S. Y., B. S. AHN, J. M. PARK, S. J. YE, I. H. KIM, AND J. I. KIM, 2014, Dosimetric comparison of $4 \mathrm{MeV}$ and $6 \mathrm{MeV}$ electron beams for total skin irradiation: Radiation Oncology, v. 9, p. 6.

PARIDA, D. K., GOURA, K., R., "Advantages and implications of high dose rate (HDR) total skin electron irradiation (TSEI) for the management of Mycosis Fungoides. Indian experience." Reports of Practical Oncology \& Radiotherapy 19.2 (2014): 104-108.

PLATONI, K., et al. "First application of total skin electron beam irradiation in Greece: setup, measurements and dosimetry." Physica Medica 28.2 (2012): 174-182.

REISNER, M. L., L. PERES, L. M. A. GUEDES, M. P. S. RORIZ, C. L. P. MAURICIO, R. Z. GRAZZIOTIN, AND P. C. V. Canary, 2010, Comparison of a New Technique to the Stanford Technique in the Total Skin Irradiation of Advanced Mycosis Fungoides using a Thermoluminescent Dosimetry: International Journal of Radiation Oncology Biology Physics, v. 78, p. S549-S549.

RUDÉN, B. “Evaluation of the clinical use of TLD,"ActaRadiol.Ther. Phys. Biol. 15: 44464, 1976. 
SCAFF, LUIZ AM. Física da radiote rapia. Vol. 1. São Paulo: Sarvier, 1997.

RADIOLOGY SUPPORT DEVICES - ALDERSON PHANTOMS. Disponível em:

http://www.rsdphantoms.com/rt_art.htm. Acessado em: 03/05/2017.

SILVEIRA, MICHELY CRISTINA DA. Distribuição da dose absorvida no tratamento da micose fungóide através da dosimetria Fricke Xilenol Gel. Diss. Univers idade de São Paulo, 2010.

SOARES, C. G.; EHRLICH, M.; PADIKAL, T. N.'AND GROMADZKI, Z. C.; Thermoluminescence dosimetry Int. J. Appl. Radiat. Isto. 33. 1007-1013 (1982).

SOUSA, L. O. de Caracterização de sistema dosimétrico de luminescência opticamente estimulada (OSL) para doses liberadas na cobaltorerapia. Dissertação de Mestrado. Universidade Federal do Rio de Janeiro, 2009.

TAYLOR, J.R. Introdução à Análise de Erros: O Estudo de Incertezas em Medições. Porto Alegre, Rio Grande do Sul: Bookman Companhia Editora Ltda., 2012.

TILLANDER, M.; RAHOLA, T.; AUTIO, T.; PARONEN, M. Experiences in Calibration with Three Different Types of Phantom.Rad.Prot.Dosim., v. 89, no. 3-4, p. 313-316, 2000.

VAN DAM, J.; MARINELLO, G. Methods for In Vivo Dosimetry in External Radiotherapy. Physics for Clinical Radiotherapy Book-let, 1 1994; ESTRO: Brussels: Belgium.

VIAMONTE, A. et al. Radiotherapy dosimetry using a commercial OSL system. Med. Phys. v. 35, n. $4,2008$.

VILLANI, D. Avaliação de dosímetros de óxido de alumínio pela técnica OSL na dosimetria de campos de fótons clínicos utilizados no tratamento radioterápico em arco modulado volumétrico-VMAT. Diss. Universidade de São Paulo, 2017.

VUOLO, J.H. Fundamentos da teoria de erros. São Paulo: Edgard Blücher, 1992.

YUKIHARA, E. G.; GAZA, R.; McKEEVER, S. W. S.; SOARES, C. G. Optically stimulated luminescence and thermoluminescence efficiencies for high-energy heavy charged particle irradiation in $\mathrm{Al}_{2} \mathrm{O}_{3}$ :C. Radiat. Meas., n. 38, p. 59-70, 2004.

YUKIHARA, E. G.; McKEEVER, S. W. S. Optically stimulated luminescence - Fundamentals and applications. Oklahoma: Jhon Wiley \& Sons, 2011.

YUKIHARA, E. G., McKEEVER, S. W. S..Optically stimulated luminescence (OSL) dosimetry in medicine. Phys. Med. Biol. 53 (2008) R351-R379.

YUSOF, M. FAHMI M. et al. "Dose measurement using $\mathrm{Al}_{2} \mathrm{O}_{3}: \mathrm{C}$ dosimeter in comparis on to $\mathrm{LiF}: \mathrm{Mg}, \mathrm{Ti}$ dosimeter and ionization chamber at low and high energy x-ray." AIP Conference Proceedings. Eds. Abdul Aziz Mohamed, et al. Vol. 1799. No. 1. AIP Publishing, 2017. 


\section{ANEXO 1}

Tabela 1: Sensibilidade e Coeficiente de Calibração do LiF:Mg,Ti

\begin{tabular}{|c|c|c|c|c|c|c|c|c|c|}
\hline LiF:Mg,Ti & $\begin{array}{l}\text { Dose } \\
(\mathrm{cGy})_{1}\end{array}$ & $\begin{array}{l}\text { Resposta } \\
\text { TL }(\mu C)_{1}\end{array}$ & $\begin{array}{l}\text { Dose } \\
(\mathrm{cGy})_{2}\end{array}$ & $\begin{array}{l}\text { Resposta } \\
\text { TL }(\mu \mathrm{C})_{2}\end{array}$ & $\begin{array}{c}\text { Sensibilidade } \\
(\mu \mathrm{C} / \mathrm{cGy})_{1}\end{array}$ & $\begin{array}{c}\text { Sensibilidade } \\
(\mu \mathrm{C} / \mathrm{cGy})_{2}\end{array}$ & $\begin{array}{c}\text { Média } \\
(\mu \mathrm{C} / \mathrm{c} \text { Gy })\end{array}$ & $\begin{array}{c}\mathrm{Ccal} \\
(\mathrm{cGy} / \mu \mathrm{c})\end{array}$ & $\begin{array}{c}\text { DPM } \\
(\mu \mathrm{C} / \mathrm{c} \text { Gy })\end{array}$ \\
\hline 1 & 147,6 & 26,76 & 246 & 40,71 & 0,181 & 0,165 & 0,173 & 5,77 & 0,008 \\
\hline 2 & 147,6 & 25,34 & 246 & 38,50 & 0,172 & 0,157 & 0,164 & 6,09 & 0,008 \\
\hline 3 & 147,6 & 25,61 & 246 & 37,90 & 0,174 & 0,154 & 0,164 & 6,11 & 0,010 \\
\hline 4 & 147,6 & 26,50 & 246 & 40,66 & 0,180 & 0,165 & 0,172 & 5,80 & 0,007 \\
\hline 5 & 147,6 & 25,63 & 246 & 39,42 & 0,174 & 0,160 & 0,167 & 5,99 & 0,007 \\
\hline 6 & 147,6 & 25,41 & 246 & 38,13 & 0,172 & 0,155 & 0,164 & 6,11 & 0,009 \\
\hline 7 & 147,6 & 26,99 & 246 & 41,50 & 0,183 & 0,169 & 0,176 & 5,69 & 0,007 \\
\hline 8 & 147,6 & 25,75 & 246 & 39,80 & 0,174 & 0,162 & 0,168 & 5,95 & 0,006 \\
\hline 10 & 147,6 & 25,75 & 246 & 38,81 & 0,174 & 0,158 & 0,166 & 6,02 & 0,008 \\
\hline 11 & 147,6 & 25,60 & 246 & 40,35 & 0,173 & 0,164 & 0,169 & 5,93 & 0,005 \\
\hline 12 & 147,6 & 25,68 & 246 & 39,00 & 0,174 & 0,159 & 0,166 & 6,01 & 0,008 \\
\hline 14 & 147,6 & 24,16 & 246 & 37,67 & 0,164 & 0,153 & 0,158 & 6,31 & 0,005 \\
\hline 15 & 147,6 & 26,65 & 246 & 41,11 & 0,181 & 0,167 & 0,174 & 5,75 & 0,007 \\
\hline 17 & 147,6 & 26,80 & 246 & 40,11 & 0,182 & 0,163 & 0,172 & 5,80 & 0,009 \\
\hline 18 & 147,6 & 23,38 & 246 & 34,55 & 0,158 & 0,140 & 0,149 & 6,69 & 0,009 \\
\hline 19 & 147,6 & 25,55 & 246 & 39,21 & 0,173 & 0,159 & 0,166 & 6,02 & 0,007 \\
\hline 20 & 147,6 & 25,07 & 246 & 38,70 & 0,170 & 0,157 & 0,164 & 6,11 & 0,006 \\
\hline 21 & 147,6 & 25,67 & 246 & 38,34 & 0,174 & 0,156 & 0,165 & 6,06 & 0,009 \\
\hline 22 & 147,6 & 26,03 & 246 & 39,65 & 0,176 & 0,161 & 0,169 & 5,93 & 0,008 \\
\hline 23 & 147,6 & 26,55 & 246 & 40,38 & 0,180 & 0,164 & 0,172 & 5,81 & 0,008 \\
\hline 24 & 147,6 & 26,66 & 246 & 40,40 & 0,181 & 0,164 & 0,172 & 5,80 & 0,008 \\
\hline 25 & 147,6 & 25,90 & 246 & 39,51 & 0,175 & 0,161 & 0,168 & 5,95 & 0,007 \\
\hline 28 & 147,6 & 25,03 & 246 & 38,56 & 0,170 & 0,157 & 0,163 & 6,13 & 0,006 \\
\hline 29 & 147,6 & 25,02 & 246 & 38,40 & 0,170 & 0,156 & 0,163 & 6,14 & 0,007 \\
\hline 30 & 147,6 & 24,78 & 246 & 37,61 & 0,168 & 0,153 & 0,160 & 6,23 & 0,008 \\
\hline 31 & 147,6 & 26,37 & 246 & 37,75 & 0,179 & 0,153 & 0,166 & 6,02 & 0,013 \\
\hline 33 & 147,6 & 26,12 & 246 & 40,10 & 0,177 & 0,163 & 0,170 & 5,88 & 0,007 \\
\hline 34 & 147,6 & 25,86 & 246 & 39,17 & 0,175 & 0,159 & 0,167 & 5,98 & 0,008 \\
\hline 36 & 147,6 & 24,69 & 246 & 38,60 & 0,167 & 0,157 & 0,162 & 6,17 & 0,005 \\
\hline 37 & 147,6 & 25,10 & 246 & 38,43 & 0,170 & 0,156 & 0,163 & 6,13 & 0,007 \\
\hline 39 & 147,6 & 26,53 & 246 & 39,95 & 0,180 & 0,162 & 0,171 & 5,85 & 0,009 \\
\hline 40 & 147,6 & 25,88 & 246 & 39,41 & 0,175 & 0,160 & 0,168 & 5,96 & 0,008 \\
\hline 41 & 147,6 & 24,74 & 246 & 37,75 & 0,168 & 0,153 & 0,161 & 6,23 & 0,007 \\
\hline 43 & 147,6 & 26,02 & 246 & 40,83 & 0,176 & 0,166 & 0,171 & 5,84 & 0,005 \\
\hline 44 & 147,6 & 26,67 & 246 & 40,75 & 0,181 & 0,166 & 0,173 & 5,77 & 0,008 \\
\hline 45 & 147,6 & 26,08 & 246 & 39,94 & 0,177 & 0,162 & 0,170 & 5,90 & 0,007 \\
\hline
\end{tabular}




\section{ANEXO 2}

Tabela 2: Sensibilidade e Coeficiente de Calibração do $\mathrm{CaSO}_{4}: \mathrm{Dy}$

\begin{tabular}{|c|c|c|c|c|c|c|c|c|c|}
\hline CaSO4:Dy & $\begin{array}{l}\text { Dose } \\
(\mathrm{cGy})_{1}\end{array}$ & $\begin{array}{l}\text { Resposta } \\
\text { TL }(\mu \mathrm{C})_{1}\end{array}$ & $\begin{array}{l}\text { Dose } \\
(\mathrm{cGy})_{2}\end{array}$ & $\begin{array}{l}\text { Resposta } \\
\text { TL }(\mu \mathrm{C})_{2}\end{array}$ & $\begin{array}{c}\text { Sensibilidade } \\
(\mu \mathrm{C} / \mathrm{c} \mathrm{Gy})_{1}\end{array}$ & $\begin{array}{l}\text { Sensibilidade } \\
(\mu \mathrm{C} / \mathrm{c} G y)_{2}\end{array}$ & $\begin{array}{c}\text { Média } \\
(\mu \mathrm{C} / \mathrm{c} \text { Gy })\end{array}$ & $\begin{array}{c}\text { Ccal } \\
(\mathrm{cGy} / \mu \mathrm{c})\end{array}$ & $\begin{array}{c}\text { DPM } \\
(\mu \mathrm{C} / \mathrm{c} \mathrm{Gy})\end{array}$ \\
\hline 21 & 147,5 & 8,331 & 245,8 & 13,30 & 0,056 & 0,054 & 0,055 & 18,08 & 0,001 \\
\hline 23 & 147,5 & 8,898 & 245,8 & 13,84 & 0,060 & 0,056 & 0,058 & 17,15 & 0,002 \\
\hline 25 & 147,5 & 7,854 & 245,8 & 11,69 & 0,053 & 0,048 & 0,050 & 19,84 & 0,003 \\
\hline 27 & 147,5 & 8,647 & 245,8 & 13,32 & 0,059 & 0,054 & 0,056 & 17,73 & 0,002 \\
\hline 211 & 147,5 & 7,869 & 245,8 & 13,04 & 0,053 & 0,053 & 0,053 & 18,80 & 0,0001 \\
\hline 212 & 147,5 & 7,556 & 245,8 & 13,11 & 0,051 & 0,053 & 0,052 & 19,13 & 0,001 \\
\hline 213 & 147,5 & 8,477 & 245,8 & 13,35 & 0,057 & 0,054 & 0,056 & 17,89 & 0,002 \\
\hline 214 & 147,5 & 7,887 & 245,8 & 12,41 & 0,053 & 0,050 & 0,052 & 19,24 & 0,001 \\
\hline 215 & 147,5 & 7,723 & 245,8 & 12,00 & 0,052 & 0,049 & 0,051 & 19,77 & 0,002 \\
\hline 216 & 147,5 & 8,063 & 245,8 & 12,65 & 0,055 & 0,051 & 0,053 & 18,84 & 0,002 \\
\hline 223 & 147,5 & 8,236 & 245,8 & 12,82 & 0,056 & 0,052 & 0,054 & 18,52 & 0,002 \\
\hline 225 & 147,5 & 7,370 & 245,8 & 11,49 & 0,050 & 0,047 & 0,048 & 20,68 & 0,002 \\
\hline 227 & 147,5 & 7,881 & 245,8 & 12,82 & 0,053 & 0,052 & 0,053 & 18,94 & 0,001 \\
\hline 230 & 147,5 & 8,425 & 245,8 & 13,80 & 0,057 & 0,056 & 0,057 & 17,66 & 0,000 \\
\hline 234 & 147,5 & 8,008 & 245,8 & 12,36 & 0,054 & 0,050 & 0,052 & 19,12 & 0,002 \\
\hline 237 & 147,5 & 8,305 & 245,8 & 13,21 & 0,056 & 0,054 & 0,055 & 18,17 & 0,001 \\
\hline 243 & 147,5 & 7,893 & 245,8 & 13,09 & 0,054 & 0,053 & 0,053 & 18,73 & 0,0001 \\
\hline 250 & 147,5 & 7,642 & 245,8 & 12,62 & 0,052 & 0,051 & 0,052 & 19,39 & 0,0002 \\
\hline 252 & 147,5 & 8,481 & 245,8 & 13,50 & 0,057 & 0,055 & 0,056 & 17,79 & 0,001 \\
\hline 257 & 147,5 & 8,446 & 245,8 & 13,07 & 0,057 & 0,053 & 0,055 & 18,11 & 0,002 \\
\hline 263 & 147,5 & 8,251 & 245,8 & 12,59 & 0,056 & 0,051 & 0,054 & 18,66 & 0,002 \\
\hline 272 & 147,5 & 8,255 & 245,8 & 13,07 & 0,056 & 0,053 & 0,055 & 18,33 & 0,001 \\
\hline 277 & 147,5 & 8,410 & 245,8 & 13,26 & 0,057 & 0,054 & 0,055 & 18,02 & 0,002 \\
\hline 279 & 147,5 & 8,393 & 245,8 & 13,16 & 0,057 & 0,054 & 0,055 & 18,11 & 0,002 \\
\hline 280 & 147,5 & 8,333 & 245,8 & 13,34 & 0,056 & 0,054 & 0,055 & 18,06 & 0,001 \\
\hline 281 & 147,5 & 7,211 & 245,8 & 11,77 & 0,049 & 0,048 & 0,048 & 20,67 & 0,001 \\
\hline 283 & 147,5 & 8,752 & 245,8 & 14,00 & 0,059 & 0,057 & 0,058 & 17,20 & 0,001 \\
\hline 285 & 147,5 & 7,763 & 245,8 & 12,73 & 0,053 & 0,052 & 0,052 & 19,15 & 0,0004 \\
\hline 292 & 147,5 & 8,325 & 245,8 & 13,35 & 0,056 & 0,054 & 0,055 & 18,06 & 0,001 \\
\hline 298 & 147,5 & 8,073 & 245,8 & 13,14 & 0,055 & 0,053 & 0,054 & 18,49 & 0,001 \\
\hline
\end{tabular}




\section{ANEXO 3}

Tabela 3: Sensibilidade e Coeficiente de Calibração do $\mu \mathrm{LiF}: \mathrm{Mg}$,Ti

\begin{tabular}{|c|c|c|c|c|c|c|c|c|c|}
\hline$\mu \mathrm{LiF}: \mathrm{Mg}, \mathrm{Ti}$ & $\begin{array}{l}\text { Dose } \\
(\mathrm{cGy})_{1}\end{array}$ & $\begin{array}{l}\text { Resposta } \\
\mathrm{TL}(\mu \mathrm{C})_{1}\end{array}$ & $\begin{array}{l}\text { Dose } \\
(\mathrm{cGy})_{2}\end{array}$ & $\begin{array}{l}\text { Resposta } \\
\mathrm{TL}(\mu \mathrm{C})_{2}\end{array}$ & $\begin{array}{l}\text { Sensibilidade } \\
(\mu \mathrm{C} / \mathrm{c} \mathrm{Gy})_{1}\end{array}$ & $\begin{array}{l}\text { Sensibilidade } \\
(\mu \mathrm{C} / \mathrm{c} \text { Gy })_{2}\end{array}$ & $\begin{array}{c}\text { Média } \\
(\mu \mathrm{C} / \mathrm{c} \mathrm{Gy})\end{array}$ & $\begin{array}{c}\text { Ccal } \\
(\mathrm{cGy} / \mu \mathrm{c})\end{array}$ & $\begin{array}{c}\text { DPM } \\
(\mu \mathrm{C} / \mathrm{c} G y)\end{array}$ \\
\hline 1 & 150,8 & 1,794 & 251,4 & 2,769 & 0,012 & 0,011 & 0,011 & 87,29 & 0,0004 \\
\hline 2 & 150,8 & 1,564 & 251,4 & 2,419 & 0,010 & 0,010 & 0,010 & 100,03 & 0,0004 \\
\hline 3 & 150,8 & 1,812 & 251,4 & 2,831 & 0,012 & 0,011 & 0,012 & 85,92 & 0,0004 \\
\hline 4 & 150,8 & 1,752 & 251,4 & 2,764 & 0,012 & 0,011 & 0,011 & 88,44 & 0,0003 \\
\hline 5 & 150,8 & 1,804 & 251,4 & 2,779 & 0,012 & 0,011 & 0,012 & 86,89 & 0,0005 \\
\hline 6 & 150,8 & 1,856 & 251,4 & 2,746 & 0,012 & 0,011 & 0,012 & 86,09 & 0,0007 \\
\hline 7 & 150,8 & 1,822 & 251,4 & 2,909 & 0,012 & 0,012 & 0,012 & 84,55 & 0,0003 \\
\hline 8 & 150,8 & 1,706 & 251,4 & 2,753 & 0,011 & 0,011 & 0,011 & 89,83 & 0,0002 \\
\hline 9 & 150,8 & 1,748 & 251,4 & 2,733 & 0,012 & 0,011 & 0,011 & 89,03 & 0,0004 \\
\hline 10 & 150,8 & 1,742 & 251,4 & 2,617 & 0,012 & 0,010 & 0,011 & 91,06 & 0,0006 \\
\hline 11 & 150,8 & 1,869 & 251,4 & 2,917 & 0,012 & 0,012 & 0,012 & 83,34 & 0,0004 \\
\hline 12 & 150,8 & 1,736 & 251,4 & 2,583 & 0,012 & 0,010 & 0,011 & 91,80 & 0,0006 \\
\hline 13 & 150,8 & 1,737 & 251,4 & 2,659 & 0,012 & 0,011 & 0,011 & 90,51 & 0,0005 \\
\hline 14 & 150,8 & 1,854 & 251,4 & 2,906 & 0,012 & 0,012 & 0,012 & 83,84 & 0,0004 \\
\hline 15 & 150,8 & 1,740 & 251,4 & 2,648 & 0,012 & 0,011 & 0,011 & 90,61 & 0,0005 \\
\hline 16 & 150,8 & 1,783 & 251,4 & 2,769 & 0,012 & 0,011 & 0,011 & 87,57 & 0,0004 \\
\hline 17 & 150,8 & 1,777 & 251,4 & 2,782 & 0,012 & 0,011 & 0,011 & 87,52 & 0,0004 \\
\hline 18 & 150,8 & 1,768 & 251,4 & 2,710 & 0,012 & 0,011 & 0,011 & 88,87 & 0,0005 \\
\hline
\end{tabular}

Como os micro LiF possuem dimensões mínimas não foi possível a identificação dos detectores, desta maneira o coeficiente de calibração utilizado para as medidas clínicas foi a média individual do coeficiente de calibração adquirido $\left(\mathrm{C}_{\text {cal }} .88,51\right)$. 


\section{ANEXO 4}

Tabela 4: Sensibilidade e Coeficiente de Calibração do $\mathrm{Al}_{2} \mathrm{O}_{3}: \mathrm{C}$

\begin{tabular}{cccccccccc}
\hline $\mathrm{Al}_{2} \mathrm{O}_{3}: \mathrm{C}$ & $\begin{array}{c}\text { Dose } \\
(\mathrm{cGy})_{1}\end{array}$ & $\begin{array}{c}\text { Resposta } \\
\text { OSL } \\
(\text { Contagens })_{1}\end{array}$ & $\begin{array}{c}\text { Dose } \\
(\mathrm{cGy})_{2}\end{array}$ & $\begin{array}{c}\text { Resposta } \\
\text { OSL } \\
(\text { Contagens })_{2}\end{array}$ & $\begin{array}{c}\text { Sensibilidade } \\
(\text { Cont/cGy })_{1}\end{array}$ & $\begin{array}{c}\text { Sensibilidade } \\
(\text { Cont/cGy })_{2}\end{array}$ & $\begin{array}{c}\text { Média } \\
\text { (Cont/cGy) }\end{array}$ & $\begin{array}{c}\text { Ccal } \\
\text { (cGy/Cont) }\end{array}$ & $\begin{array}{c}\text { DPM } \\
(\text { Cont/c Gy) }\end{array}$ \\
\hline 17 & 144 & 944119 & 240 & 1522850 & 6556,4 & 6345,21 & 6450,80 & 0,00016 & 105,59 \\
62 & 144 & 986233 & 240 & 2027521 & 6848,8 & 8448,00 & 7648,42 & 0,00013 & 799,58 \\
65 & 144 & 130208 & 240 & 2226468 & 904,22 & 9276,95 & 5090,59 & 0,00020 & 4186,4 \\
67 & 144 & 864463 & 240 & 1751374 & 6003,2 & 7297,39 & 6650,30 & 0,00015 & 647,09 \\
71 & 144 & 111163 & 240 & 1961072 & 771,97 & 8171,13 & 4471,55 & 0,00022 & 3699,6 \\
73 & 144 & 931273 & 240 & 1688280 & 6467,2 & 7034,50 & 6750,84 & 0,00015 & 283,66 \\
85 & 144 & 929620 & 240 & 1516129 & 6455,7 & 6317,20 & 6386,45 & 0,00016 & 69,245 \\
90 & 144 & 924362 & 240 & 1646303 & 6419,2 & 6859,60 & 6639,39 & 0,00015 & 220,21 \\
97 & 144 & 102612 & 240 & 1871484 & 712,58 & 7797,85 & 4255,22 & 0,00024 & 3542,6 \\
103 & 144 & 923624 & 240 & 2021389 & 6414,1 & 8422,45 & 7418,25 & 0,00013 & 1004,2 \\
114 & 144 & 107381 & 240 & 1925828 & 745,70 & 8024,28 & 4384,99 & 0,00023 & 3639,3 \\
125 & 144 & 923496 & 240 & 1730578 & 6413,2 & 7210,74 & 6811,95 & 0,00015 & 398,79 \\
127 & 144 & 135511 & 240 & 2779172 & 941,05 & 11579,9 & 6260,47 & 0,00016 & 5319,4 \\
128 & 144 & 943421 & 240 & 1782474 & 6551,5 & 7426,98 & 6989,25 & 0,00014 & 437,72 \\
140 & 144 & 747850 & 240 & 1314999 & 5193,4 & 5479,16 & 5336,28 & 0,00019 & 142,88 \\
149 & 144 & 122297 & 240 & 2483340 & 849,28 & 10347,3 & 5598,27 & 0,00018 & 4749,0 \\
150 & 144 & 109193 & 240 & 2104132 & 758,28 & 8767,22 & 4762,75 & 0,00021 & 4004,5 \\
156 & 144 & 870080 & 240 & 1740682 & 6042,2 & 7252,84 & 6647,53 & 0,00015 & 605,31 \\
\hline
\end{tabular}

